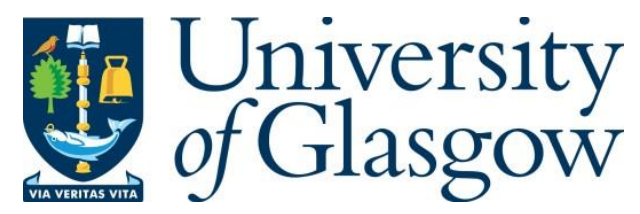

Ebiloma, G. U., Balogun, E. O., Cueto-Díaz, E. J., de Koning, H. P. and Dardonville, C. (2019) Alternative oxidase inhibitors: mitochondrion-targeting as a strategy for new drugs against pathogenic parasites and fungi. Medicinal Research Reviews, 39(5), pp. 1553-1602. (doi:10.1002/med.21560).

There may be differences between this version and the published version. You are advised to consult the publisher's version if you wish to cite from it.

This is the peer reviewed version of the following article:

Ebiloma, G. U., Balogun, E. O., Cueto-Díaz, E. J., de Koning, H. P. and Dardonville, C. (2019) Alternative oxidase inhibitors: mitochondrion-targeting as a strategy for new drugs against pathogenic parasites and fungi. Medicinal Research Reviews, 39(5), pp. 1553-1602, which has been published in final form at 10.1002/med.21560. This article may be used for non-commercial purposes in accordance with Wiley Terms and Conditions for Self-Archiving.

http://eprints.gla.ac.uk/178458/

Deposited on: 22 January 2019

Enlighten - Research publications by members of the University of Glasgow http://eprints.gla.ac.uk 


\section{Alternative Oxidase inhibitors: mitochondrion-targeting as a strategy for new drugs against pathogenic parasites and fungi}

Running title: Alternative oxidase inhibitors

Godwin U. Ebiloma ${ }^{\mathrm{a}, \mathrm{b}}$, Emmanuel O. Balogun ${ }^{\mathrm{c}, \mathrm{d}}$, Eduardo J. Cueto-Díaz ${ }^{\mathrm{e}}$, Harry P. de Koning ${ }^{\mathrm{b}}$, Christophe Dardonville $\mathrm{e}^{*}$

${ }^{a}$ Graduate School of Science and Technology, Department of Applied Biology, Kyoto Institute of Technology, Kyoto 606-8585, Japan.

${ }^{\mathrm{b}}$ Institute of Infection, Immunity and Inflammation, College of Medical, Veterinary and Life Sciences, University of Glasgow, Glasgow, United Kingdom.

c Department of Biochemistry, Ahmadu Bello University, Zaria 2222, Nigeria.

${ }^{d}$ Department of Biomedical Chemistry, Graduate School of Medicine, The University of Tokyo, 7-3-1 Hongo, Bunkyo-Ku, 113-0033 Tokyo, Japan.

e Instituto de Química Médica, IQM-CSIC, C/Juan de la Cierva 3, E-28006 Madrid, Spain.

Acknowledgements. Funding from the Spanish Ministerio de Economia y Competitividad (grant SAF2015-66690-R) and the Japan Society for the Promotion of Science (JSPS grant$17 \mathrm{~F} 17420)$ is gratefully acknowledged. 


\begin{abstract}
The Alternative Oxidase, AOX, is a ubiquitous terminal oxidase of plants and many fungi, catalyzing the 4-electron reduction of oxygen to water alongside the cytochrome-based electron transfer chain. Unlike the classical electron transfer chain, however, the activity of AOX does not generate ATP but has functions such as thermogenesis and stress response. As it lacks a mammalian counterpart, it has been investigated intensely in pathogenic fungi. However, it is in African trypanosomes, which lack cytochrome-based respiration in their infective stages, that trypanosome alternative oxidase (TAO) plays the central and essential role in their energy metabolism. TAO was validated as a drug target decades ago and among the first inhibitors to be identified was salicylhydroxamic acid (SHAM), which produced the expected trypanocidal effects, especially when potentiated by co-administration with glycerol to inhibit anaerobic energy metabolism as well. However, the efficacy of this combination was too low to be of practical clinical use. The antibiotic ascofuranone proved a much stronger TAO inhibitor and was able to cure Trypanosoma vivax infections in mice without glycerol and at much lower doses, providing an important proof of concept milestone. Systematic efforts to improve the SHAM and ascofuranone scaffolds, aided by the elucidation of the TAO crystal structure, provided detailed SAR information and reinvigorated the drug discovery effort. Recently, the coupling of mitochondrion-targeting lipophilic cations to TAO inhibitors has dramatically improved drug targeting and trypanocidal activity while retaining target protein potency. These developments appear to have finally signposted the way to preclinical development of TAO inhibitors.
\end{abstract}

KEYWORDS: Trypanosome Alternative Oxidase; mitochondrial targeting; structure-aided drug design; lipophilic cation; triphenylphosphonium, structure-activity relationship; ascofuranone; salicylhydroxamic acid analogues; synthetic strategies 


\section{Outline}

1. Introduction

2. Alternative oxidases in human and veterinary parasites

2.1. Origin of the plant-like alternative oxidase of trypanosomes

2.2. Role of TAO in trypanosome metabolism

2.2.1. TAO is essential for bloodstream form respiration

2.2.2. The role of TAO in procyclic trypanosomes: control of ROS and surface coat composition

2.3. Alternative oxidases in pathogenic and agrochemically important fungi

3. Validation of TAO as drug target in African trypanosomes

3.1. Validation and functional expression studies

3.2. In vitro studies with early inhibitors

3.3. Studies with TAO inhibitors in in vivo models of African trypanosomiasis:

3.4. Production of TAO using recombinant DNA technology

4. Progress in chemical scaffolds and development of AOX inhibitors

4.1. Hydroxamate derivatives

4.1.1. Primary and secondary benzhydroxamic acids

4.1.2. $N$-hydroxy heterocycles

4.1.3. Alkyloxybenzhydroxamic acids and related compounds

4.2. Other iron chelators: tropolones, 8-hydroxyquinolines, and pyridine derivatives

4.3. Mono, di- and trihydroxybenzoic acid, benzaldehyde, and benzoate derivatives

4.3.1. Benzoic acid derivatives

4.3.2. Benzoate and benzamide derivatives

4.3.3. Benzaldehyde and benzophenone derivatives

4.4. 3-chloro-4-hydroxybenzonitrile derivatives

4.5. Ubiquinone analogues

4.6. Natural products: isoprenoid antibiotics

4.6.1. Ascofuranone derivatives

4.6.2. Colletochlorin B derivatives

4.6.3. Ilicicolin derivatives

5. Structure-aided inhibitor design

5.1. TAO structure

5.2. Ascofuranone as template for inhibitor design

5.2.1. Ascofuranone pharmacophore

5.2.2. Synthetic strategies towards ascofuranone derivatives

5.2.2.1. Arene alkylation strategies

5.2.2.2. Non-aromatic alkylation/aromatization strategies

5.2.2.3. Recent strategies

5.3. Mitochondrial targeting strategy using lipophilic cations

6. Outlook and clinical perspective 


\section{INTRODUCTION}

The alternative oxidase (AOX) is ubiquitous throughout the plant kingdom and also common among some pathogenic and agrochemically important fungi. ${ }^{1-3}$ AOX is widespread among human parasites such as Trypanosoma brucei (the causative agent of African trypanosomiasis), ${ }^{4}$ Cryptosporidium parvum ${ }^{5,6}$ and Blastocystis hominis (intestinal parasites), ${ }^{2,7,8}$ and opportunistic human pathogens such as the fungus Candida albicans. ${ }^{9}$ In all of these organisms, AOX plays a critical role in their respective life cycles and since the protein is absent from mammals, it has become a novel therapeutic target for the treatment of diseases caused by such organisms.

AOX is a membrane-bound ubiquinol oxidase with a heme-free diiron active site that catalyzes the cyanide- and antimycin-A-resistant oxidation of ubiquinol and the reduction of oxygen to water in a four-electron process. ${ }^{10}$ Thus, AOX short-circuits the mitochondrial electron-transport chain prior to proton translocation by complexes III and IV, thus drastically reducing ATP formation. ${ }^{8}$ In plants, it plays a key role in cellular metabolism, thermogenesis, and energy homeostasis. ${ }^{1,11}$ In T. brucei, a protozoan parasite that causes African trypanosomiasis in humans (sleeping sickness) ${ }^{4}$ and in livestock (nagana) ${ }^{12}$ throughout sub-Saharan Africa, the trypanosome alternative oxidase (TAO) is located in their single mitochondrion and essential for the respiration of bloodstream form (BSF) parasites that cause the clinical symptoms and lack the canonical oxidative phosphorylation processes. ${ }^{13-17}$ In effect, in BSF trypanosomes, TAO is the sole terminal oxidase enzyme to re-oxidize the NADH that accumulates during glycolysis, and, as TAO has no counterpart in mammalian cells and is conserved among T. brucei subspecies, ${ }^{16}$ it has been validated as a promising target for the chemotherapy of African trypanosomiasis. ${ }^{15,18}$ With reference to TriTrypDB (http://tritrypdb.org/tritrypdb/), genes syntenic to T. brucei brucei AOX (Tb927.10.7090) are present in other organisms including those causing serious human (T. $b$. gambiense) and veterinary (T. congolense, T. evansi, T. vivax) diseases. However, these are not syntenic in T. cruzi and Leishmania spp. Tb927.10.9760 is a truncated, and presumed to be inactive form of AOX, and is referred to as AOX2 in Gene DB. It is this gene that is syntenic in Leishmania and T. cruzi, but to date its role has been much less studied in those organisms.

Due to its uniqueness and its critical role in the trypanosome's metabolism, the search for clinically effective TAO inhibitors has been on for over 40 years. Nevertheless, there is still no TAO inhibitor at an advance stage of clinical development for the treatment of African trypanosomiasis, or for any other pathogenic parasite or fungal infection. However, the recent elucidation of the TAO 3D-structure by Shiba et al. ${ }^{10}$ has opened new paths in the search for AOX inhibitors and has rekindled interest in this subject as evidenced by the increasing number of papers published on this subject in recent years. However, no article has reviewed the state-ofthe-art on the SAR and structure-aided design of TAO inhibitors over the last 40 years. A 
systematic review of the state of chemistry, SAR and structure-aided design of TAO inhibitors, and the recent efforts at improved mitochondrial targeting of the inhibitors, is sorely needed in order to progress towards genuine clinical candidates.

Hence, in this review, we address these issues by reviewing the different classes of AOX inhibitors reported in the literature since the discovery of the first few inhibitors (e.g. SHAM). This will be helpful for researchers working in this re-emerging field, especially since this review will for the first time bring all biological data and target validation evidence together with a complete overview of the inhibitor design efforts of decades. Since most inhibitors of alternative oxidases were developed specifically as TAO inhibitors, this review covers those in particular depth, although inhibitors of other AOXs are also included. Furthermore, we address structureaided inhibitor design and recent strategies for mitochondrial targeting of the inhibitors that have resulted in a major increase in anti-parasite potency. This includes the description of the 3Dstructure of TAO, the development of the ascofuranone pharmacophore, and the synthetic strategies to obtain these inhibitors. The perspectives for the clinical implementation of optimized TAO inhibitors against African trypanosomiasis and other pathogenic parasites and fungi will be discussed.

\section{ALTERNATIVE OXIDASES IN HUMAN AND VETERINARY PARASITES}

The alternative oxidase, AOX, is a non-protonmotive ubiquinol-oxygen oxidoreductase which couples the oxidation of ubiquinol with the reduction of molecular oxygen to water; the enzyme is insensitive to inhibitors of the cytochrome oxidase (COX) pathway. While it has long been documented as ubiquitous within the plant kingdom, it has also become evident that it is present in other organisms including some parasites that causes devastating diseases in humans and essential livestock.

Initially it was observed that medically important apicomplexan parasites including Plasmodium falciparum use a cyanide-insensitive AOX-mediated respiration that can be inhibited by AOX inhibitors such as propyl gallate (110), 8-hydroxyquinoline (71) and salicylhydroxamic acid (SHAM). ${ }^{19,20}$ Although this observation shows the existence of an alternative pathway of respiration in this parasite, it does not offer any information concerning the molecular nature of the oxidase involved. Moreover, when the P. falciparum and Toxoplasma gondii genome projects were completed and annotated, it did not identify any protein that is similar to those previously identified for plants, protozoa or fungi AOXs. ${ }^{21,22}$ Homologues of AOX have however been found in other human parasites including Cryptosporidium parvum. ${ }^{6,23}$ C. parvum is another apicomplexan protozoan parasite that infects humans, causing a diarrheal disease called cryptosporidiosis; there is currently no satisfactory chemotherapy available, making it a 
potentially fatal disease, particularly in elderly, young and immunosuppressed individuals. It can also cause longer-term problems, including stunting in malnourished children. ${ }^{24,25}$ Suzuki et al. ${ }^{23}$ presented the first direct evidence for the presence of a cyanide-insensitive quinol oxidase (AOX) in C. parvum. The C. parvum AOX ( $C p \mathrm{AOX}$ ) coding sequence was identified and the full-length $C p \mathrm{AOX}$ cDNA was cloned, providing AOX sequence from the phylum apicomplexa for the first time. Roberts et al. ${ }^{6}$ also identified and sequenced putative AOX sequences from both type 1 and 2 strains of $C$. parvum. The $C p A O X$ genes encode a polypeptide of 336 amino acids having a predicted $N$-terminal targeting sequence similar to those found in proteins targeted to the mitochondria of other species. $C p A O X$ was reported to be inhibited by ascofuranone $(\mathbf{1 8 8})^{6}$ and the potential of AOX as a novel target for chemotherapy against $C$. parvum was further corroborated by the inhibition of in vitro growth of $C$. parvum by SHAM (2) and 8hydroxyquinoline (71). ${ }^{6}$

An AOX has also been reported to be present in other intestinal parasites such as Blastocystis hominis $^{2,6-8,23}$ where it was thought that AOX helps Blastocystis cope with oxygen stress conditions in the intestine of the host and avoid the formation of reactive oxygen species. ${ }^{26}$

The presence of AOX in the opportunistic human pathogen Candida albicans has also been reported. Several studies have been conducted in order to further understand the role of AOX in Candida albicans. One of such studies is that conducted by Yan et al., ${ }^{9}$ which analyzed the effects of combinations of antifungal azoles and either the COX inhibitor cyanide or the AOX inhibitor SHAM on the mitochondrial respiration. Strains of C. albicans deleted for AOX were also studied for susceptibility to azoles and for the generation of intracellular reactive oxygen species (ROS). It was observed that the induction of the alternative respiratory pathway by cyanide reduced their sensitivity to azoles, while inhibition of the alternative respiration by SHAM drastically increased their sensitivity to azoles. This was clear evidence that this fungus expressed both the classical cytochrome-mediated electron-transfer chain and an AOX, and that inhibition of either pathway hypersensitizes to inhibitors of the other pathway. As such, the combination of SHAM with fluconazole (an inhibitor of the cytochrome P450 enzyme 14 $\alpha$-demethylase) displayed a synergistic effect against clinical isolates of C. albicans. ${ }^{9}$ As ROS attained substantially higher levels after exposure to antifungals in the absence of AOX than in control cells, it appears that at least one function of Candida AOX is the mitigation of oxidative stress. ${ }^{9}$

AOX has also been identified in African trypanosomes, the causative agent of sleeping sickness (or human African trypanosomiasis (HAT)) and the various species causing animal African trypanosomiasis (AAT) including Trypanosoma vivax ${ }^{27}$ and Trypanosoma brucei. ${ }^{14,16}$ Several Trypanosoma species and subspecies are of great medical or economic concern on the African continent where they cause HAT and/or AAT, affecting cattle rearing and agricultural 
development in resource-poor communities. ${ }^{12,28,29}$ Two subspecies of Trypanosoma brucei infect humans, each causing slightly different pathologies, both almost invariably lethal, although there are emerging, sporadic reports of long-term asymptomatic cases. ${ }^{30}$ Trypanosoma brucei gambiense is found in central and western Africa where it causes a relatively chronic form of the disease which may develop over a number of years. $T$. b. rhodesiense on the other hand is found in southern and east Africa where it causes an acute illness that could lead to death within weeks. ${ }^{14,16,31}$

Even though these trypanosomes and their vector are localized to Africa, imported human cases in Europe are well documented, ${ }^{32,33}$ and the veterinary form of trypanosomiasis has spread to become a major economic issue from Southern Asia to much of South America, as species such as Trypanosoma equiperdum, T. evansi and T. vivax have adapted to tsetse-independent transmission modes, fatally infecting high value animals such as horses, camels, cattle and waterbuffalo. $^{12}$

\subsection{Origin of the plant-like alternative oxidase of trypanosomes}

Investigations into the cyanide-resistant respiration of plants lead to the discovery of the second terminal oxidase in the mitochondrial respiratory chain called the alternative oxidase. AOX was first identified in plants in the $1920 \mathrm{~s}^{34,35}$ and it has since been thoroughly researched. Indeed, most of the information we have about the AOX class of proteins today is as a result of the intensive research carried out on alternative oxidases from plants.

Genes encoding AOX are ubiquitous in the Kingdom Plantae, where the enzyme plays a crucial role in thermogenesis, cellular metabolism, and energy homeostasis; it is also generally believed to be a major stress-induced protein. ${ }^{1,11}$ For instance, a small group of "thermogenic" plants were able to maintain a very high rate of uncoupled, and hence heat-releasing AOX respiration, thereby heat-up their reproductive tissues to temperatures that are well above ambient. ${ }^{36-38}$ This provides the needed optimal temperatures for floral development or simply serves to attract pollinators. Nevertheless, most plants are intrinsically non-thermogenic, in which case the expression of the AOX gene in them must be for other purposes. Indeed, AOX play crucial roles in plants but its function varies, depending on the type of plant and its physiological state. The activity of AOX optimizes the process of photosynthesis, ${ }^{11}$ by ensuring that the redox balance in the cell is maintained. Substantial amounts of reductants are generated during photosynthesis, which, when allowed to accumulate, would lead to the process of photo-inhibition in the chloroplasts. These excess reductants are exported from the chloroplasts to the mitochondria, where they are oxidized in the electron transport chain non-phosphorylating pathway. ${ }^{39}$ 
The activity of AOX is also significant when certain environmental conditions or metabolic processes produce cytochrome oxidase (COX)-inhibiting compounds, which decrease the activity of the COX pathway. Examples are nitric oxide (NO), which is produced in plants that are under stress conditions, ${ }^{40-42}$ cyanide, which is produced upon increased synthesis of ethylene in plants ${ }^{43}$ and hydrogen sulphide $\left(\mathrm{H}_{2} \mathrm{~S}\right)$, which is produced in the process of detoxification of endogenous cyanogenic compounds by $\beta$-cyanoalanine synthase. ${ }^{43}$ Phosphorus deficiency in some plants is another example of environmental conditions that can limit the activity of the COX pathway, as inorganic phosphorus $\left(\mathrm{P}_{\mathrm{i}}\right)$ is necessary for ATP synthesis, and increased ADP levels suppress the COX pathway and consequently increase AOX activity. ${ }^{44}$

The study of plant AOX paved the way for the identification of alternative ways of respiration in protozoa including pathogenic organisms such as Trypanosoma brucei..$^{14,45,46}$

The trypanosome was first discovered in 1895 by Sir David Bruce as the etiological agent of the cattle disease nagana. ${ }^{47,48}$ T. brucei, like most pathogenic parasites undergo various lifecycle changes and have developed a range of physiological functions that are indispensable for their survival within the specialized environment of the insect (tsetse fly) vector and/or mammalian host. For instance, they adapt to a low oxygen tension in their host using diverse metabolic pathways that are quite distinct from those of their host. The parasite's mitochondrion undergoes substantial changes in its composition and morphology as a result of this environmental and development adaptation. ${ }^{15}$

The parasite lives as the bloodstream form (BSF) in the mammalian host and as the procyclic form in the tse-tse fly vector; in whichever form it exists, it is well equipped for its environment, with unique energy metabolism. The procyclic form, for instance, meets its ATP synthesis requisite from a cyanide-sensitive and cytochrome-dependent respiratory chain similar to that present in the mitochondria of mammalian cells, ${ }^{45}$ whereas no significant expression of cytochromes has been reported in the long-slender BSF of the parasite living freely in the blood of the mammalian host. Yet, BSF respire at a very high rate; their glucose consumption rate is 100 -fold higher than that of the procyclics or their mammalian host cells..$^{14,49,50}$ In 1960, Grant and Sargent discovered the glycerol-3-phosphate oxidase system (GPO) as the unique enzyme system responsible for this type of respiration. ${ }^{51}$

At least two enzymes were reported to be contained in the GPO: a glycerol-3-phosphate oxidase and glycerol-3-phosphate dehydrogenase.$^{50,51}$ Using isopycnic sucrose gradient centrifugation, Opperdoes and his co-workers established for the first time, that GPO is present in the same fraction as all the other mitochondrial enzymes, such as malate dehydrogenase, oligomycinsensitive ATPase, and isocitrate dehydrogenase..$^{52}$ 
Following this discovery, Fairlamb and Bowman reported the partial purification of the holoenzyme complex from $T$. brucei, ${ }^{53}$ showing that the glycerol-3-phosphate dehydrogenase component has FAD as cofactor. Afterwards, Clarkson and his co-workers ${ }^{17}$ established that the dehydrogenase component of the GPO system is connected to the terminal oxidase via the coenzyme Q9. Consequently, the oxidase component of GPO is a ubiquinol oxidase, which transfers electrons to molecular oxygen. It was also revealed at the time, that the electron transfer via the terminal oxidase was not coupled to the translocation of protons or to ATP production in the mitochondria. ${ }^{17}$ These findings contributed to the discovery of the first specific inhibitors of GPO, salicylhydroxamic acid (SHAM) and ascofuranone. ${ }^{17,54,55}$ Considering the similarities observed between the T. brucei GPO and AOX from higher plants, and because ubiquinol was eventually identified as the substrate (instead of glycerol-3-phosphate), the trypanosome GPO was eventually renamed as the trypanosome alternative oxidase (TAO) by Clarkson and his coworkers, ${ }^{17}$ and this name has now been widely accepted by all researchers in this field.

Using antibodies previously raised against the AOX from the flowering plant Sauromatum guttatum, Chaudhuri et al. ${ }^{56}$ identified TAO as a $33 \mathrm{kDa}$ protein in the mitochondria of T. brucei, which was successively purified from the mitochondria of BSF and confirmed to have ubiquinol oxidase activity. TAO is approximately 100-fold higher expressed in BSF than in procyclic $T$. brucei,${ }^{16}$ as the latter form expresses complexes III and IV and is capable of synthesizing ATP through oxidative phosphorylation, whereas the BSF depend solely on TAO for respiration.

In 1996, Chaudhuri and Hill identified a single copy TAO gene (Tb927.10.7090) following their successful design of primers for the cloning of TAO from gDNA of T. brucei, using areas of high conservation found in plant AOXs. This enabled its recombinant expression in E. coli, which was instrumental in the characterization of its kinetic parameters and of course the screening for inhibitors. ${ }^{57}$ However, this research was initially hampered by the presence of endogenous ubiquinol oxidase activities in native E. coli, in the form of the cytochrome $b o$ and $b d$ complexes. This was overcome by overexpression of rTAO in a $\underline{\Delta}$ hemeA mutant E. coli (FN102), which is unable to synthesize the heme needed for cytochrome assembly. In addition to further refinements in the production, solubilization and purification of rTAO has enabled high quality kinetic, structural and inhibitor studies. ${ }^{10,45}$

The AOX gene of T. brucei contains 990 nucleotides encoding the 330 amino acids full length protein, including the predicted $N$-terminal Mitochondrial Targeting Signal (MTS) of 25 amino acid residues. As the MTS is cleaved off after transportation of the protein to the mitochondrion, the physiologically functional and relevant form of TAO is lacking the MTS sequence. ${ }^{58}$ However, until recently only the full-length protein had been produced and studied by the various authors, despite difficulties associated with its stability, solubility and yield, ${ }^{10,45,59-61}$ and although 
it is clearly desirable to conduct inhibitor studies with the physiologically relevant form of the protein. When a $\triangle \mathrm{MTS}$ rTAO, lacking the first 75 nucleotides, was produced it was found to have relatively higher activity, solubility and stability compared to the full-length enzyme..$^{13,62}$

\subsection{Role of TAO in trypanosome metabolism}

\subsubsection{TAO is essential for bloodstream form respiration}

Biochemical studies have shown that TAO is bound to the mitochondrial inner-membrane and catalyzes the cyanide- and antimycin-A-resistant, non-protonmotive oxidation of ubiquinol, and the associated four-electron reduction of molecular oxygen to water. This type of respiration short-circuits the mitochondrial electron-transport chain before proton translocation by complexes III and IV, thus severely reducing ATP formation. ${ }^{1,2,34,45,63}$ It is only physiologically possible because bloodstream trypanosomes, having direct access to an inexhaustible supply of glucose, produce enough ATP by glycolysis alone.

TAO expression occurs at almost all stages of the T. brucei life-cycle, but the level of expression is developmentally regulated as the functionality of TAO depends on the developmental stage of the parasite. For instance, in the tsetse fly, TAO is expressed at a low level to allow for respiratory plasticity which helps the parasite survive the very harsh environment in the midgut of the fly; ${ }^{14}$ however, these procyclic forms have a fully functional electron transport chain, and express TAO together with COX and all the tricarboxylic acid (TCA) cycle proteins. Conversely, the BSFs present in the mammalian hosts do not express COX or most TCA cycle proteins, ${ }^{50,64}$ and their mitochondria do not contain the succinate dehydrogenase complex (complex II) ${ }^{28}$ or use the classical electron transport chain to generate the proton-motive force over the inner mitochondrial membrane. ${ }^{65,66}$ Instead, TAO is up-regulated through a post-transcriptional mechanism and the parasite relies exclusively on TAO as the sole terminal oxidase in its mitochondrial electron transport chain. The post-transcriptional nature of the up-regulation ensures that although the steady-state level of TAO mRNA in the parasite is only five-fold greater, the TAO protein level is approximately 100 -fold greater than that of the procyclic form. ${ }^{67}$

This arrangement means BSF rely solely on the catabolism of blood glucose, taken up efficiently by the THT1 transporter, ${ }^{68}$ as its source of energy ${ }^{50}$ and in order to ensure the required high glycolytic flux the trypanosome developed a unique organelle, the glycosome, which is the compartment where glycolysis takes place. ${ }^{69}$ This organelle contains a 100-fold higher concentration of glycolytic enzymes compared to the cytoplasm of a typical cell, allowing the glycolytic reaction to take place with high efficiency, with pyruvate as its end product, which is normally secreted by the parasite, through a Pyruvate Transporter (TbPT0) that is related to a 
plant gene family rather than mammalian carboxylate transporters. ${ }^{70}$ The glyceraldehyde dehydrogenase (GAPDH) step of glycolysis generates reducing equivalents in the form of NADH, which must be re-oxidized to $\mathrm{NAD}^{+}$and this requires the regeneration of dihydroxyacetone phosphate (DHAP) from glycerol-3-phosphate (G-3-P). ${ }^{71}$ During this process, Glycerol-3phosphate dehydrogenase (G-3-PDH) oxidizes G-3-P to DHAP, facilitating the transfer of 4 electrons to ubiquinol, ${ }^{14}$ which is subsequently oxidized to ubiquinone by TAO to convert molecular oxygen to water (Figure 1a). Thus, under aerobic conditions, a molecule of glucose in the BSF produces a net yield of just two molecules of ATP, as no ATP is generated by the electrons transferred to TAO.
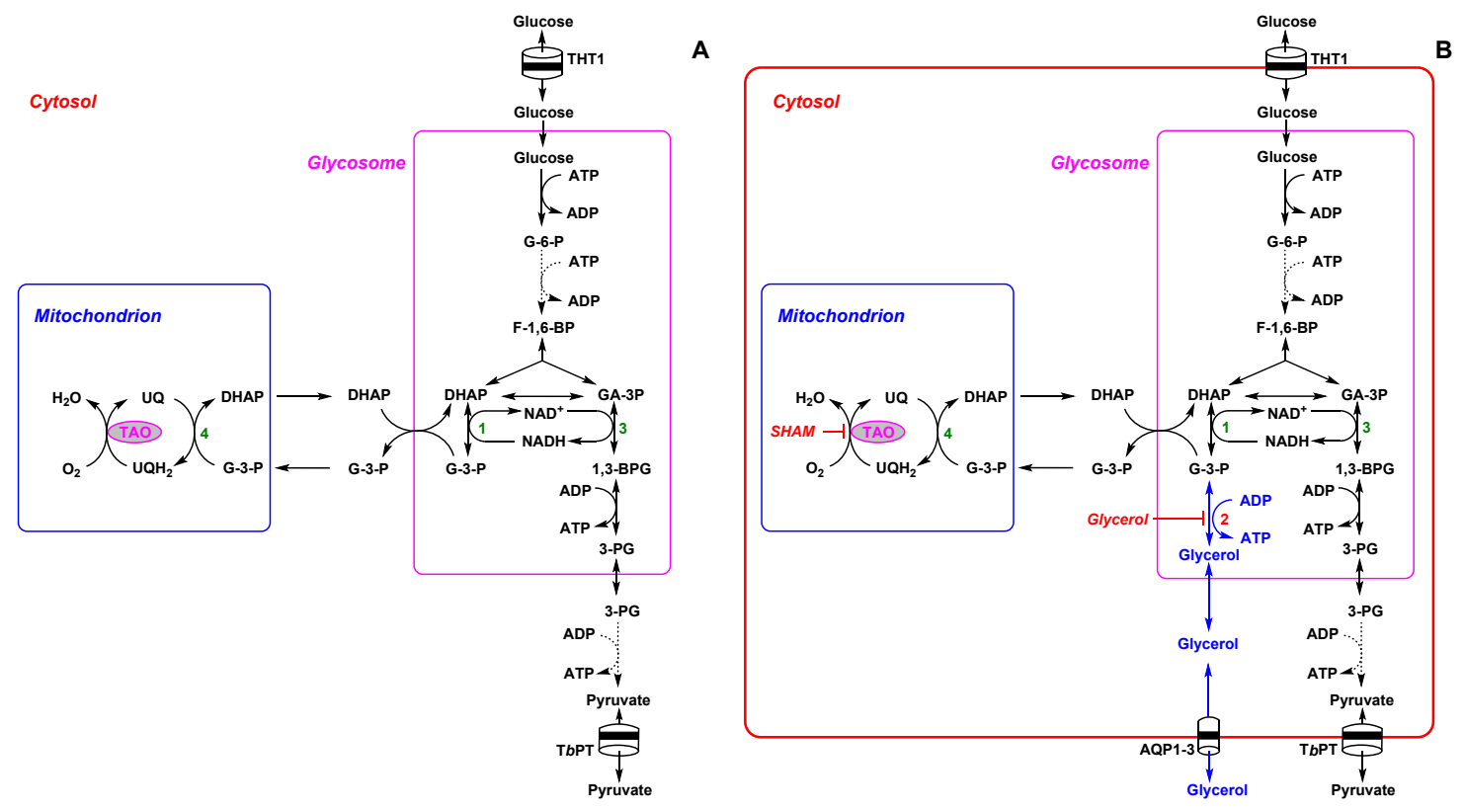

Figure 1. A scheme of aerobic (a) and anaerobic (b) glycolysis in bloodstream-form Trypanosoma brucei. The solid lines represent reactions catalysed by a single enzyme, whereas the dashed lines represent multiple sequential reactions. G-6-P = glucose-6-phosphate; F-1,6-BP $=$ fructose-1,6-bisphosphate; GA-3-P = glyceraldehyde-3-phosphate; 1,3-BPG = 1,3bisphosphoglycerate; 3-PG = 3-phosphoglycerate; DHAP = dihydroxyacetone phosphate; G-3-P = glycerol-3-phosphate; 1 = Glycerol-3-phosphate dehydrogenase; $2=$ Glycerol kinase; $3=$ glyceraldehyde-3-phosphate dehydrogenase (GAPDH); 4 = Glycerol-3-phosphate dehydrogenase (G-3-PDH).

Conversely, under anaerobic condition or when TAO is inhibited by inhibitors such as SHAM or ascofuranone, only one mole of ATP per mole of glucose is produced as G-3-P can no longer be reformed to DHAP, leading to the production of equimolar amounts of pyruvate and glycerol as waste products to be released (Figure 1b). ${ }^{14}$ Although this halves its energy production to a single ATP/glucose, BSF can survive these conditions for short periods, as the conversion of G-3-P to 
glycerol by the enzyme glycerol kinase (GK) ensures that the glycosomal NAD ${ }^{+}$NADH balance is maintained. This means that the inhibition of TAO alone is not sufficient to rapidly kill the BSF although T. brucei cultures were sterilized by SHAM within $24 \mathrm{~h},{ }^{72}$ due to the accumulation of glycerol in the medium. Once a millimolar concentration of glycerol is attained, the reverse action of glycerol kinase will dominate, due to mass action of glycerol, producing G-3-P from glycerol, leading to a halt of the anaerobic glycolysis taking place in the glycosome. ${ }^{73}$ Indeed, coadministration of $0.5 \mathrm{mM}$ glycerol with SHAM or ascofuranone (a TAO inhibitor) led to an immediate death and disappearance of the parasites from the blood of $T$. vivax-infected mice. ${ }^{74}$ Helfert et al. ${ }^{72}$ also saw that reducing TAO expression with $\mathrm{RNA}_{\mathrm{i}}$ killed the parasites. These results show that TAO is essential for the respiration of BSF T. brucei. Over-production of TAO protein in the procyclic form causes a preferential shift from COX-mediated respiration to TAOmediated respiration ${ }^{75}$ but the attempted overexpression of the TAO in BSF did not appear to yield a significant increase in $\mathrm{TAO}$ protein, or a shift in inhibitor $\mathrm{EC}_{50}$ values; this was attributed to the already very high level of TAO in these cells. ${ }^{13}$

\subsubsection{The role of TAO in procyclic trypanosomes: control of ROS and surface coat composition}

One of the major roles of the AOX in photosynthetic plants is to protect the photosynthetic machinery from reactive oxygen species (ROS) through the rapid turnover of NADH. Maxwell and co-workers discovered that the overexpression of AOX resulted in cells with lower ROS levels. ${ }^{41}$ Several studies have suggested that TAO similarly protects trypanosomes against ROS. ${ }^{15,18,76}$ For instance, Fang and Beattie ${ }^{76}$ found that inhibiting TAO with SHAM elevates the levels of ROS in the mitochondria of procyclic trypanosomes, causing increased oxidative damage to cellular proteins. Conversely, inhibiting the cytochrome $b c_{1}$ complex with antimycin A, or treating cells with hydrogen peroxide (either of which increases cellular ROS levels), resulted in increased expression and activity of TAO. ${ }^{76}$ The possibility that TAO acts to prevent damaging oxidative stress by ROS has not been extensively studied in the long-slender bloodstream form of T. brucei, where its role in respiration is of primary importance; however, TAO-mediated ROS protection has been suggested to inhibit programmed cell death (PCD)-like phenomena in BSF T. b. rhodesiense under stress conditions such as high cell density or cold temperature. ${ }^{77}$

The surface of the procyclic form of $T$. brucei that resides in the midgut of tsetse flies is covered by several million copies of invariant glycosylphosphatidylinositol-anchored proteins known as procyclins. They are the products of a small multigene family known to encode unusual proteins containing an extensive tandem repeat unit of characteristic amino acid sequences at the $\mathrm{C}$ terminus. It has been suggested that procyclins protect the procyclics against proteases and/or 
participate in tropism, which directs the parasites from the tse-tse fly midgut to its salivary glands prior to transmission to a new host. ${ }^{78,79}$ The two major types of procyclin are GPEET and EP, which contain an internal pentapeptide repeat motif (rich in Gly-Pro-Glu-Glu-Thr repeats), and a dipeptide internal repeat motif (rich in Glu-Pro repeats), respectively.

The expression of GPEET and EP in T. brucei is developmentally regulated in the tsetse fly midgut, with the GPEET component downregulated in late procyclics. ${ }^{80}$ Vassella et al. ${ }^{81}$ showed that the inhibition of TAO activity by SHAM in procyclics of T. brucei repressed the expression of GPEET procyclin, whereas repression of the pyruvate dehydrogenase or succinyl-CoA synthetase boosted GPEET expression in late procyclics. Similarly, the overexpression of the TAO protein was shown to increase GPEET expression. ${ }^{75}$ Thus, the balance between cytochromeand TAO-mediated respiration, and the associated differences in ROS-protection, appears to directly regulate the expression of cell-surface glycoproteins.

\subsection{Alternative oxidases in pathogenic and agrochemically important fungi}

While AOX is essentially ubiquitous within the plant kingdom, it is also found, although more sporadically, in the other kingdoms. AOX has been found in yeasts, algae, free-living amoebae, slime molds, nematodes, protists, mollusks, a few animal species (but not mammals), bacteria (but not Archaea), as well as fungi. ${ }^{46,57,82-84}$ In prokaryotes, AOX is restricted to some $\alpha$ proteobacteria such as Novosphingobium aromaticivorans, ${ }^{85}$ and it is probable that AOX entered eukaryotic ancestries through the ancient proteobacterial endosymbiont that gave rise to mitochondria. ${ }^{3,11}$ Although this oxidase is thus present in many organisms, its function may vary: in thermogenic plants, AOX activity is linked with the production of heat; in other organisms AOX activity is essential for ROS control, and for the maintenance of metabolic homeostasis such as carbon metabolism, cellular energy demand and redox state.

AOX has been studied intensely in some human-infective fungi, as well as some agrochemically important fungi such as Magnaporthe grisea (rice blast fungus) and Chalara fraxinea (U.K. dieback Ash disease). ${ }^{1-3}$ For instance, when certain phytopathogenic fungi were exposed to commercial fungicidal agents that targeted their mitochondrial $b c_{1}$ complex, they expressed a plant-like AOX, apparently as an alternative respiratory mechanism, which conferred a degree of fungicide resistance on these pathogens. ${ }^{2,86}$. For example, AOX was induced in M. grisea after treatment with the cytochrome $b c_{1}$ complex inhibitor SSF-126 ((E)-2-methoxyimino- $N$-methyl2-(2-phenoxyphenyl)-acetamide), ${ }^{87}$ as well as by hydrogen peroxide; ${ }^{88}$ the expression levels correlated with the activity of AOX-mediated respiration. As treatment of M. grisea mitochondria with SSF-126 induced the generation of superoxide, ${ }^{87}$ it is possible that this respiratory inhibitor 
and peroxide similarly induce AOX expression through the production of ROS, with AOX acting in response to oxidative stress.

Indeed, it is becoming clear that, in numerous fungi, AOX plays a crucial role in the response of cells to various types of stress. This conclusion is based mainly on observations of increased AOX transcripts during e.g. oxidative stress in Aspergillus niger ${ }^{89}$ A. fumigatus, ${ }^{90}$ Magnaporthe grisea ${ }^{88}$ Hansenula anomala,${ }^{91}$ Candida albicans, ${ }^{9}$ Paracoccidioides brasiliensis $;{ }^{92}$ after heat shock in Yarrowia lipolytica and Aspergillus niger ${ }^{89,93}$ and during osmotic stress in A. niger ${ }^{89}$ In pathogenic fungi such as $P$. brasiliensis ${ }^{94}$ and Cryptococcus neoformans, ${ }^{95}$ virulence decreased upon deletion of the AOX gene, suggesting a significant role for this enzyme during infection.

The hypothesis that AOX is needed for pathogenicity in many of the economically most important fungi was also studied in Ustilago maydis, a dimorphic fungus of the phylum basidiomycetes that infects maize. ${ }^{96,97}$ U. maydis depends on mitochondrial function for ATP synthesis..${ }^{98,99}$ CárdenasMonroy et al. ${ }^{100}$ found that AOX expression in this fungus was induced during the stationary phase, signifying an important role for AOX at high cell densities, when the nutrients become limiting. However, using AOX overexpressing and AOX null U. maydis, it was concluded that AOX was dispensable for the normal biology of this fungus, even though essential in the response to respiratory stress.

Given the important cellular functions of AOX in fungi, and its major roles in pathogenicity and drug resistance, further research in this area, including the development of inhibitors specific for fungal AOXs, would appear to be a priority. The possibility of treatment combining traditional fungicides with such inhibitors deserves particular attention.

\section{VALIDATION OF TAO AS DRUG TARGET IN AFRICAN TRYPANOSOMES}

A recent trend in drug discovery is that some pharmaceutical companies have shifted away from high throughput screening (HTS) for the development of novel therapeutics, to a rational drug discovery (RDD) approach. ${ }^{101}$ RDD is a high-tech approach to drug development that usually entails using the 3-dimensional structure of a particular drug target molecule (often a protein) for the design of a small effector molecule (an inhibitor/activator or an agonist/antagonist) to affect the function of the target molecule in the organism, and bring about a desired therapeutic effect. As prerequisites in the early stage, it is important to identify the drug target and to validate that it is worthy and druggable, i.e. that its function can be modulated by a drug to elicit a desired therapeutic response. The process of target validation assesses whether a molecular target merits the development of pharmaceuticals for therapeutic application. ${ }^{102}$ Certain criteria are used for the assessment of a suitable drug target. In the context of African trypanosomiasis, as is the case 
for most infectious diseases, a good drug target should be essential for the parasite survival (or proliferation) in the host and, preferably, absent or not essential to the host (although the latter obstacle can be overcome with agents of sufficient specificity for the pathogen target). The trypanosome alternative oxidase fulfils these criteria, as it is central to ATP synthesis in the bloodstream forms of African trypanosomes and no homolog of the gene is present in mammals. ${ }^{14,103}$

\subsection{Validation and functional expression studies}

The AOXs of plants are encoded mostly by multigene families and differential expression of the separate gene products varies with growth conditions, which regulate their expression at specific developmental stages, and in response to external stressors such as fungal pathogens, heat and drought. ${ }^{104,105,106}$ In contrast, TAO is probably a single copy gene in the genome of African trypanosomes, but in a similar fashion its expression level changes dramatically as the parasites encounter different environmental conditions in the course of their life cycle. The gene is upregulated while the trypanosome is in the mammalian blood but is turned low as they transit to the insect-stage procyclic forms, as discussed in section 2.2.2. The functionality of TAO as a terminal oxidase was demonstrated in hemA-deficient bacteria, which lack the canonical terminal oxidase activity of cytochromes $b o$ or $b d$ due to their inability to synthesize heme. ${ }^{107,108}$ For these mutant bacteria strain to grow, the growth medium must be supplemented with 5-aminolevulinic acid (ALA) to bypass the hemA function and enable the bacteria to produce the heme required for the cytochrome activities. Growth of the mutant bacteria in the absence of ALA was restored when complemented by functional expression of the TAO gene, and was sensitive to SHAM and ascofuranone (AF) but insensitive to cyanide. ${ }^{109,110}$

It is clear that there is sufficient pharmacological evidence for the essentiality of TAO, however, all attempts to knockout even one copy of the TAO genes have been unsuccessful. Nevertheless, Helfert and colleagues could achieve a considerable reduction in the level of the corresponding mRNA by expressing a homologous double-stranded RNA (TAO dsRNA) using inducible RNA interference (RNAi). After $48 \mathrm{~h}$ induction of TAO-targeted dsRNA expression, the analogous mRNA virtually disappeared resulting in reduction of the growth rate by half, and oxygen consumption rate was reduced by fourfold. As expected, the mutants were more susceptible to the trypanocidal effect of SHAM than the controls. ${ }^{72}$

Knockout of all copies of the TAO genes would provide direct genetic evidence about the essentiality of TAO but the repeated failure to achieve this to date strongly suggests that this may be impossible, at least without additional adaptations, and that complete loss of TAO is indeed 
lethal to the trypanosome. An obvious explanation for this would be that the TAO is absolutely critical for respiration in T. brucei as shown by all the pharmacological evidence.

\subsection{In vitro studies with early inhibitors}

The earliest method of in vitro testing of drugs on African trypanosomes relied heavily on the use of Tobie's medium, which is a biphasic culture method that involves transfer of the parasite cells into a secondary medium requiring addition of heat inactivated defibrinated blood. Effect of the drugs was evaluated microscopically. ${ }^{111,55}$ This has been replaced by the use of simpler and more economic monophasic culture method in which the parasites are maintained in all-liquid medium, Hirumi's modified Iscove's medium 9 (HMI-9) supplemented with $10 \%$ fetal bovine serum, at 37 ${ }^{\circ} \mathrm{C}$ and in a $5 \% \mathrm{CO}_{2}$ atmosphere. ${ }^{112}$ Drugs in appropriate vehicles such as phosphate buffered saline, dimethyl sulfoxide or ethanol are added to cultures in wells of microtiter plates and incubated for a pre-determined period after which the proportion of surviving cells can be estimated by direct count under the microscope ${ }^{113}$ or using a chromogen such as resazurin (Alamar blue), which is bio-activated by enzymes in living cells. ${ }^{14,115}$ The conversion of the resulting metabolite resorufin is quantified spectrophotometrically or fluorometrically and it is proportional to the number of living cells. ${ }^{116}$ After the discovery by Schonbaum et al. ${ }^{117}$ that $\mathrm{m}$ chlorobenzhydroxamic acid ( $m$-CLAM, 9) was the most potent inhibitor of the cyanideinsensitive respiratory pathway of plants, Evans and Brown ${ }^{55}$ reported that it also displayed inhibitory activity against the cyanide-insensitive respiration of African trypanosomes. They utilized the biphasic culture method to test the anti-trypanosomal potency of $m$-CLAM and recorded that it killed the parasites by specifically blocking the cyanide-insensitive respiration in BSFs. Interestingly, high concentrations of $m$-CLAM effectively killed monomorphic longslender BSFs with $100 \%$ potency but spared some of the parasites of pleomorphic culture, implying that the inhibitor has a very low effect on the cyanide-sensitive respiration that is becoming expressed in the short-stumpy bloodstream forms that are pre-adapted for uptake by the tsetse fly vector (but also still express high levels of TAO). ${ }^{118}$ Therefore, $m$-CLAM was the first inhibitor of TAO shown to possess anti-Trypanosoma activity, although the potency is very low as up to $3000 \mu \mathrm{M}$ is required for the complete killing of the parasites in a time period of 20 minutes. ${ }^{55}$ This concentration is too high for investigation in animal models because at such high concentration, hydroxamic acids also start to inhibit the conventional cyanide-sensitive respiration, which is the main energy metabolism pathway in animals. ${ }^{117} \mathrm{~A}$ few years later, Opperdoes and co-workers found a more potent hydroxamic acid derivative, SHAM. ${ }^{119}$ At a concentration of $1000 \mu \mathrm{M}$, SHAM completely (>99\%) inhibited TAO and blocked aerobic respiration in African trypanosomes but ATP synthesis and parasite motility did not follow the same pattern as ATP was detectable and a substantial population of the parasites remained 
actively motile. However, a complete shutdown of the ATP synthesis and motility was recorded when SHAM was combined with $5 \mathrm{mM}$ glycerol, ${ }^{120,121}$ implying that the inhibition of TAO would be therapeutic only in the presence of a high concentration of glycerol. The inhibition constant $K_{\mathrm{i}}$ of SHAM for respiratory arrest of trypanosomes was estimated as $29 \mu \mathrm{M}$, and $500 \mu \mathrm{M}$ was required for the effective killing of the parasites, ${ }^{122,123}$ initiating a search for more potent TAO inhibitors that could be used for drug development. As a result, several hydroxamic acid derivatives were prepared and screened for enzyme inhibition and in vitro trypanocidal activity ${ }^{124}$ of which $p$ - $n$-tetradecyloxybenzhydroxamic acid (57) was found to be the most potent. Compound 57 displayed over 70 -fold better inhibitory potency against the enzyme $\left(K_{\mathrm{i}}=0.43 \mu \mathrm{M}\right)$ and 400 times greater trypanocidal activity when compared to SHAM. ${ }^{123,125}$ Recent efforts have led to the discovery of more potent compounds with potencies several thousands of times more potent than SHAM. ${ }^{13,113,126}$

\subsection{Studies with TAO inhibitors in in vivo models of African trypanosomiasis}

The preclinical phase of drug development requires that the identified drug candidates be tested in animal models for further investigations on physiological efficacy and safety. With respect to the TAO inhibitors reported to date, the in vivo experimental models that have been used are laboratory mice and rats, and goats. Fundamentally, co-administration of TAO inhibitors with glycerol is required for the chemotherapy of African trypanosomiasis in animals. ${ }^{120,127,121,128-130}$ The treatment outcomes reported from studies with SHAM and derivatives are complicated owing to drug- and parasite-related factors. The drug-associated factors include high therapeutic dosages, low solubilities, toxicity of the compounds at high dose, and their pharmacokinetics (blood concentration of SHAM and glycerol declines rapidly). The parasite-related factors are (1) the level of parasitemia before commencement of treatment, (2) ability of the parasites to exist in both monomorphic and pleomorphic forms, and (3) abilities of the parasites to reversibly migrate from the circulation to other niches and organs such as the brain, testes and adipose tissue. ${ }^{131-133}$

The therapeutic dosage of SHAM plus glycerol is impractically and dangerously high. Van der Meer et al. reported that doses of $355 \mathrm{mg} / \mathrm{kg}$ SHAM plus $1216 \mathrm{mg} / \mathrm{kg}$ body weight glycerol, respectively, ${ }^{134}$ which resulted in plasma concentrations of 2 and $20 \mathrm{mM}$, respectively, cleared $T$. vivax parasitaemia in goats but had severe toxic effects included the deaths of some of the treated animals. ${ }^{134}$ Moreover, as a result of the poor solubility of SHAM, large volumes of up to $1 \mathrm{~L}$ of the drug mixture solution are required for the treatment of goats. At therapeutic dosage, animals (goats, rats and mice) infected with different species of African trypanosomes were cured although variations were recorded in the degrees of cure. While goats infected with $T$. vivax eventually relapsed after apparent cure, ${ }^{134}$ mice that were infected with different strains of 
trypanosomes were permanently cured. ${ }^{135}$ Infection of animals with monomorphic bloodstream forms resulted in complete cure ${ }^{127,135}$ but failures were recorded when animals were infected with pleomorphic trypanosome strains, ${ }^{136}$ despite initial clearance of parasitaemia. ${ }^{136}$ It could be argued that these treatment failures could be due to the presence of short-stumpy forms, which also express the cytochrome-dependent (SHAM-insensitive) respiration, but this is unlikely as these forms are in irreversible growth arrest until they can transform into procyclics in the tsetse fly. ${ }^{118}$ However, the pleomorphic cell lines may have a higher preference for extravascular niches where the drug concentration may not reach the therapeutic level.

The low solubility and toxicity of SHAM has stimulated the design of SHAM derivatives that are more potent, less toxic and display improved solubility (see section 4). ${ }^{62,126}$ Likewise, efforts to find alternative TAO inhibitors has led to the discovery of ascofuranone (AF), ${ }^{113}$ and its safety and efficacy has been tested in mice infected with African trypanosomes. ${ }^{74,137}$ Remarkably, treatment with AF does not require the intravenous route, and can administered intraperitoneally or orally, both of which were able to clear parasitaemia after $30 \mathrm{~min}$ and $180 \mathrm{~min}$, respectively, in the presence of glycerol. Complete elimination of the T. b. brucei was achieved with $25 \mathrm{mg} / \mathrm{kg}$ $\mathrm{AF}$ and $1000 \mathrm{mg} / \mathrm{kg}$ glycerol via the IP route or with $100 \mathrm{mg} / \mathrm{kg} \mathrm{AF}$ and $1000 \mathrm{mg} / \mathrm{kg}$ glycerol for the oral route. ${ }^{137}$ However, AF was also able to cure T. vivax-infected mice without coadministration of glycerol, as a single i.m. dose of $50 \mathrm{mg} / \mathrm{kg}$ or $6 \mathrm{mg} / \mathrm{kg}$ i.m. on 4 consecutive days. $^{74}$

\subsection{Production of TAO using recombinant DNA technology}

Structural elucidation of a particular drug target protein molecule has the potential to greatly accelerate the success of drug discovery efforts. Protein X-ray crystallography is a major technique that is used for the determination of protein structure, and a major limitation is the ability to obtain sufficient quantities (often milligram order) of the isolated, pure protein. It is practically impossible to obtain sufficient amounts of most proteins directly from eukaryotic cells, and this was a major problem until after recombinant DNA (rDNA) technology was invented in the early $1970 \mathrm{~s},{ }^{138,139,140}$ allowing the efficient production of eukaryotic proteins in bacteria.

$\mathrm{TAO}$ is one of the at least 72 proteins found in the mitochondrial membrane sub-fraction of African trypanosomes (estimation, based on the presence of at least one predicted transmembrane domain in each protein) $)^{141}$ and it is localized in the inner membrane. ${ }^{10}$ These parasites contain one mitochondrion per cell. ${ }^{142}$ Therefore, the yield of even partially purified TAO obtainable from large-scale cultures of the parasites was very low $(0.2 \mathrm{mg})^{56}$ and insufficient for RDD. Hence, rDNA technology was adopted for the production of recombinant TAO (rTAO) for structural studies. After the T. b. brucei TAO gene was identified by Chaudhuri et al, ${ }^{57}$ it was cloned into 
the $\mathrm{pET} 15 \mathrm{~b}$ plasmid vector and used to transform FN102 E. coli strain for overexpression, and purification of the protein. ${ }^{109,143}$ This also enabled the expression of hexahistidine-tagged rTAO carrying a thrombin cutting site, ${ }^{143,144}$ both features facilitating the purification of rTAO.

Being a terminal oxidase, the activity of TAO is similar to those of E. coli cytochromes $b o$ and $b d$ complexes, which are expressed for respiratory proton pumping during aerobic and anaerobic conditions, respectively. ${ }^{107,107}$ The presence of these two respiratory enzymes in the E. coli expression host for TAO will interfere and complicate the enzymatic assay during the downstream analyses for TAO expression. To solve this problem, the quinol oxidase activity of the expression host was ablated by blocking the synthesis of the enzymes' cofactor, heme. This is achieved by deletion (through P1 transduction) of the gene that encodes glutamyl-tRNA reductase, ${ }^{145}$ the enzyme that catalyzes the first step of heme biosynthesis in E. coli. The ubiquinol oxidase activity of TAO is heme-independent, therefore it is functionally expressed in the resultant heme-deficient mutant E. coli strain - in fact, the strain is only able to grow because rTAO functions as the sole terminal oxidase in the respiratory chain of the mutants, complementing the heme-deficiency. The mutant cells not complemented with TAO can only grow when the culture is supplemented with ALA, an early precursor of heme synthesis upstream of glutamyl-tRNA reductase.

TAO consists of 330 amino acid residues and its $N$-terminal 25 residues (MFRNHASRITAAAAPWVLRTACRQK) form the mitochondrial targeting signal (MTS), which is cleaved off after it has entered the mitochondrion, creating $\triangle$ MTS-rTAO. ${ }^{58}$ Until recently all studies used expression of full-length rTAO (FL-rTAO), i.e. including the MTS, ${ }^{61,109,144,146}$ but this may not accurate reflect the activity or pharmacology of $\triangle$ MTS-rTAO. Therefore, FL-rTAO and $\triangle$ MTS-rTAO were recently overexpressed and purified under the same conditions and it was found that the later presented 2- to 4-fold better properties in terms of solubility, protein yield, and specific activity, ${ }^{13}$ implying that the MTS may affect protein folding, and we strongly recommend the use of $\triangle \mathrm{MTS}-\mathrm{rTAO}$ for studies leading to RDD. Residues 1-30 were not visible in the crystal structures of TAO because of the flexibility of that sequence, ${ }^{10}$ reinforcing the argument that the splicing off does not substantially affect the catalytic core domains.

Cellular fractionation shows that rTAO localizes in the membrane fraction of the expression host and membrane solubilization is therefore an important step in the purification of rTAO. This requires the use of an appropriate detergent that will release the enzyme from the membrane without negative consequences. Earlier, the detergent NP-40 was used ${ }^{56}$ but it is associated with certain undesirable effects on the enzyme. As a result, Kita's group performed screening of alternative detergents including those that have been reported to work well for plant AOXs, and found digitonin to be better in terms of maintaining rTAO stability. ${ }^{144}$ Further optimization was necessary because the yield of rTAO was very low: only $0.38 \mathrm{mg}$ was obtainable from 10 liters 
of culture. ${ }^{144}$ After a further series of screening and optimization, $1.4 \%(w / v)$ of $n$-octyl- $\beta$-Dglucopyranoside (OG) was described to be better at maintaining the protein's activity and improving the yield, which increased to $5-9 \mathrm{mg} / 10 \mathrm{~L}$ culture (Table 1). The OG was changed to $0.042 \%(w / v) n$-dodecyl- $\beta$-D-maltopyranoside during the elution step of the purification. ${ }^{13,61,45}$

Table 1. Effect on the solubilization detergent on the TAO activity and recovery of purified TAO. $\mathrm{OG}=n$-octyl- $\beta$-D-glucopyranoside

\begin{tabular}{lllll}
\hline Detergent & $\begin{array}{l}\text { TAO yield } \\
(\mathrm{mg} / 10 \mathrm{~L})\end{array}$ & $\begin{array}{l}\text { Specific activity } \\
(\mathrm{mole} / \mathrm{min} / \mathrm{mg})\end{array}$ & $\begin{array}{l}\text { Recovery } \\
(\%)\end{array}$ & Reference \\
\hline $1 \%$ Digitonin & 0.378 & 41.5 & 3.1 & Nihei $^{144}$ \\
\hline $1.4 \%$ OG & 8.95 & 207 & 13.2 & Kido $^{45}$ \\
\hline
\end{tabular}

\section{PROGRESS IN CHEMICAL SCAFFOLDS AND AOX INHIBITOR DEVELOPMENT}

Diphenylamine (1) was the first molecule reported to inhibit the cyanide-insensitive respiratory pathway in various plant systems. ${ }^{147,148}$ This compound was later found to inhibit oxygen uptake in bloodstream forms of $T$. brucei, ${ }^{149}$ a result that was confirmed a few years later by Clarkson et $a l$ who reported a low activity $\left(\mathrm{K}_{\mathrm{i}}=455 \mu \mathrm{M}\right)$ for this unique inhibitor. ${ }^{124}$

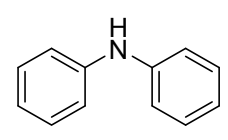

1

\subsection{Hydroxamate derivatives}

\subsubsection{Primary and secondary benzhydroxamic acids}

Almost fifty years ago, Schonbaum et al. ${ }^{117}$ described the first hydroxamate inhibitors of the alternate oxidase pathway of plant mitochondria. These primary benzhydroxamic acids $(\mathbf{2}, \mathbf{4}$, 8-10, 12, 13, 18-23) specifically and reversibly inhibited the cyanide-insensitive respiratory pathway in munk bean (Phaseolus aureus) and skunk cabbage (Symplocarpus foetidus). $m$-Chloro and $m$-iodobenzhydroxamic acids ( $\mathbf{9}$ and $\mathbf{1 0}$, respectively) were the most potent inhibitors tested with $\mathrm{IC}_{50}$ values $<50 \mu \mathrm{M}$ (Figure 2). ${ }^{117}$ One year later, in 1973, Evans and Brown reported that $m$-CLAM (9) inhibited the cyanide-insensitive respiration of bloodstream forms of $T$. brucei in vitro. ${ }^{55,150}$ Opperdoes and co-workers showed that SHAM (2) was another powerful inhibitor of 
the $\alpha$-glycerophosphate oxidase (GPO) system of $T$. brucei. ${ }^{151}$ Specifically, this system oxidizes glycerol-3-phosphate (G3P) using an electron transport system in the inner mitochondrial membrane consisting of G3P dehydrogenase, ubiquinone, and the trypanosome alternative oxidase (TAO). SHAM was shown to inhibit GPO non-competitively $\left(\mathrm{K}_{\mathrm{i}}=21 \mu \mathrm{M}\right) .{ }^{124}$

NOTE: for consistency, we will refer to inhibition of GPO, as measured by the inhibition of oxygen uptake, for the earlier studies on AOX inhibitors (before 1996) and to inhibition of TAO for later studies using the recombinant rTAO enzyme. ${ }^{57}$

Only primary and secondary aromatic hydroxamates are active (Figures 2-3), whereas aliphatic and alpha-amino acid hydroxamates did not inhibit the T. brucei GPO. ${ }^{123,124} m$-Substituted benzhydroxamates with a chlorine (9) or iodine (10) atom at $\mathrm{C} 2$ were equipotent inhibitors and twice as active as SHAM. o-Substituted benzhydroxamic acids with hydrogen bond (HB) donating groups such as $\mathrm{OH}(2)$ or $\mathrm{NH}_{2}(3)$ gave the most potent inhibitors. Among the SHAM analogues, 3- and 5-substituted derivatives (20-24) provided no improvement in inhibition compared to 2. According to this study, no correlation exists between the inhibition of GPO and either the acidity $\left(\mathrm{p} K_{\mathrm{a}}\right)$ or the affinity for iron of the hydroxamate derivatives. ${ }^{124}$ 

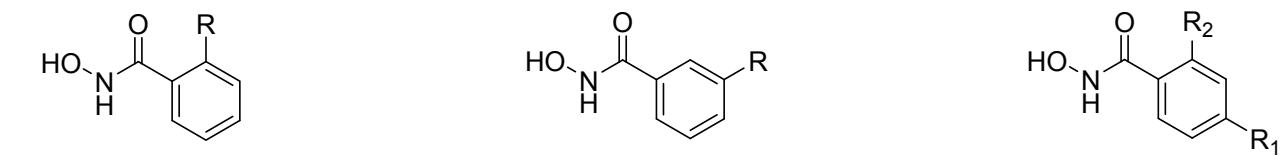

\begin{tabular}{lll} 
Cpd & $\mathrm{R}$ & T. brucei $K_{\mathrm{i}}(\mu \mathrm{M})$ \\
\hline $\mathbf{2}(\mathrm{SHAM})$ & $\mathrm{OH}$ & 21 \\
$\mathbf{3}$ & $\mathrm{NH}_{2}$ & 33 \\
$\mathbf{4}$ & $\mathrm{H}$ & 152 \\
$\mathbf{5}$ & $\mathrm{Me}$ & 169 \\
$\mathbf{6}$ & $\mathrm{F}$ & 300 \\
$\mathbf{7}$ & $\mathrm{Cl}$ & 567
\end{tabular}

\begin{tabular}{lll} 
Cpd & $\mathrm{R}$ & T. brucei $K_{\mathrm{i}}(\mu \mathrm{M})$ \\
\hline $\mathbf{8}$ & $\mathrm{F}$ & $\mathrm{N} / \mathrm{A}$ \\
$\mathbf{9}(m$-CLAM $)$ & $\mathrm{Cl}$ & 10 \\
$\mathbf{1 0}$ & $\mathrm{I}$ & 11 \\
$\mathbf{1 1}$ & $\mathrm{Br}$ & 20 \\
$\mathbf{1 2}$ & $\mathrm{Me}$ & 23 \\
$\mathbf{1 3}$ & $\mathrm{NO}_{2}$ & 329
\end{tabular}

\begin{tabular}{llll} 
Cpd & $\mathrm{R}_{1}$ & $\mathrm{R}_{2}$ & T. brucei $K_{\mathrm{i}}(\mu \mathrm{M})$ \\
\hline $\mathbf{1 4}$ & $\mathrm{NMe}_{2}$ & & 13.2 \\
$\mathbf{1 5}$ & $\mathrm{Cl}$ & $\mathrm{Cl}$ & 52 \\
$\mathbf{1 6}$ & $\mathrm{NO}_{2}$ & & 62 \\
$\mathbf{1 7}$ & $\mathrm{OH}$ & & 1043 \\
$\mathbf{1 8}$ & $\mathrm{Cl}$ & & $\mathrm{N} / \mathrm{A}$ \\
$\mathbf{1 9}$ & & $\mathrm{CO}_{2} \mathrm{H}$ & N/A
\end{tabular}<smiles>[R]c1cccc(C(=O)NO)c1O</smiles><smiles>[R]c1ccc(O)c(C(=O)NO)c1</smiles>

\begin{tabular}{lll} 
Cpd & $\mathrm{R}$ & T. brucei $K_{\mathrm{i}}(\mu \mathrm{M})$ \\
\hline $\mathbf{2}$ & $\mathrm{H}$ & 21 \\
$\mathbf{2 0}$ & $\mathrm{OH}$ & 19 \\
$\mathbf{2 1}$ & $\mathrm{Me}$ & 40
\end{tabular}

$$
\begin{array}{lll}
\text { Cpd } & \mathrm{R} & \text { T. brucei } K_{\mathrm{i}}(\mu \mathrm{M}) \\
\hline \mathbf{2 2} & \mathrm{OH} & 38
\end{array}
$$$$
23 \mathrm{Br} \quad 55
$$$$
24 \text { Me } 77
$$<smiles>O=C(NO)c1cc(O)c(O)c(O)c1</smiles>

29: $K_{\mathrm{i}}=132 \mu \mathrm{M}$ (T. brucei)

$\mathrm{IC}_{50}(\mu \mathrm{M})$

\begin{tabular}{lll} 
& \multicolumn{2}{c}{$\mid \mathrm{C}_{50}(\mu \mathrm{M})$} \\
\cline { 2 - 3 } Cpd & Skunk cabbage & Mung bean \\
\hline $\mathbf{2}$ & 260 & 60 \\
$\mathbf{4}$ & 400 & 90 \\
$\mathbf{8}$ & 240 & 60 \\
$\mathbf{9}$ & 160 & 30 \\
$\mathbf{1 0}$ & 50 & 20 \\
$\mathbf{1 2}$ & 350 & 90 \\
$\mathbf{1 3}$ & 300 & 60 \\
$\mathbf{1 8}$ & 320 & 90 \\
$\mathbf{1 9}$ & 1070 & 210 \\
$\mathbf{2 5}$ & 220 & $\mathrm{~N} / \mathrm{A}$ \\
$\mathbf{2 6}$ & 810 & 240 \\
$\mathbf{2 7}$ & 1300 & 180 \\
$\mathbf{2 8}$ & 890 & 160
\end{tabular}

Figure 2. $K_{\mathrm{i}}$ and $\mathrm{IC}_{50}$ values for the inhibition of the cyanide-insensitive terminal oxidase pathway (inhibition of oxygen uptake) of $T$. brucei, skunk cabbage, and mung bean by primary benzhydroxamic acids. ${ }^{55,117,124,150}$

Secondary benzhydroxamic acids showed decreased potency compared with the primary hydroxamates (Figure 3, compare 9 vs 30-34). ${ }^{124}$ Even though the inhibitory effect seemed to depend on the size of the $N$-alkyl substituent ( $n$-hexyl $>\mathrm{Me}>c$-hexyl $>\mathrm{Ph}$ ) - and be limited by the bulkiness of $\mathrm{R}$ - no clear trend was detected with regards to the potency of inhibition for these secondary hydroxamates. 
Figure 3. $K_{\mathrm{i}}$ values for the inhibition of the AOX pathway (inhibition of oxygen uptake) of $T$. brucei by secondary benzhydroxamic acids. ${ }^{124}$

\subsection{2. $N$-hydroxy heterocycles}

Clarkson et al also evaluated a series of heterocyclic compounds in which the hydroxamate moiety was part of the ring system (Figure 4). The activity of 1,4-dihydroxy-2(1H)-quinolinone 36 and its 3-bromo analogue $\mathbf{3 7}$ was comparable to that of the most active benzhydroxamates shown in Figures 2 and 3. ${ }^{123,124}$ Parent compound 35, lacking the 4-hydroxy group, was a significantly less potent inhibitor of T. brucei AOX.

Aurachins are quinoline antibiotics isolated from myxobacteria. ${ }^{152}$ Aurachin $\mathrm{C}$ analogues with an $n$-decyl (38a) or $n$-octyl (38b) chains strongly inhibit the cyanide-insensitive NADH oxidation of higher plant mitochondria. ${ }^{153}$ Similarly to 35 , the aurachin D analogue $\mathbf{3 8 c}$, lacking the 4-OH group, was much less effective than $\mathbf{3 8 a}$ and $\mathbf{3 8 b}$ indicating that the $N-\mathrm{OH}$ group is essential for potent AOX inhibition. ${ }^{154}$ However, both types of aurachins are not specific AOX inhibitors as they also act strongly at the $\mathrm{Q}_{\mathrm{i}}$ site of the cytochrome $b c_{1}$ complex. ${ }^{153}$ Compound $\mathbf{3 8 a}$ also inhibits T. vivax AOX in the micromolar range (Figure 4). ${ }^{155}$

Other $N$-hydroxyheterocyclic compounds such as 4-hydroxy-2H-benzo[b][1,4]thiazin-3(4H)ones (41-45), 2-dodecyl-1-hydroxyquinolin-4(1H)-one (38), 1-hydroxy-3-methylquinazoline2,4(1H,3H)-dione (39), and 1,3-dihydroxy-1,3-dihydro-2 $H$-benzo[d]imidazol-2-one (40) were less active than the 1,4-dihydroxy-2(1H)-quinolinones. Of note was the lack of activity of the 1,1dioxo derivative 46 compared with 41 . 
<smiles>[R1]c1c(C)c(=O)c2ccccc2n1[R2]</smiles>

\begin{tabular}{llll} 
Cpd & $\mathrm{R}_{1}$ & $\mathrm{R}_{2}$ & $K_{\mathrm{i}}(\mu \mathrm{M})$ \\
\hline $\mathbf{3 5}$ & $\mathrm{H}$ & & $172-238$ \\
$\mathbf{3 6}$ & $\mathrm{OH}$ & & 27 \\
$\mathbf{3 7}$ & $\mathrm{OH}$ & $\mathrm{Br}$ & $10-83$
\end{tabular}<smiles>Cn1c(=O)c2ccccc2n(O)c1=O</smiles><smiles>O=c1n(O)c2ccccc2n1O</smiles>

40: $K_{\mathrm{i}}=1650$ $\mu \mathrm{M}$ \begin{tabular}{lllll} 
& $\mathrm{R}_{1}$ & $\mathrm{R}_{2}$ & $\mathrm{IC}_{50}$ \\
\hline 38a (Aurachin $\mathrm{C}_{1-10}$ ) & $n$-decyl & $\mathrm{OH}$ & 28
\end{tabular} 38b (Aurachin $\mathrm{C}_{1-8}$ ) $n$-octyl $\mathrm{OH}$ 38c (Aurachin $\mathrm{D}_{1-10}$ ) $n$-decyl $\mathrm{H}$<smiles>[R]c1ccc2c(c1[R2])N(O)C(=O)C([R3])S2</smiles>

\begin{tabular}{lllll}
$\mathrm{Cpd}$ & $\mathrm{R}_{1}$ & $\mathrm{R}_{2}$ & $\mathrm{R}_{3}$ & $K_{\mathrm{i}}(\mu \mathrm{M})$ \\
\hline $\mathbf{4 1}$ & $\mathrm{H}$ & & & 527 \\
$\mathbf{4 2}$ & $\mathrm{Me}$ & & & 152 \\
$\mathbf{4 3}$ & & $\mathrm{CF}_{3}$ & & 837 \\
$\mathbf{4 4}$ & & & $\mathrm{CH}_{2} \mathrm{CO}_{2} \mathrm{Me}$ & 768 \\
$\mathbf{4 5}$ & & & $\mathrm{Me}$ & $>2000$
\end{tabular}

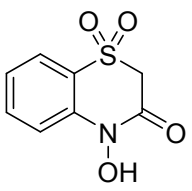

46: $K_{\mathrm{i}}>2000 \mu \mathrm{M}$, inactive

Figure 4. $K_{\mathrm{i}}$ values for the inhibition of $T$. brucei alternative oxidase pathway (inhibition of oxygen uptake) by heterocyclic $N$-hydroxy compounds. $\mathrm{IC}_{50}$ value for the inhibition of $T$. vivax AOX. ${ }^{123,124,155}$

\subsubsection{Alkyloxybenzhydroxamic acids and related compounds}

In these series of alkyloxybenzhydroxamic acids, the inhibitory activity against GPO depends on the length and the position (para $>$ ortho) of the alkyloxy substitutent (Figure 5). Increasing the number of methylene units in the alkyl chain results in an increase of GPO inhibition even though this effect is not linear (47-58). The best activity was observed with the $n$-tetradecyl chain in para position (57). Indeed, this compound displayed the highest inhibitory activity $\left(K_{\mathrm{i}}=0.43 \mu \mathrm{M}\right)$ among all the reported hydroxamate series. ${ }^{123}$ These data confirmed that lipophilic substituents enhance GPO inhibition and that substitution in para to the hydroxamate group is preferred (compare 50/60, 54/61, and 56/62). However, long chain para-alkyloxybenzhydroxamates have limited aqueous solubility. Replacement of the ether with an amide linkage $(\mathbf{6 3}, 64)$ was detrimental to the activity while providing no significant improvement in solubility. ${ }^{123} \mathrm{~A}$ summary of the SAR of benzhydroxamic acid derivatives is presented in Figure 6.

Grady et al. showed that the mechanism of inhibition of these long chain hydroxamates is reversible and that they are not acting as detergents. Compound $\mathbf{5 6}$ was shown to kill 100\% of $T$. b. brucei bloodstream forms in vitro, at a concentration of 50-100 $\mu \mathrm{M}$ in the presence of $10 \mathrm{mM}$ glycerol. Thus, 56 was 10-20 times more active than SHAM in killing trypanosomes in vitro. However, the limited solubility of $\mathbf{5 6}$ or $\mathbf{5 7}$ prevented in vivo activity. ${ }^{123}$ 


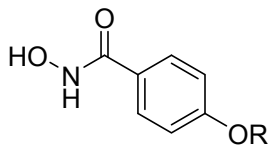<smiles>[R]Oc1cccc(C(=O)NO)c1</smiles>

\begin{tabular}{llll} 
Cpd & $\mathrm{R}$ & $K_{\mathrm{i}}$ & $\mathrm{IC}$ \\
\hline $\mathbf{4 7}$ & $\mathrm{Me}$ & 18.6 & 191 \\
$\mathbf{4 8}$ & $\mathrm{Et}$ & 13.9 & 120 \\
$\mathbf{4 9}$ & $n$-Pr & 8.3 & 70 \\
$\mathbf{5 0}$ & $n$-Bu & 13.9 & 136 \\
$\mathbf{5 1}$ & $n$-Pent & 19.3 & 201 \\
$\mathbf{5 2}$ & $n$-hexyl & 9.4 & 77 \\
$\mathbf{5 3}$ & $n$-heptyl & 5.8 & 55 \\
$\mathbf{5 4}$ & $n$-octyl & 7.0 & 59 \\
$\mathbf{5 5}$ & $n$-decyl & 3.6 & 36 \\
$\mathbf{5 6}$ & $n$-dodecyl & 1.1 & 10 \\
$\mathbf{5 7}$ & $n$-tetradecyl & 0.43 & 2.8 \\
$\mathbf{5 8}$ & $n$-hexadecyl & 1.0 & 19 \\
$\mathbf{5 9}$ & Bn & & 200
\end{tabular}<smiles>CCCCCCCCC(=O)Nc1cccc(C(=O)NO)c1</smiles>

63: $K_{\mathrm{i}}=50 \mu \mathrm{M}$

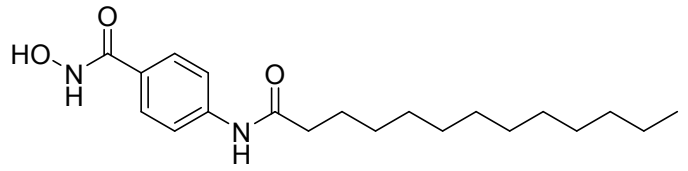

64: $K_{\mathrm{i}}=103 \mu \mathrm{M}$

Figure 5. $K_{\mathrm{i}}$ and $\mathrm{IC}_{90}$ values for the inhibition of $T$. brucei alternative oxidase pathway (inhibition of oxygen uptake) by alkyloxybenzhydroxamic acids and related compounds. ${ }^{123}$

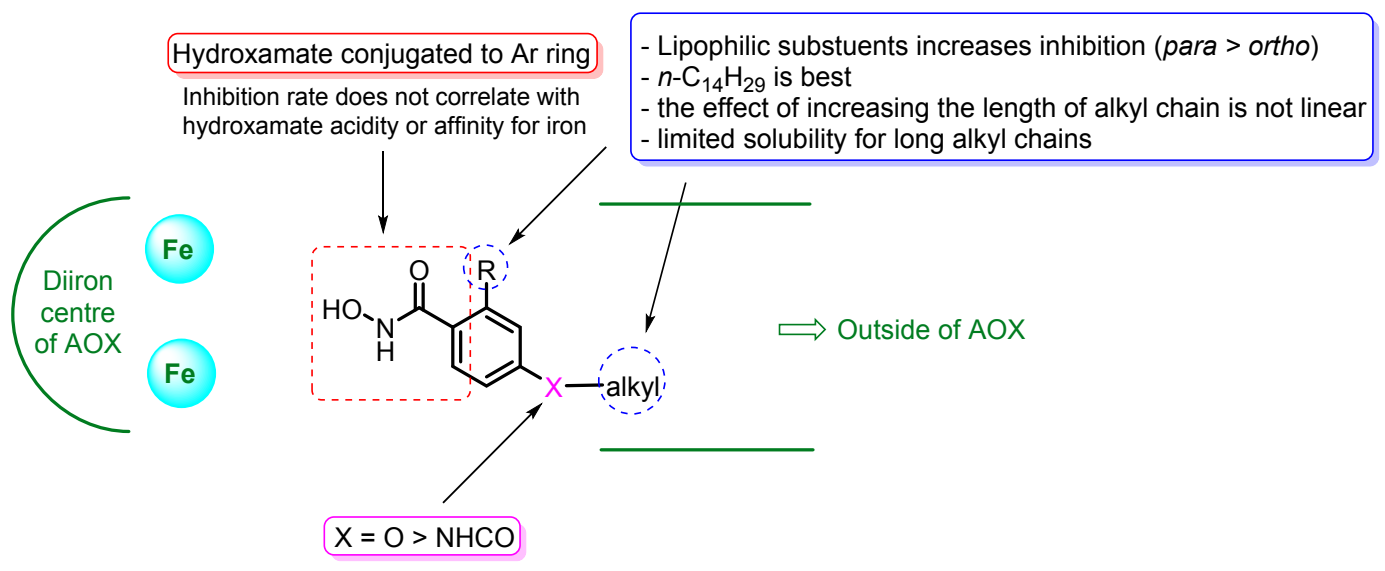

Figure 6. SAR of benzhydroxamic acid derivatives

\subsection{Other iron chelators: tropolones, 8-hydroxyquinolines, and pyridine derivatives}

In addition to hydroxamates, several classes of iron-chelating agents - tropolone (65-69), 8hydroxyquinoline $(\mathbf{7 0}, \mathbf{7 1})$, and pyridine derivatives $\mathbf{( 7 2 - 7 6 )}$ - were assayed as GPO inhibitors (Figure 7). ${ }^{124}$ Tropolone $\left(67, K_{\mathrm{i}}=122 \mu \mathrm{M}\right)$ was 2.5 times more active than 4,5-benzotropolone (68). However, the most potent inhibitor of this series was the 3-bromo benzotropolone derivative 65 which was 6- and 15-times more potent than 67 and $\mathbf{6 8}$, respectively. In contrast, 8hydroxyquinoline derivatives $\mathbf{( 7 0 ,} \mathbf{7 1})$ were poor inhibitors and the (5-hydroxy-2(hydroxymethyl)-4H-pyran-4-one 73 and pyridines 74-76 were all inactive. Among these iron chelators, lipophilic aromatic substituents enhanced inhibition (compare 67/68/65, 70/71) 
whereas hydrophilic anionic substituents (sulfonate $\mathbf{7 2}$ vs 71 ) had the opposite effect. These findings, which were in line with the SAR of benzhydroxamates (Figure 6), supported the view that iron binding per se plays at best a minor role in GPO inhibition and that other lipophilic interactions with the TAO binding site are essential.<smiles>O=c1ccc2ccc(Br)cc2cc1O</smiles>

65: $K_{\mathrm{i}}=18 \mu \mathrm{M}$<smiles>Oc1c(Br)cc(Br)c2cccnc12</smiles>

70: $K_{\mathrm{i}}=413 \mu \mathrm{M}$<smiles>CC(C)c1ccccc(=O)c1O</smiles>

66: $K_{\mathrm{i}}=110 \mu \mathrm{M}$<smiles>Oc1cccc2cccnc12</smiles>

71: $K_{\mathrm{i}}=780 \mu \mathrm{M}$<smiles>O=c1cccccc1O</smiles>

67: $K_{\mathrm{i}}=122 \mu \mathrm{M}$

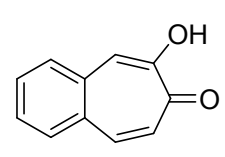

68: $K_{\mathrm{i}}=303 \mu \mathrm{M}$<smiles>O=c1c(O)cccc2cc(O)c(O)c(O)c12</smiles>

69 (Purpurogallin)

\subsection{Mono, di- and trihydroxybenzoic acid, benzaldehyde, and benzoate derivatives}

\subsubsection{Benzoic acid derivatives}

Sidow et al. showed that neither benzoic acid nor 4-hydroxybenzoic acid (90) inhibit the alternative oxidase pathway in mung bean mitochondria. ${ }^{156}$ The same result was observed in $T$. brucei. ${ }^{125}$ In contrast, 2,4-dihydroxybenzoic acid $\mathbf{8 0}$ or other 2-substituted-4-hydroxybenzoic acids $(\mathbf{7 8}, \mathbf{8 1}-\mathbf{8 3})$ are $>10$-times more potent inhibitors against rTAO, indicating that the ortho substituent at C-2 (e.g. OH, F, Me) is essential for potent inhibition by 4-hydroxybenzoic acid derivatives (Figure 8$){ }^{13}$

Gallic acid (79), a known iron chelator that lacks the 2-OH group, is a micromolar inhibitor of $T$. brucei GPO. ${ }^{125}$ In contrast, this compound does not inhibit the alternative pathway in mung bean mitochondria at a concentration up to $1 \mathrm{mM} .{ }^{156}$ Removal of the 4-OH $(\mathbf{8 4}-\mathbf{8 8})$ or protection with a methoxy group (91) yields inactive compounds indicating that the 4-OH group is important for 
potent inhibition of benzoic acid derivatives. Substitution of the 4-OH group with a geranyl tail enhanced the inhibition potency against recombinant TAO enzyme by approximately 50 - to 100 fold (compare 80/92, 81/93, 82/94, and 83/95) yielding single digit micromolar inhibitors. ${ }^{126}$ Amazingly, the introduction of one more isoprenyl unit in the farnesyl derivative 96 led to a further improvement in inhibition by 3 -orders of magnitude $\left(\mathrm{IC}_{50}=3.1 \mathrm{nM}\right){ }^{126}$ The SAR of benzoic acid derivatives is summarized in Figure 9.<smiles>[R2]c1cc(C(=O)O)c([R7])c(O)c1O</smiles>

\begin{tabular}{lllll} 
Cpd & $\mathrm{R}_{1}$ & $\mathrm{R}_{2}$ & $K_{\mathrm{i}}$ & $\mathrm{IC}_{90}(\mu \mathrm{M})$ \\
\hline $\mathbf{7 7}$ & $\mathrm{H}$ & \multicolumn{2}{l}{730} & \\
$\mathbf{7 8}$ & $\mathrm{OH}$ & \multicolumn{3}{c}{32} \\
79 & $\mathrm{H}$ & $\mathrm{OH}$ & \multicolumn{2}{c}{218}
\end{tabular}<smiles>[R]c1cc(OC/C(C)=C/CC/C(C)=C/CO)cc([R2])c1C(=O)O</smiles><smiles>[R7]Oc1c([R2])cc([R])cc1C(=O)O</smiles>

\begin{tabular}{lllll} 
Cpd & $\mathrm{R}_{1}$ & $\mathrm{R}_{2}$ & $\mathrm{R}_{3}$ & $K_{\mathrm{i}}(\mu \mathrm{M})$ \\
\hline $\mathbf{8 4}$ & $\mathrm{H}$ & & & $>1000$ \\
$\mathbf{8 5}$ & $\mathrm{H}$ & $\mathrm{OH}$ & & $>1000$ \\
$\mathbf{8 6}$ & $\mathrm{H}$ & $\mathrm{OH}$ & $\mathrm{Br}$ & $>1000$ \\
$\mathbf{8 7}$ & $\mathrm{Me}$ & $\mathrm{OMe}$ & & $>1000$ \\
$\mathbf{8 8}$ & $\mathrm{H}$ & & $\mathrm{OH}$ & $>1000$
\end{tabular}<smiles>[R20]CC=C(C)CCC=C(C)CCC=C(C)COc1cc(C)c(C(=O)O[R20])c(O)c1</smiles>

\begin{tabular}{llll} 
Cpd & $\mathrm{R}_{1}$ & $\mathrm{R}_{2}$ & $\mathrm{IC}_{50}(\mu \mathrm{M})$ \\
\hline $\mathbf{9 2}$ & $\mathrm{OH}$ & & 2.1 \\
$\mathbf{9 3}$ & $\mathrm{OH}$ & $\mathrm{Me}$ & 2.4 \\
$\mathbf{9 4}$ & $\mathrm{Me}$ & & 0.92 \\
$\mathbf{9 5}$ & $\mathrm{F}$ & & 1.1
\end{tabular}

\begin{tabular}{llll} 
Cpd & $\mathrm{R}_{1}$ & $\mathrm{R}_{2}$ & $\mathrm{IC}_{50}(\mu \mathrm{M})$ \\
\hline $\mathbf{8 0}$ & $\mathrm{OH}$ & & 116 \\
$\mathbf{8 1}$ & $\mathrm{OH}$ & $\mathrm{Me}$ & 143 \\
$\mathbf{8 2}$ & $\mathrm{Me}$ & & 112 \\
$\mathbf{8 3}$ & $\mathrm{F}$ & & 115
\end{tabular}<smiles>[R]Oc1c([R])cc(C(=O)O)cc1[R]</smiles>

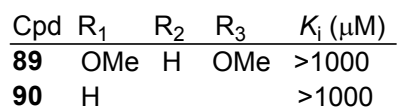
$91 \mathrm{OMe} \mathrm{Me} \mathrm{H}>1000$

Figure 8. $K_{\mathrm{i}}$ and $\mathrm{IC}_{90}$ values for the inhibition of $T$. brucei alternative oxidase pathway (inhibition of oxygen uptake) by benzoic acid derivatives. ${ }^{125} \mathrm{IC}_{50}$ values for the inhibition of purified rTAO. ${ }^{13,126}$

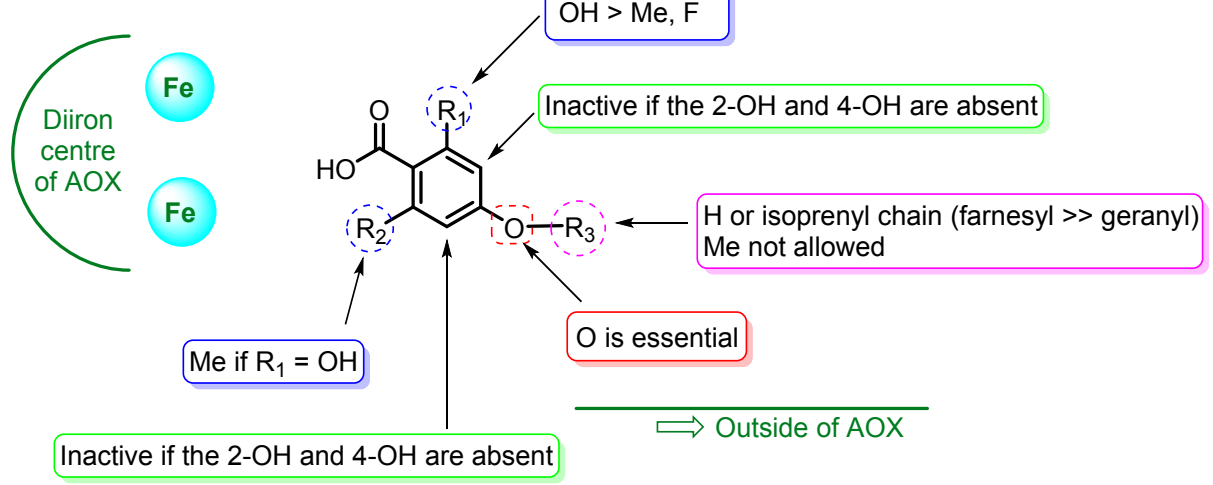

Figure 9. SAR of benzoic acid derivatives 


\subsubsection{Benzoate and benzamide derivatives}

The methyl and ethyl hydroxybenzoates $(98,100-102,106,108-109,116-129)$ display comparable SAR to that of hydroxybenzoic acids 77-97, suggesting a similar mode of binding to TAO, with the carboxylate group in close proximity to the diiron catalytic center (Figures 8 and 10). ${ }^{13,126}$ Esters of 2,5-dihydroxybenzoic acid $(\mathbf{1 0 6}, \mathbf{1 0 7})$ had no inhibitory effect even though the orientation of the hydroxyl groups better mimics that of ubiquinol. ${ }^{125}$ Substitution of the 4-OH group with a lipophilic geranyl (123-126) or C14 alkyl chain (127) yielded low micromolar inhibitors. ${ }^{126}$ In contrast, the benzoate derivatives with a larger alkyl substituent $\left(\mathrm{R}_{1}\right)$ are expected to bind AOX in a different way, with the ester alkyl chain pointing outward from the active site (Figure 11B). In this series, the $K_{\mathrm{i}}$ decreases as the length of $\mathrm{R}_{1}$ increases (Figures 10: 102-115 and Figure 11A: 130-144). Submicromolar inhibitors were obtained when the alkyl chain is $\geq$ C6 (141-144). The most potent inhibitor, dodecyl 3,4-dihydroxybenzoate $144\left(\mathrm{IC}_{90}=0.88 \mu \mathrm{M}\right)$, was almost 12-fold stronger inhibitor than its benzhydroxamic acid counterpart $56\left(\mathrm{IC}_{90}=10\right.$ $\mu \mathrm{M}) .{ }^{123,125}$ In the 3,4-dihydroxybenzoate series, methylation of the $3-\mathrm{OH}(\mathbf{1 3 3}, \mathbf{1 3 7})$ or $4-\mathrm{OH}$ (138) was detrimental to inhibition.

The 2-hydroxybenzamide compounds $\mathbf{1 5 1}$ and $\mathbf{1 5 2}$ were designed as analogues of the benzoic acid 150 with a solubility-enhancing carbohydrate moiety. These compounds inhibited rTAO competitively with micromolar $\mathrm{IC}_{50}$ values (Figure 11). They also inhibited parasite respiration and parasite growth $\left(\mathrm{EC}_{50}=16.5,33.6\right.$, and $33.1 \mu \mathrm{M}$ for $\mathbf{1 5 0}, \mathbf{1 5 1}$, and 152, respectively) in a dose-dependent manner. ${ }^{157}$

3,4-Dihydroxybenzoates have significant trypanocidal activity in mice when combined with glycerol (15 mg/kg p.o.). For instance, the i.p. administration of $143(800 \mathrm{mg} / \mathrm{kg})$ combined with glycerol reduced the parasitemia; no cures were obtained with this dose but no overt toxicity was observed either, and a higher dose might have been possible. The combination of glycerol and $n$ propyl gallate (110) suppressed the parasitemia to a lesser extent and it was also more toxic to the mice. ${ }^{125}$ 
<smiles>[R]OC(=O)c1ccc(O)cc1</smiles>

\begin{tabular}{llll} 
Cpd & $\mathrm{R}_{1}$ & $K_{\mathrm{i}}(\mu \mathrm{M})$ & $\mathrm{IC}_{90}(\mu \mathrm{M})$ \\
\hline $\mathbf{9 8}$ & $\mathrm{Me}$ & $>1000$ & \\
$\mathbf{9 9}$ & $n-\mathrm{Pr}$ & 2800
\end{tabular}<smiles>[R6]Oc1c([R3])cc([R2])cc1C([R20])=O</smiles>

\begin{tabular}{llcccc} 
Cpd & $\mathrm{R}_{1}$ & $\mathrm{R}_{2}$ & $\mathrm{R}_{3}$ & $K_{\mathrm{i}}(\mu \mathrm{M})$ & $\mathrm{IC}_{90}(\mu \mathrm{M})$ \\
\hline $\mathbf{1 0 0}$ & $\mathrm{Me}$ & \multicolumn{4}{c}{120} \\
101 & $\mathrm{Me}$ & & $\mathrm{Me}>1000$ \\
102 & $\mathrm{Me}$ & $\mathrm{Br}$ & 500 \\
103 & $n$-Pr & & & 462 \\
104 & $n$-octyl & & & 426 \\
105 & $n$-dodecyl & & & 194
\end{tabular}<smiles>[R]OC(=O)c1cc(O)ccc1O</smiles>

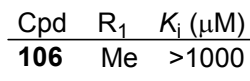<smiles>[R2]C(=O)c1cc([R2])c(O)c(O)c1[R3]</smiles><smiles>[R]c1cc(C(=O)OCC)c([R])c([R])c1[R]</smiles>

\begin{tabular}{|c|c|c|c|c|c|c|}
\hline \multirow[b]{2}{*}{ Cpd } & \multirow[b]{2}{*}{$\mathrm{R}_{1}$} & \multirow[b]{2}{*}{$\mathrm{R}_{2}$} & \multirow[b]{2}{*}{$\mathrm{R}_{3}$} & \multicolumn{2}{|c|}{ T. brucei } & \multirow{2}{*}{$\frac{\text { Munk bean }}{K_{\mathrm{i}}(\mu \mathrm{M})}$} \\
\hline & & & & $K_{i}$ & $I C_{90}$ & \\
\hline 108 & $\mathrm{Me}$ & $\mathrm{OH}$ & & & 451 & $5-6$ \\
\hline 109 & Et & $\mathrm{OH}$ & & & & $4-5$ \\
\hline 110 & $n-\operatorname{Pr}$ & $\mathrm{OH}$ & & 6.3 & & 3 \\
\hline 111 & $n$-Bu & $\mathrm{OH}$ & & & & $2-3$ \\
\hline 112 & $n$-Bu & $\mathrm{OMe}$ & & & 450 & \\
\hline 113 & $n$-Bu & $\mathrm{H}$ & $\mathrm{OH}$ & & 370 & \\
\hline 114 & $n$-octyl & $\mathrm{OH}$ & & 1.6 & & $0.3-0.4$ \\
\hline 115 & $n$-dodecyl & $\mathrm{OH}$ & & & 3.3 & \\
\hline
\end{tabular}

\begin{tabular}{|c|c|c|c|c|c|}
\hline \multirow[b]{2}{*}{ Cnd } & \multicolumn{5}{|c|}{ Munk bea } \\
\hline & $\mathrm{R}_{1}$ & $\mathrm{R}_{2}$ & $\mathrm{R}_{3}$ & $\mathrm{R}_{4}$ & $K_{\mathrm{i}}(\mu \mathrm{M})$ \\
\hline 116 & $\mathrm{H}$ & & & & $>1000$ \\
\hline 117 & $\mathrm{OH}$ & & & & $>1000$ \\
\hline 118 & & $\mathrm{OH}$ & & & $>1000$ \\
\hline 119 & & & $\mathrm{OH}$ & & 60 \\
\hline 120 & & $\mathrm{OH}$ & $\mathrm{OH}$ & & $12-15$ \\
\hline 121 & & $\mathrm{OH}$ & & $\mathrm{OH}$ & $>1000$ \\
\hline
\end{tabular}<smiles>[R20]OC/C=C(\C)CC/C=C(\C)COc1ccc(C(=O)OC)c([R7])c1</smiles><smiles>[R20]C(=O)c1c([R2])cc(OCCCNCBr)cc1O</smiles>

\begin{tabular}{llll} 
Cpd & $\mathrm{R}_{1}$ & $\mathrm{R}_{2}$ & $\mathrm{IC}$ \\
\hline 120 & $(\mu \mathrm{M})$
\end{tabular}

$123 \mathrm{OH} \quad \mathrm{Ac}>5$

$124 \mathrm{Me} \quad 1.7$

$125 \mathrm{Me}$ Ac $>5$

$126 \mathrm{~F}>5$

Figure 10. $K_{\mathrm{i}}$ and $\mathrm{IC}_{90}$ values for the inhibition of the alternative oxidase pathway (inhibition of oxygen uptake) in $T$. brucei ${ }^{13,125,126}$ and munk bean ${ }^{156}$ by benzoate derivatives. IC $_{50}$ values for the inhibition of purified rTAO. 
A<smiles>[R]OC(=O)c1ccc(O[R])c(O[R6])c1</smiles>

\begin{tabular}{|c|c|c|c|c|c|}
\hline Cpd & $\mathrm{R}_{1}$ & $\mathrm{R}_{2}$ & $\mathrm{R}_{3}$ & $K_{\mathrm{i}}(\mu \mathrm{M})$ & $\mathrm{IC}_{90}(\mu \mathrm{M})$ \\
\hline 130 & $\mathrm{H}$ & & & 730 & \\
\hline 131 & $\mathrm{Me}$ & & & 68 & \\
\hline 120 & Et & & & & 54 \\
\hline 132 & $n-\operatorname{Pr}$ & & & 3.0 & \\
\hline 133 & $n-\mathrm{Pr}$ & $\mathrm{Me}$ & & $>1000$ & \\
\hline 134 & $i-\operatorname{Pr}$ & & & 4.9 & \\
\hline \multicolumn{2}{|c|}{135 sec-Bu } & & & 10.6 & \\
\hline 136 & $n$-Bu & & & & 22 \\
\hline 137 & $n$-Bu & $\mathrm{Me}$ & & $>1000$ & \\
\hline 138 & $n$-Bu & & $\mathrm{Me}$ & $>80$ & \\
\hline 139 & $i-\mathrm{Bu}$ & & & 3.2 & \\
\hline 140 & i-pentyl & & & 10.4 & \\
\hline 141 & $n$-hexyl & & & 0.53 & 5.6 \\
\hline 142 & $n$-octyl & & & 0.55 & 4.3 \\
\hline 143 & $n$-decyl & & & 0.37 & 3.3 \\
\hline 144 & $n$-dodecyl & & & & 0.88 \\
\hline
\end{tabular}<smiles>[R]NC(=O)c1ccc(O)c(O)c1</smiles>

\begin{tabular}{lll} 
Cpd & $\mathrm{R}_{1}$ & $\mathrm{IC}_{90}(\mu \mathrm{M})$ \\
\hline 145 & $\mathrm{Et}$ & 368
\end{tabular}

$146 n-\mathrm{Bu} \quad 9.4$

147 n-hexyl 11

148 n-octyl 4.5

149 n-decyl 0.62
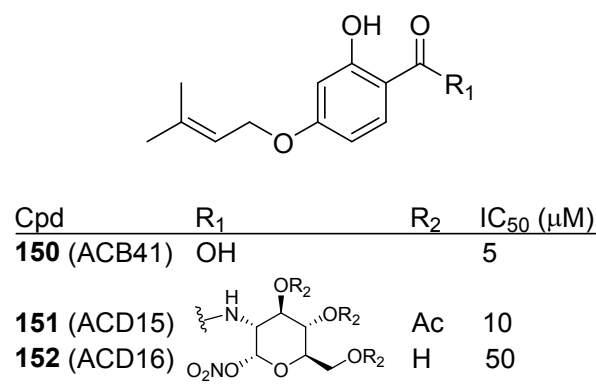

\section{B}

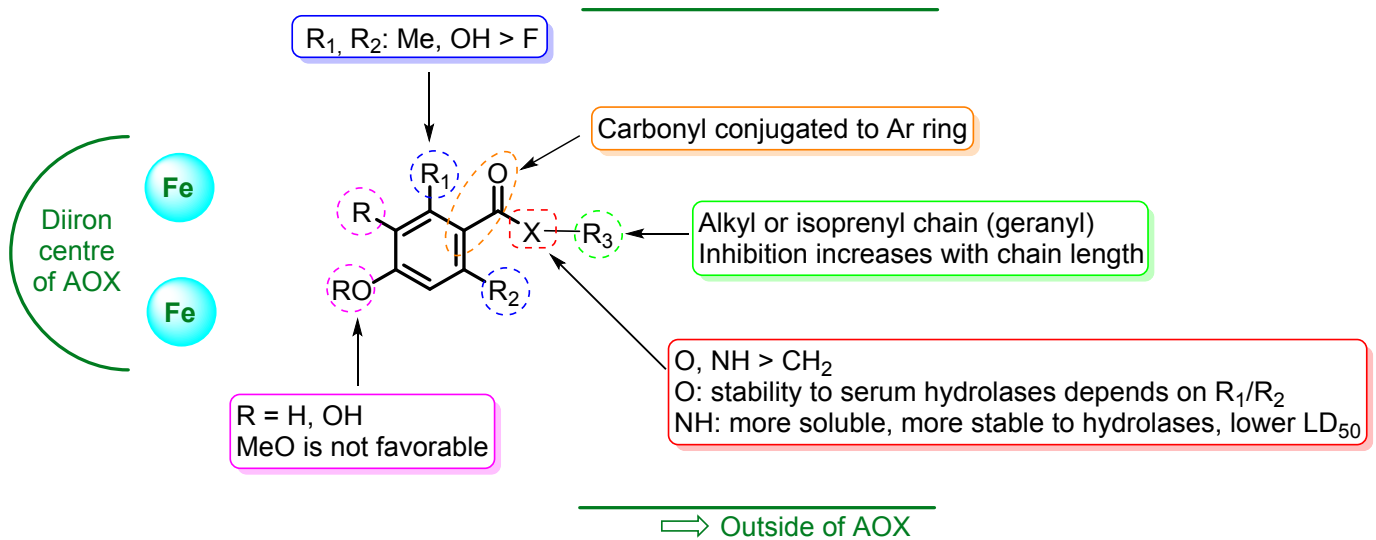

Figure 11. (A) $K_{\mathrm{i}}$ and $\mathrm{IC}_{90}$ values for the inhibition of $T$. brucei alternative oxidase pathway (inhibition of oxygen uptake) by 3,4-dihydroxybenzoate, 3,4-dihydroxybenzamide, and 2,4dihydroxybenzoic acid derivatives. $\mathrm{IC}_{50}$ values for the inhibition of purified rTAO. (B) SAR and binding orientation of benzoate and benzamide derivatives with large $\mathrm{R}_{1}$ alkyl substituents.

The replacement of the benzoate linkage with a benzamide group (145-149) produced inhibitors that were more soluble and more stable to serum hydrolases in vivo than the 3,4dihydroxybenzoate analogues, and several were more active $(\mathbf{1 4 6}, \mathbf{1 4 9})$ against the target enzyme than the corresponding ester (136 and 143). ${ }^{158}$ In fact, the $n$-butyl-3,4-dihydroxybenzamide 146 was found to be curative in $T$. b. brucei-infected mice ( $450 \mathrm{mg} / \mathrm{kg}$ by i.p. dosage) when coadministrated with glycerol ( $15 \mathrm{~g} / \mathrm{kg}$ p.o. in 3 doses at hourly intervals). The in vivo toxicity of the benzamide 145-149 and benzoate compounds $(136,141-143)$ decreased when the alkyl chain contained more than 6 methylene units. Of note, the amides had slightly lower $\mathrm{LD}_{50}$ values than 
the ester counterparts. ${ }^{158}$ Importantly, 3,4-dihydroxy aromatic compounds (153) are inactive if the carboxyl (e.g. acid) group is not linked directly to the phenyl ring (Figure 12).

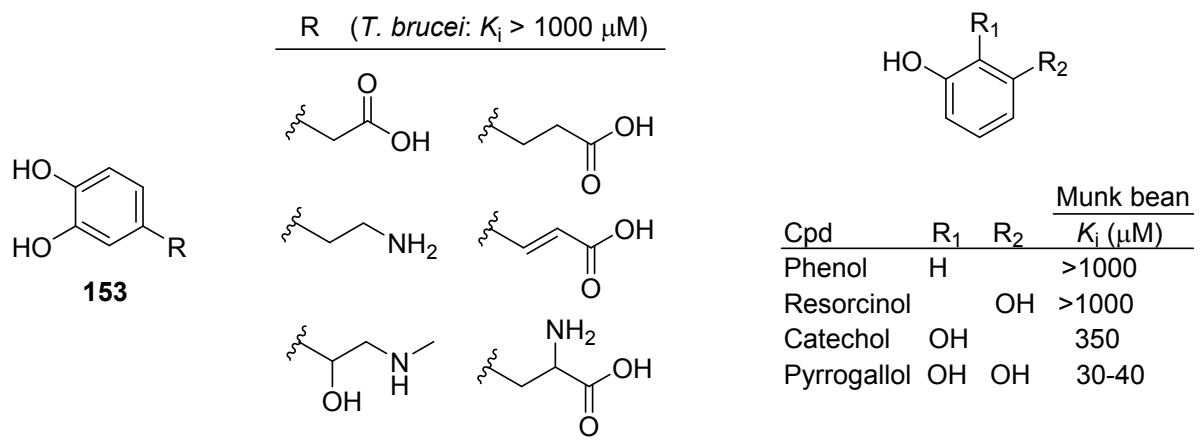

Figure 12. $K_{\mathrm{i}}$ values for the inhibition of the alternative oxidase pathway (inhibition of oxygen uptake) by miscellaneous phenol derivatives ${ }^{125,156}$

A series of highly potent TAO inhibitors based on the 4-hydroxybenzoate scaffold were described recently (Figure 13). These compounds inhibited the physiologically relevant form of TAO, i.e. that lacking the $N$-terminal 25 amino acid mitochondrial targeting sequence ( $\triangle \mathrm{MTS}-\mathrm{TAO}$ ), in the low nanomolar range. ${ }^{13}$ As observed with the previous benzoate series, a correlation between inhibitory activity and methylene chain length was observed, the longest alkyl chains giving the best inhibitors: $\mathrm{C} 14(\mathbf{1 5 9}-\mathbf{1 6 1})>\mathrm{C} 16(\mathbf{1 6 3}, \mathbf{1 6 4})>\mathrm{C} 12(\mathbf{1 5 7})>>\mathrm{C} 10(\mathbf{1 5 6})>\mathrm{C} 6(\mathbf{1 5 5})>\mathrm{C} 4$ (154). Geranyl substituent at $R_{3}(\mathbf{1 6 5})$ gave an inhibitor equipotent ${ }^{126}$ to the tetradecane chain analogues 158-161. 4-Hydroxybenzoates dimers with a C14 (168) or C16 (169) methylene linker were equipotent to their monomer counterparts (158 and 163, respectively) showing that the second pharmacophore unit (i.e. 2,4-dihydroxybenzoate group) does not add to the inhibition potency with such long alkyl linkers. In contrast, dimers with shorter linkers $(\mathrm{C} 10, \mathrm{C} 12)$ were 2to 20 -fold more inhibitory than their monomer counterparts $(157 / 167$ and $156 / 166$, respectively). ${ }^{13}$ Interestingly, the 4-hydroxybenzoate derivatives displayed in Figure 13 are more potent TAO inhibitors than the corresponding 4-alkoxy benzoic acid (92-95) and benzoate analogues $(\mathbf{1 2 2 - 1 2 7}, \mathbf{1 2 9})$ shown in Figures 8 and 10.

Most of these 4-hydroxybenzoate inhibitors $\mathbf{1 5 4}-\mathbf{1 6 5}$ were active in the micromolar range against wild-type and drug-resistant strains of T. brucei in vitro $\left(\mathrm{EC}_{50}<25 \mu \mathrm{M}\right)$ whereas the dimers (166170) were less effective $\left(\mathrm{EC}_{50}>25 \mu \mathrm{M}\right) .^{13}$ 
<smiles>[R]OC(=O)c1c([R])cc(O)cc1[R]</smiles>

$\begin{array}{llll}\text { Cpd } & \mathrm{R}_{1} & \mathrm{R}_{2} & \mathrm{R}_{3}\end{array}$

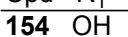

$155 \mathrm{OH}$

$156 \mathrm{OH}$

$157 \mathrm{OH}$

$158 \mathrm{OH}$

$159 \mathrm{OH} \mathrm{Me}$

$160 \mathrm{Me}$

$161 \mathrm{Me}$

$162 \mathrm{~F}$

$163 \mathrm{OH}$

$164 \mathrm{OH}$

$165 \mathrm{OH}$

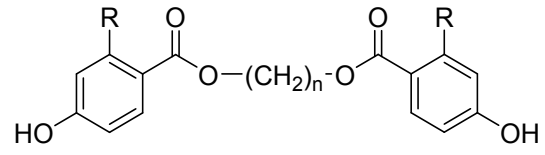

\begin{tabular}{llll} 
Cpd & $\mathrm{R}$ & $\mathrm{n}$ & $\mathrm{IC}_{50}(\mu \mathrm{M})$ \\
\hline $\mathbf{1 6 6}$ & $\mathrm{OH}$ & 10 & 0.0069 \\
167 & $\mathrm{OH}$ & 12 & 0.007 \\
168 & $\mathrm{OH}$ & 14 & 0.0157 \\
169 & $\mathrm{OH}$ & 16 & 0.0123 \\
170 & $\mathrm{Me}$ & 14 & 0.013
\end{tabular}

Figure 13. $\mathrm{IC}_{50}$ values for the inhibition of purified rTAO by 4-hydroxybenzoate derivatives. ${ }^{13}$

\subsubsection{Benzaldehyde and benzophenone derivatives}

Benzaldehyde derivatives were first investigated as analogues of benzoic and benzhydroxamic acids (Figure 14). In these aldehyde (171-179) and ketone series (181-185), two adjacent hydroxyl groups are necessary to inhibit the AOX pathway: $R_{1} / R_{2}(\mathbf{1 7 1})>R_{1} / R_{2} / R_{3}(\mathbf{1 7 2})>R_{2} / R_{3}$ (173). Other orientations of hydroxyl groups $(176-178)$ or methylation of one $(174,178)$ or both (175) $\mathrm{OH}$ groups abolished activity. ${ }^{125}$ Aldehydes 171-173 were found to be much better inhibitors (3- to 30 -fold) than their respective benzoic acid counterparts $\mathbf{7 7}, \mathbf{7 8}$, and $\mathbf{8 5}$. ${ }^{124,125}$

The natural isoprenoid antibiotic ascofuranone (188) is one of the most potent (subnanomolar) inhibitors of TAO reported to date (Figure 14). ${ }^{113}$ The alkoxy analogues of AF substituted in para (186) and ortho position (187) with a geranyl tail are less inhibitory than AF by 3 orders of magnitude. ${ }^{159}$ In contrast, the more lipophilic 2-hydroxy-4-alkyloxy derivative $\mathbf{1 8 0}$ is a nanomolar inhibitor $\left(\mathrm{IC}_{50}=73 \mathrm{nM}\right) .{ }^{126}$ These data, which agree with the SAR reported for benzoate and benzoic acid derivatives, further demonstrate that the effects of the substituent (tail) in para of the carbonyl group are mainly due to non-specific lipophilic interactions. 
Figure 14. $K_{\mathrm{i}}$ and $\mathrm{IC}_{90}$ values for the inhibition of $T$. brucei alternative oxidase pathway (inhibition of oxygen uptake) by benzaldehyde and keto derivatives. $\mathrm{IC}_{50}$ values for the inhibition of purified rTAO. ${ }^{59,113,125,126,159}$

\subsection{3-chloro-4-hydroxybenzonitrile derivatives}

After the groups of Kita, investigating the pharmacophore of ascofuranone (188), reported that the electron withdrawing cyano group was a useful alternative to its formyl group, ${ }^{59}$ West et al. investigated the SAR of 3-chloro-4-hydroxybenzonitrile analogues. ${ }^{159,160}$ With the aim of reducing the lipophilicity of the tail region of inhibitor $\mathbf{2 0 0}$, and thereby improve its physicochemical properties including the predicted CNS Multiparameter Optimization (MPO) ${ }^{161}$ score, they introduced different polar groups (amide, ether) in the lipophilic tail (Figure 15). ${ }^{160} \mathrm{~A}$ large decrease in inhibition potency compared to the $n$-octyl analogue 190 was observed with amide (191-196) and ether groups (197-199), showing that even minor increases in polarity in this part of the lipophilic tail are not tolerated. The introduction of polarity at the terminal part of the chain $(195,196,198,199)$ seemed to be somewhat better tolerated but these compounds were inactive in vitro against $T$. b. brucei, ${ }^{160}$ probably because of poor cellular uptake. This shows that alternative strategies are needed in order to improve the physicochemical properties of these TAO inhibitors. 
With regards to the alkyl chain analogues, TAO inhibition and T. brucei growth inhibition correlated with chain length and $\operatorname{cogP} ;{ }^{160}$ compounds 200-207 showed a distinct decrease in potency for each carbon reduction, in line with previous SAR reports. ${ }^{59}$ In particular, a notable decrease in TAO inhibition was observed for alkyl chains $\leq \mathrm{C} 3$.
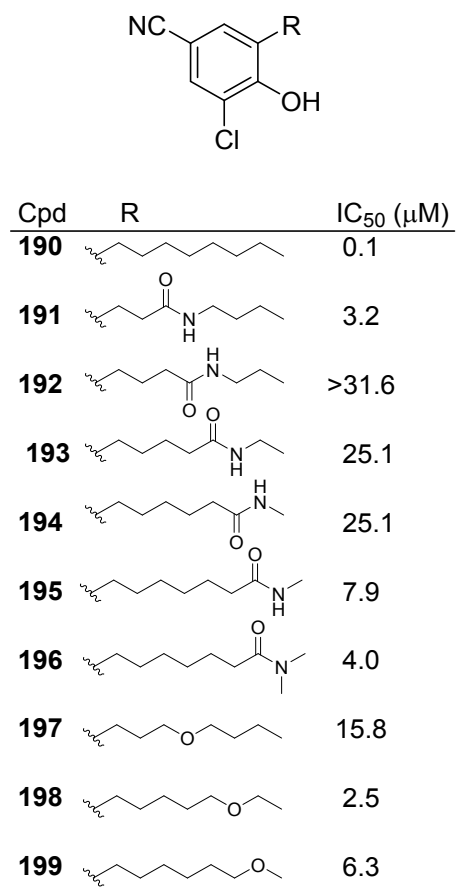<smiles>[R6]Oc1c(Br)cc(C#N)c(C)c1Cl</smiles>

\begin{tabular}{llll} 
Cpd & $\mathrm{R}_{1}$ & $\mathrm{R}_{2}$ & $\mathrm{IC}_{50}(\mu \mathrm{M})$ \\
\hline $\mathbf{2 0 0}$ & $n$-octyl & & 0.0013 \\
$\mathbf{2 0 1}$ & $n$-octyl & $\mathrm{Me}$ & 31.6 \\
$\mathbf{2 0 2}$ & $n$-heptyl & & 0.0032 \\
$\mathbf{2 0 3}$ & $n$-hexyl & & 0.0063 \\
$\mathbf{2 0 4}$ & $n$-pentyl & & 0.0158 \\
$\mathbf{2 0 5}$ & $n$-butyl & & 0.02 \\
$\mathbf{2 0 6}$ & $n$-propyl & & 0.079 \\
$\mathbf{2 0 7}$ & Me & & 0.631
\end{tabular}

0.631

Figure 15. 3-chloro-4-hydroxybenzonitrile derivatives: influence of tail hydrophilicity and methylene chain length on rTAO inhibition. ${ }^{159,160}$

\subsection{Ubiquinone analogues}

AOX enzymes catalyze the oxidation of ubiquinol to ubiquinone with concomitant four-electron reduction of oxygen to water (Figure 16). ${ }^{8,162}$ Hence, different ubiquinone-like compounds derived from 1,4-naphthoquinone $(\mathbf{2 0 8}, \mathbf{2 0 9})$ and 4,7-dioxobenzothiazol $(\mathbf{2 1 0})$ were assayed as AOX inhibitors. Maesaquinone (208) was found to inhibit the AOX pathway in plant mitochondria isolated from Arum maculatum spadices, with $\mathrm{IC}_{50}<0.3 \mu \mathrm{M}$; it also inhibited the cytochrome pathway, albeit at approximately one order of magnitude higher concentrations. ${ }^{163}$

Ubiquinone analogues 209 and 210 also inhibited the AOX pathway of T. brucei with much lower $K_{\mathrm{i}}$ values (20- to 600-times) than SHAM (2). A more polar analogue of 209 lacking the lipophilic side-chain, 2-hydroxynaphthoquinone (211), had little effect (20\% inhibition) at a $50 \mu \mathrm{M}$ concentration (Figure 16). ${ }^{164}$ 
<smiles>CCCCCCCCCCCC1=C(O)C(=O)c2scnc2C1=O</smiles>

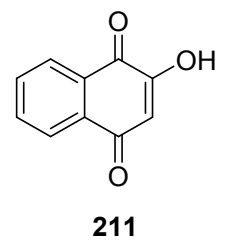<smiles>CC(C)=CCC/C(C)=C/CC/C(C)=C/Cc1c(O)c2ccccc2oc1=O</smiles>

212 (Ferulenol)

Figure 16. $K_{\mathrm{i}}$ values for the inhibition of $T$. brucei alternative oxidase pathway (inhibition of oxygen uptake) by ubiquinol analogues. ${ }^{164}$

\subsection{Natural products: isoprenoid antibiotics}

\subsubsection{Ascofuranone derivatives}

Ascofuranone (AF, 188) was the first natural isoprenoid antibiotic reported to inhibit TAO in the subnanomolar range. ${ }^{113}$ It was later found to be active in vivo in mouse models of T. brucei and T. vivax infections. ${ }^{74,130,137}$ Because of its remarkable inhibitory potency and its promising curative activity, SAR studies were performed ${ }^{59,159,160}$ and a pharmacophore was defined (see section 5.2.1.). ${ }^{59}$ Analogues were synthesized to try to circumvent the unwanted features of ascofuranone (e.g. electron rich aromatic ring, aldehyde group, phenol, and lipophilic side chain) that may contribute to the rapid blood clearance, low oral bioavailability, and potential toxicity of this compound (Figures 17-18). 
A methyl group at C-6 is important but not essential for inhibition as shown by the 3-fold loss of activity of 214 vs 188 (Figure 17). Replacement of the formyl group $\left(\mathrm{R}_{1}\right)$ with an acetyl group $(215,217,218)$ gave similar inhibitory activity as AF whereas an oxime group (216) reduced the potency by 2 orders of magnitude. Other electron withdrawing group preferred at $R_{1}$ were $\mathrm{NO}_{2}$ (223) $>\mathrm{CN}(\mathbf{2 2 4})>>\mathrm{CO}_{2} \mathrm{Me}(\mathbf{2 5 2}) .{ }^{59}$ A carbonyl linkage between the phenyl ring and the alkyl tail is favored $(\mathbf{2 1 9}, \mathbf{2 2 1})$ in comparison with a methylene linker $(\mathbf{2 2 0}, \mathbf{2 2 2}) .{ }^{10}$<smiles>[R]c1c([R2])c(Cl)c(O)c(C/C=C(\C)CC/C=C(\C)[C@@H]2CC(=O)C(C)(C)O2)c1O</smiles>

\begin{tabular}{llll} 
Cmpd & $\mathrm{R}_{1}$ & $\mathrm{R}_{2}$ & $\mathrm{IC}_{50}(\mathrm{nM})$ \\
\hline $\mathbf{1 8 8}(\mathrm{AF})$ & $\mathrm{CHO}$ & $\mathrm{Me}$ & 0.13 \\
$\mathbf{2 1 4}$ & $\mathrm{CHO}$ & & 0.45 \\
$\mathbf{2 1 5}$ & $\mathrm{COMe}$ & $\mathrm{Me}$ & 2.5 \\
$\mathbf{2 1 6}$ & (C=NOH) & $\mathrm{Me}$ & 28
\end{tabular}<smiles>[R]C(C)=CCC/C(C)=C/Cc1c(O)c(Cl)c(C)c(C(C)=O)c1O</smiles>

\begin{tabular}{lll} 
Cmpd & $\mathrm{R}$ & $\mathrm{IC}_{50}(\mathrm{nM})$ \\
\hline $\mathbf{2 1 7}$ & $\mathrm{CH}_{2} \mathrm{OCO}^{t} \mathrm{Bu}$ & 0.70 \\
$\mathbf{2 1 8}$ & $\mathrm{Me}$ & 0.15
\end{tabular}<smiles>[R]CCCCCCCCC[X]c1c(O)c([R])c(C)c(Cl)c1O</smiles>

\begin{tabular}{lllll} 
Cmpd & $\mathrm{R}_{1}$ & $\mathrm{R}_{2}$ & $\mathrm{X}$ & $\mathrm{IC}_{50}(\mathrm{nM})$ \\
\hline $\mathbf{2 1 9}(\mathrm{K} 2-9)$ & $\mathrm{H}$ & & $\mathrm{C}=\mathrm{O}$ & 250 \\
$\mathbf{2 2 0}(\mathrm{K} 4-9)$ & $\mathrm{H}$ & & $\mathrm{CH}_{2}$ & 4000 \\
$\mathbf{2 2 1}$ & $\mathrm{Cl}$ & $\mathrm{Me}$ & $\mathrm{C}=\mathrm{O}$ & 200 \\
$\mathbf{2 2 2}$ & $\mathrm{Cl}$ & $\mathrm{Et}$ & $\mathrm{CH}_{2}$ & 10000 \\
$\mathbf{2 2 3}$ & $\mathrm{NO}_{2}$ & $\mathrm{Et}$ & $\mathrm{CH}_{2}$ & 0.45 \\
$\mathbf{2 2 4}$ & $\mathrm{CN}$ & $\mathrm{CH}_{2} \mathrm{OCO}^{t} \mathrm{Bu}$ & $\mathrm{CH}_{2}$ & 6.0 \\
$\mathbf{2 2 5}$ & $\mathrm{Ac}$ & $\mathrm{CH}_{2} \mathrm{OCO}^{t} \mathrm{Bu}$ & $\mathrm{CH}_{2}$ & 100
\end{tabular}

Figure 17. SAR of ascofuranone (AF): modification of the aromatic head. $\mathrm{IC}_{50}$ values for the inhibition of purified rTAO. ${ }^{10,59}$

The low nanomolar $\mathrm{IC}_{50}$ values of alkyl chain derivatives of $\mathrm{AF}(\mathbf{2 3 2}, \mathbf{2 4 3}, \mathbf{2 4 4})$ and alkyl analogues lacking the furanone ring (228-231) show that the geranyl chain and the furanone ring are not essential for potent inhibition of TAO. In these series, the optimum chain length for potent inhibition is between 9 and 12 carbon atoms (229-231). The analogue with a chain shorter than C3 (226) was 1000-fold less inhibitory than AF indicating that hydrophobic interaction is required for inhibition. Bulky groups at the end of the isoprenyl or alkyl tail have little influence on TAO inhibiton $(\mathbf{2 1 7}, \mathbf{2 3 5}, \mathbf{2 4 2})$ suggesting that these groups are not interacting with the enzyme, possibly because they are located at the surface or outside TAO. Taking into account these SAR results, compound 247 was synthesized as the most potent $\mathrm{TAO}$ inhibitor reported to date $\left(\mathrm{IC}_{50}=\right.$ $0.06 \mathrm{nM}){ }^{59}$ 
<smiles>[R]C=Cc1c(O)c(Cl)c(C)c(C=O)c1O</smiles>

\begin{tabular}{lll} 
Cpd & $\mathrm{R}$ & $\mathrm{IC}_{50}(\mathrm{nM})$ \\
\hline $\mathbf{2 2 6}$ & $\mathrm{Me}$ & 100 \\
$\mathbf{2 2 7}$ & $n$-Pr & 3.8 \\
$\mathbf{2 2 8}$ & $n$-pentyl & 0.7 \\
$\mathbf{2 2 9}$ & $n$-heptyl & 0.38 \\
$\mathbf{2 3 0}$ & $n$-octyl & 0.38 \\
$\mathbf{2 3 1}$ & $n$-decyl & 0.45 \\
$\mathbf{2 3 2}$ & &
\end{tabular}<smiles>[R]C(C)=CCC/C(C)=C/Cc1c(O)c(Cl)c(C)c(C=O)c1O</smiles>

\begin{tabular}{lll}
$\mathrm{Cpd}$ & $\mathrm{R}$ & $\mathrm{IC}_{50}(\mathrm{nM})$ \\
\hline $\mathbf{2 3 3}$ & $\mathrm{CH}_{2} \mathrm{OH}$ & 1.2 \\
$\mathbf{2 3 4}(\mathrm{AF} 27790 \mathrm{OH})$ & $\left.\mathrm{CH}^{2} \mathrm{OH}\right) \mathrm{CH}_{3}$ & 0.48 \\
$\mathbf{2 3 5}$ & $\mathrm{CH}_{2} \mathrm{OCO}^{t} \mathrm{Bu}$ & 0.4 \\
$\mathbf{2 3 6}$ & $\mathrm{CH}_{2} \mathrm{CH}_{2} \mathrm{OAC}$ & 1.4 \\
$\mathbf{1 8 8}(\mathrm{AF})$ &
\end{tabular}<smiles>[R3]c1c(Cl)c(C)c(C=O)c(O)c1CCC([R])CCCC([R])[R]</smiles>

\begin{tabular}{lllll} 
Cpd & $\mathrm{R}_{1}$ & $\mathrm{R}_{2}$ & $\mathrm{R}_{3}$ & $\mathrm{IC}_{50}(\mathrm{nM})$ \\
\hline $\mathbf{2 3 7}$ & $\mathrm{CO}_{2} \mathrm{H}$ & & $\mathrm{OH}$ & 40 \\
$\mathbf{2 3 8}$ & $\mathrm{CH}_{2} \mathrm{OH}$ & & $\mathrm{OH}$ & 6.0 \\
$\mathbf{2 3 9}$ & $\left(\mathrm{CH}_{2}\right)_{4} \mathrm{CO}_{2} \mathrm{H}$ & & $\mathrm{OH}$ & 4.2
\end{tabular}

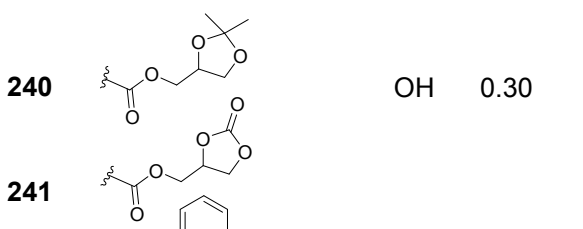

242

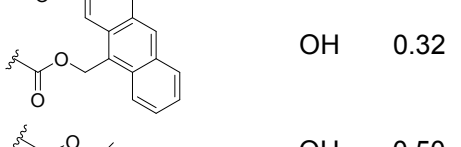

243<smiles>CCC1CC(=O)C(C)(C)O1</smiles>

$\mathrm{OH} \quad 0.50$

244<smiles>CC1CC(=O)C(C)(C)O1</smiles>

245<smiles>CC1CC(=O)C(C)(C)O1</smiles>

OMe 4.0

246 Et

$30 \%$ inhibition at $50 \mu \mathrm{M}$

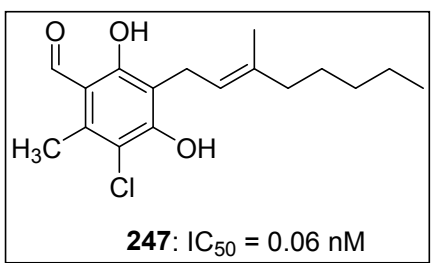

Figure 18. SAR of ascofuranone: modification of the aliphatic tail. $\mathrm{IC}_{50}$ values for the inhibition of purified rTAO. ${ }^{10,59}$

\subsubsection{Colletochlorin B derivatives}

Colletochlorin B (CCB, 189), a fungal metabolite isolated from Colletotrichum nicotianae that contains a diprenyl side chain, ${ }^{168}$ is a close analogue of AF (188) that strongly inhibits TAO. However, unlike AF and AF2779OH (234), CCB is toxic to mice. ${ }^{10}$

Due to their structural similarities, AF and CCB display comparable SAR (Figure 19). For instance, electron withdrawing groups at $\left.\mathrm{R}_{1} \mathbf{( 2 4 8 - 2 5 2}\right)$ are preferred $\left(\mathrm{CHO} \approx \mathrm{CN} \approx \mathrm{Ac}>\mathrm{CO}_{2} \mathrm{Me}\right.$ $>\mathrm{C}=\mathrm{NOH}, \mathrm{CH}_{3}$ ). For the nitrile analogue 249 , however, a drop in efficacy was observed against T. brucei even though enzyme inhibitory potency was retained. A methyl group at $\mathrm{R}_{2}$ contributes significantly to the inhibition of TAO $(\mathbf{1 8 9}, \mathbf{2 4 9}, \mathbf{2 5 8})$ albeit to a lesser extent than that of a chlorine atom at $\mathrm{R}_{3}(\mathbf{2 5 8}, \mathbf{2 5 9}) .{ }^{159}$ 
An interesting analogue is the bicyclic 1,2-isoxazole 253, a synthetic intermediate to access the nitrile analogue 249 that displays high inhibitory potency against $\mathrm{TAO}\left(\mathrm{IC}_{50}=5 \mathrm{nM}\right)$ and $T . b$. brucei $\left(\mathrm{EC}_{50}=0.1 \mu \mathrm{M}\right)$.<smiles>[R2]c1c([R])c(Cl)c(O)c(CC=C(C)CCC=C(C)C)c1O</smiles>

\begin{tabular}{lllll}
$\mathrm{Cpd}$ & $\mathrm{R}_{1}$ & $\mathrm{R}_{2}$ & $\mathrm{IC}_{50}(\mathrm{nM})$ & $\mathrm{IC}_{50}(\mathrm{nM})$ \\
\hline $\mathbf{1 8 9}(\mathrm{CCB})$ & $\mathrm{CHO}$ & $\mathrm{Me}$ & 4.0 & 0.2 \\
$\mathbf{2 4 8}$ & $\mathrm{CHO}$ & & 100 & 0.23 \\
$\mathbf{2 4 9}$ & $\mathrm{CN}$ & $\mathrm{Me}$ & 4.0 & \\
$\mathbf{2 5 0}$ & $\mathrm{CN}$ & & 25 & \\
$\mathbf{2 5 1}$ & $(\mathrm{C}=\mathrm{NOH})$ & 794 & \\
$\mathbf{2 5 2}$ & $\mathrm{CO}_{2} \mathrm{Me}$ & $\mathrm{Me}$ & & 45
\end{tabular}<smiles>[R2]c1cc(O)c(CC=C(C)CCC=C(C)C)c(O)c1C=O</smiles>

\begin{tabular}{llll} 
Cpd & $\mathrm{R}_{2}$ & $\mathrm{IC}_{50}(\mathrm{nM})$ & $\mathrm{IC}_{50}(\mathrm{nM})$ \\
\hline $\mathbf{2 5 4}$ & $\mathrm{Me}$ & $3.2 \times 10^{3}$ & 0.5 \\
$\mathbf{2 5 5}$ & $\mathrm{OH}$ & $3.2 \times 10^{3}$ & \\
$\mathbf{2 5 6}$ & $\mathrm{H}$ & $4.0 \times 10^{3}$ & \\
$\mathbf{2 5 7}$ & $\mathrm{H}$ & & 38
\end{tabular}<smiles>[R]c1c([R])c(OC(C)=O)c(CC=C(C)CCC=C(C)C)c(O)c1C=O</smiles>

\begin{tabular}{llll}
$\mathrm{Cpd}$ & $\mathrm{R}_{2}$ & $\mathrm{R}_{3}$ & $\mathrm{IC}_{50}(\mathrm{nM})$ \\
\hline $\mathbf{2 5 8}$ & $\mathrm{Me}$ & $\mathrm{Cl}$ & 320 \\
$\mathbf{2 5 9}$ & $\mathrm{H}$ & $\mathrm{Cl}$ & $0.5 \times 10^{3}$ \\
$\mathbf{2 6 0}$ & $\mathrm{Me}$ & & $4.0 \times 10^{3}$ \\
$\mathbf{2 6 1}$ & $\mathrm{H}$ & & $3.2 \times 10^{3}$
\end{tabular}<smiles>CC(=O)Oc1c(Cl)c(C)c(C)c(O)c1C/C=C(\C)CCC=C(C)C</smiles>

262: $I C_{50}=2.0 \times 10^{3} \mathrm{nM}$

Figure 19. $S A R$ of colletochlorin $B(C C B)$. $\mathrm{IC}_{50}$ values for the inhibition of purified rTAO reported by West et al $l^{159,160}$ and Saimoto et a ${ }^{59}$ (left and right $\mathrm{IC}_{50}$ values, respectively).

\subsubsection{Ilicicolin derivatives}

The effect of ilicicolin antibiotics, isolated from a Verticillum $s p$ fungus, ${ }^{169}$ was tested against AOX from T. vivax (Figure 20). ${ }^{155}$ The kinetic analysis of the inhibition of T. vivax by these antibiotics showed that compounds 263-265 act as (apparently) non-competitive inhibitors, similarly to $\mathrm{AF}^{113}$ and SHAM. ${ }^{157}$ Ilicicolin D (263) was the best (low nanomolar) inhibitor whereas the acetylated analogue $\mathbf{2 6 4}$ was nearly 30 times less potent. Removal of one double bond in the tail part of the molecule (265) led to a 3-fold drop in inhibition relative to $\mathbf{2 6 3}$. Removal of the chlorine atom at $\mathrm{C} 3$ of the phenyl ring led to a 14 -fold fall in inhibition potency $(265 / 266)$.

Comparing the $\mathrm{IC}_{50}$ value of the farnesyl derivative $267(150 \mathrm{nM})$ with that of its geranyl analogue 254 (Figure 19, $3.2 \mu \mathrm{M}$ ) indicates that an extra isoprenyl unit in the chain seems to be favorable to AOX inhibition (keeping aside the difference in trypanosome species being used for the test: 
T. vivax and T. brucei for $\mathbf{2 6 7}$ and 254, respectively). This effect is in line with that observed for the benzoic acid series (see section 4.3.1). It is also congruent with the higher resemblance of the farnesyl group with the isoprenyl chain of the natural substrate ubiquinol.
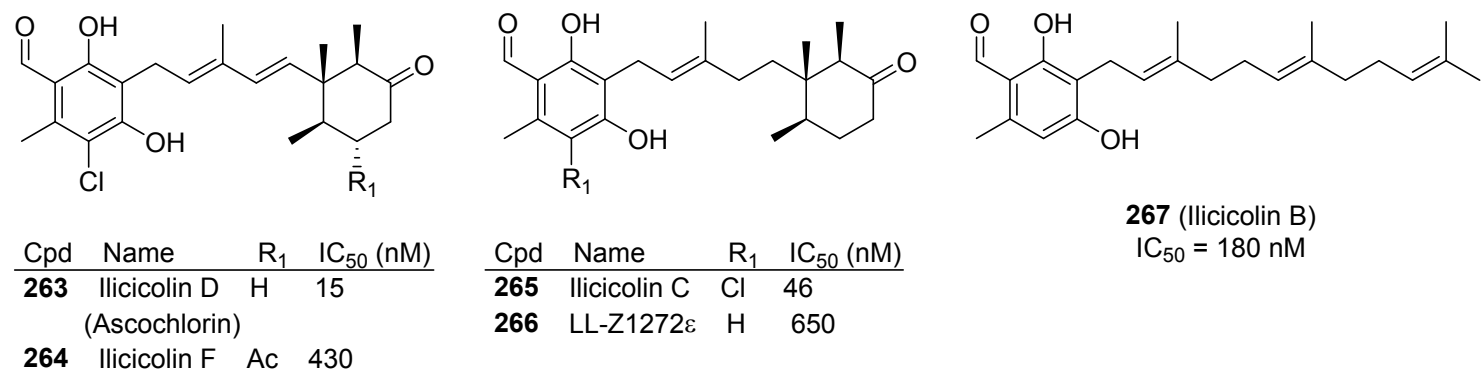

\begin{tabular}{llll} 
Cpd & Name & $\mathrm{R}_{1}$ & $\mathrm{IC}_{50}(\mathrm{nM})$ \\
\hline $\mathbf{2 6 5}$ & Ilicicolin C & $\mathrm{Cl}$ & 46 \\
$\mathbf{2 6 6}$ & LL-Z1272\& & $\mathrm{H}$ & 650
\end{tabular}

267 (Ilicicolin B) $\mathrm{IC}_{50}=180 \mathrm{nM}$

Figure 20. SAR of ilicicolin derivatives. $\mathrm{IC}_{50}$ value for the inhibition of $T$. vivax AOX.

\section{STRUCTURE-AIDED INHIBITOR DESIGN}

\subsection{TAO structure}

Although TAO was first identified and described as a promising target for the design of new and safe anti-Trypanosoma drug a long time ago, ${ }^{120,17}$ its structure was determined only recently, ${ }^{10}$ and it is the first and the only structure of any alternative oxidase to date. The long gap between its discovery and structure solution was attributable to problems such as low purification yield and protein instability. ${ }^{144}$ Commendably, these problems were eventually solved by Kita's group, ${ }^{45}$ allowing them to crystallize $\mathrm{TAO}^{61}$ and determine its structure. ${ }^{10}$ The structure of TAO was determined by X-ray crystallography in ligand-free/apo form and in complex with its inhibitors at a resolution of up to $2.3 \AA .{ }^{10}$ Judging from the quality indicators resolution, $\mathrm{R}_{\text {work }}$ and $\mathrm{R}_{\text {free }}$ and Ramachandran plots (Figure 21), the 3-D structure solution is of acceptable quality and accuracy for Structure-Aided Drug Design (SADD) (Table 2). Interestingly, known inhibitors of TAO (SHAM and AF) had earlier been discovered, ${ }^{119,113}$ making SADD targeting TAO a lot easier. Guided by the TAO structure, efforts are currently ongoing to modify AF and SHAM structures in order to obtain more potent inhibitors with better drug-like properties. . $^{13,59,62,159,160}$

Before the crystal structure of TAO was determined, investigations into its molecular architecture used a combination of biochemical data (enzymatic activity, electrophoresis, site-directed mutagenesis, electron paramagnetic resonance (EPR), inductively coupled plasma-mass spectrometry, (ICP-MS)) and bioinformatics by homology modelling, and the combined studies led to the prediction that TAO was a non-heme di-iron membrane protein and included a helix bundle core. ${ }^{14,16,45}$ 


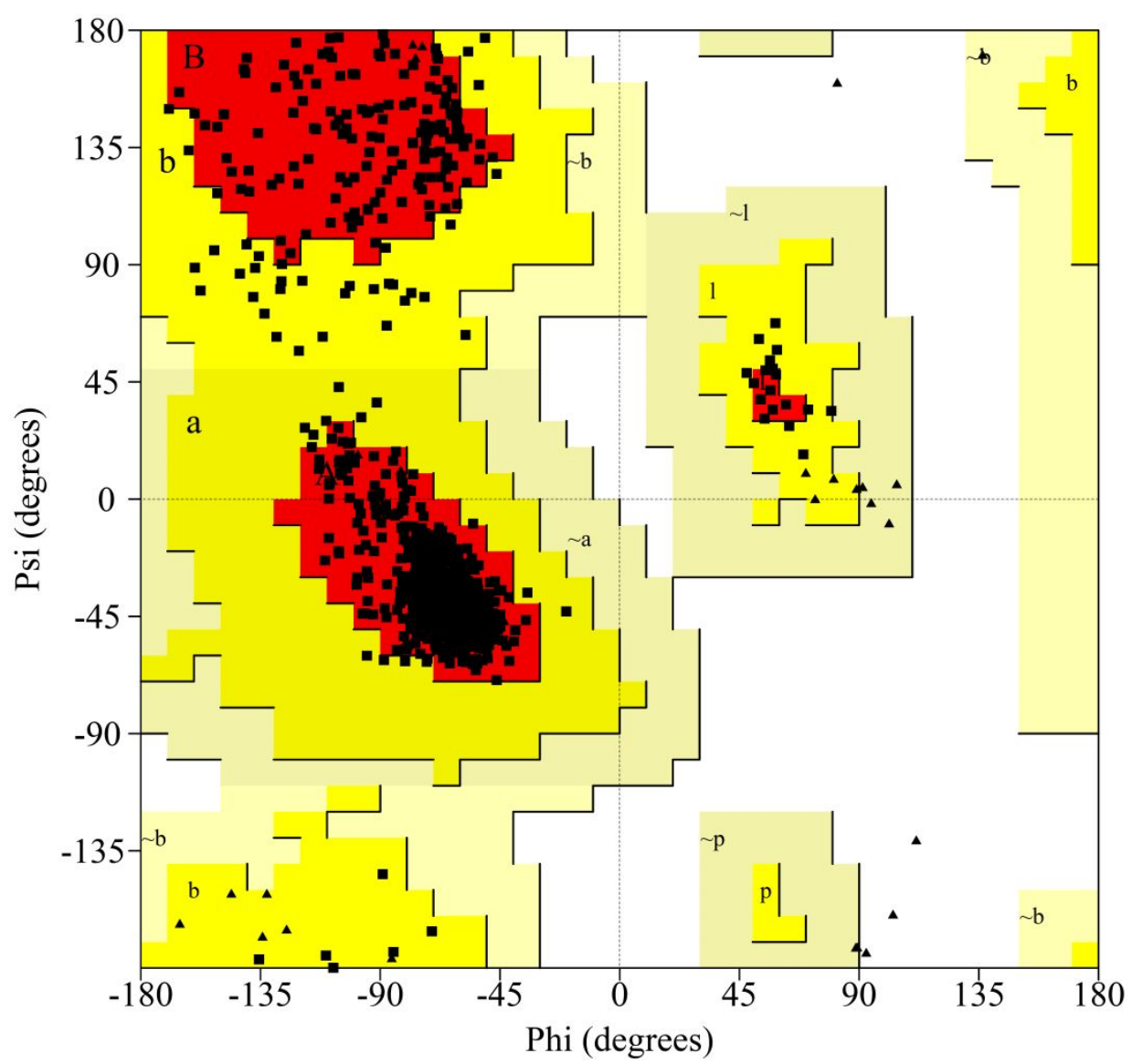

Figure 21. Ramachandran Plot statistics for TAO-CCB (PDB ID: 3W54). PROCHECK was used to prepare and assess the quality of the TAO structure data and for its suitability for use in SADD. $93.3 \%$ of the residues were in most favored regions, $6.7 \%$ in additional allowed regions, and none in generously allowed and disallowed regions $(0.0 \%)$. The statistics reveals that the structure is above the acceptable accuracy cut-off of $90 \%$, hence, may be useful for SADD.

Table 2. Data collection and refinement statistics for TAO (3W54) in comparison with the acceptable limits for SADD. The deposited structure qualifies to be used for SADD

\begin{tabular}{lll} 
Determinants of quality & TAO & $\begin{array}{l}\text { Acceptable limit } \\
\text { for SADD }\end{array}$ \\
\hline Resolution $(\AA)$ & 2.3 & 2.5 \\
$\mathrm{R}_{\text {work }}$ & 18.5 & 25 \\
$\mathrm{R}_{\text {free }}$ & 22.7 & 28 \\
Ramachandran $(\%)$ & 93.3 & 90
\end{tabular}


These predicted structural elements were confirmed by the crystal structure, which additionally revealed that, unlike as earlier model, TAO is functionally a dimer and a monotopic membrane protein (i.e. membrane-attached but lacking a membrane-spanning domain) (Figure 22A). ${ }^{10}$ The enzyme is a homodimer and the monomers lack any $\beta$ sheet but is made up of six long antiparallel helices $(\alpha \mathrm{L} 1-\alpha \mathrm{L} 6)$ and four short helices $(\alpha \mathrm{S} 1-\alpha \mathrm{S} 4)$ (Figures 22A \& B). The dimer interphase accounts for about $35 \%$ of the total dimer accessible surface and is formed by highly conserved amino acid residues, which are located in helices $\alpha \mathrm{L} 2, \alpha \mathrm{L} 3$, and $\alpha \mathrm{L} 4$ of each monomer of TAO. In addition to the long helices, the long portion of the N-terminus (Pro31 to Arg62), forming $\alpha \mathrm{S} 1$ $\alpha \mathrm{S} 3$ and the adjoining loops, extends to form part of the dimer interphase (Figure 22C). Helix $\alpha \mathrm{S} 4$ (Val242-Tyr246) is not directly involved in the interphase formation; it partly interacts with the long arm within the same chain and contributes to stabilizing the long arm for inter-chain interaction (Figure 22C). The amino acids that forms $\alpha \mathrm{L} 1, \alpha \mathrm{L} 4$, the C-terminal of $\alpha \mathrm{L} 2$, and Nterminal of $\alpha \mathrm{L} 5$ are largely hydrophobic. As such, these helices formed a broad surface, which was proposed to be the part of each monomer that is used for anchorage to the inner mitochondrial membrane, ${ }^{10}$ as earlier predicted by Anderson and Norlund. ${ }^{170}$

Importantly, the structure revealed that TAO lacks a transmembrane helix; Shiba et a ${ }^{10}$ calculated that only about $8.4 \AA$ of the membrane-interacting surface, corresponding to a helix radius, is 'inserted' into the membrane (Figure 22A). This confirmed that TAO is peripheral monotopic protein using conserved positively charged amino acids (Arg106, Arg180, Arg203, and Arg207) at the membrane interphase for interaction with negatively charged phospholipid head groups of the mitochondrial inner membrane. ${ }^{10,1}$ This monotopic (interaction with only one leaflet of the membrane lipid bilayer) nature of TAO is similar to that of prostaglandin $\mathrm{H}_{2}$ synthase (PGHS2), ${ }^{171,172}$ except that while TAO is barely inserted beyond the phospholipid head of the membrane leaflet, a longer portion of PGHS-2 is inserted into the entire leaflet, making PGHS-2 an integral monotopic protein. ${ }^{172}$ 
A

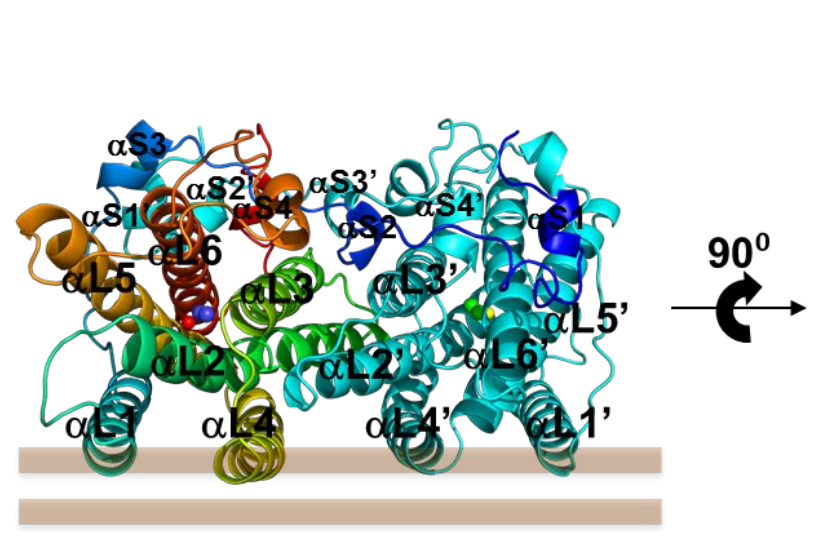

C

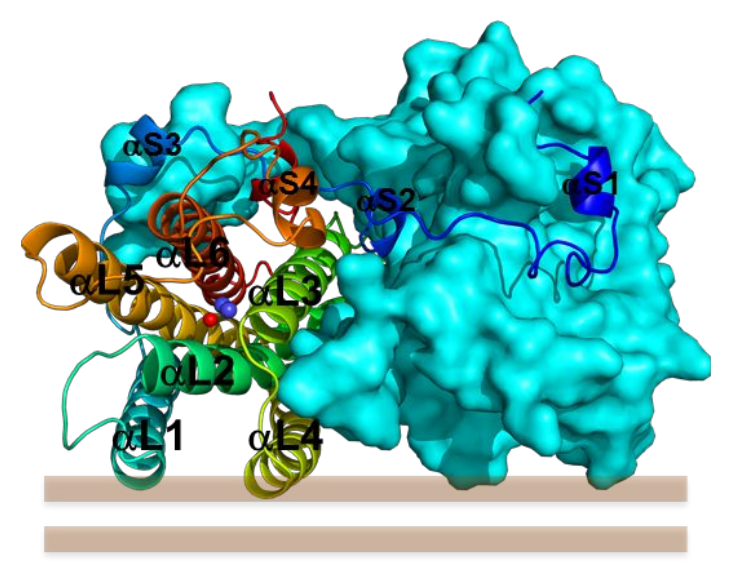

B

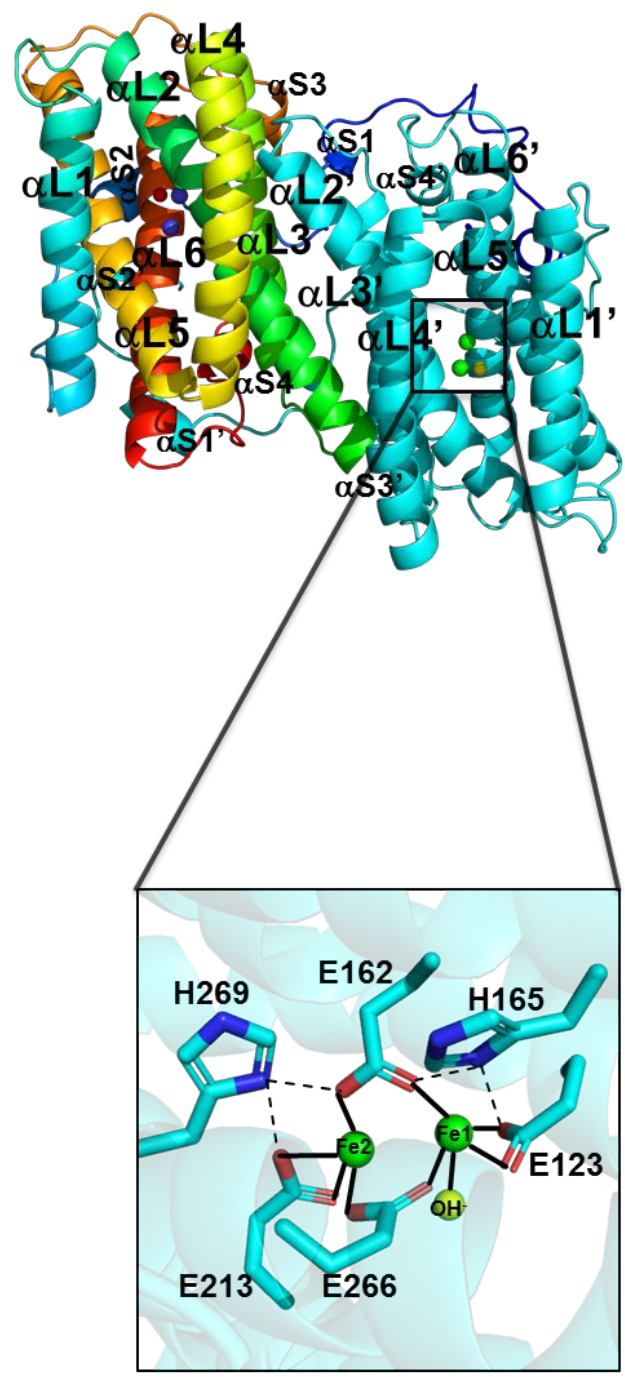

Figure 22. X-ray crystal structure of TAO. Long $\alpha$-helices are labeled $\alpha \mathrm{L}$, while short helices are labelled $\alpha \mathrm{S}$. Diiron and hydroxo atoms are shown as spheres. (A) Cartoon representation of the dimeric structure viewed roughly parallel to the helix axes. Helices are shown as ribbons. Chain A is rainbow-colored while chain B is colored cyan. Each monomer consists of six long helices $\left(\alpha \mathrm{L} 1-\alpha \mathrm{L} 6\right.$ in chain $\mathrm{A}, \alpha \mathrm{L} 1^{\prime}-\alpha \mathrm{L} 6^{\prime}$ ' in chain B) and four short helices $(\alpha \mathrm{S} 1-\alpha \mathrm{S} 4$ in chain $\mathrm{A}$ and $\alpha \mathrm{S} 1$ ' $-\alpha \mathrm{S} 4$ ' in chain B). Except for the N-terminal arm, each monomer is shaped as a compact cylinder. Horizontal beige bars depict the two leaflets of the inner mitochondrial membrane, where residues of $\alpha \mathrm{L} 1, \alpha \mathrm{L} 4$ and portions of $\alpha \mathrm{L} 2$ and $\alpha \mathrm{L} 5$ form the membrane-anchoring base. (B) Membrane side of the monomers. Length of the long helices could be visualized to appreciate the broad surface formed by $\alpha \mathrm{L} 1$ and $\alpha \mathrm{L} 4$ for membrane interaction. (C) Dimer formation. Two monomer chains A and B intimately associated to form the functional dimer of TAO. Chain A is represented as cartoon while chain B as surface model. The monomers 'hug' each other with their long N-terminal arm where the short helices are located, additionally, helices $\alpha \mathrm{L} 2, \alpha \mathrm{L} 3$, and $\alpha \mathrm{L} 4$ participate in the dimerization. (D) A zoom-in on the diiron center. The diiron center is created by six amino acid residues, Glu123, Glu162, His165, Glu213, Glu266, and His269. Two iron ions ( $\mathrm{Fe} 1$ and $\mathrm{Fe} 2$ shown as green spheres) are ligated by the glutamate residues via coordinate bonds (shown as solid lines). Iron ion $\mathrm{Fe} 1$ directly coordinates the hydroxo group in the diiron center. The histidine residues participate in the stabilization of the diiron center by forming hydrogen bonds with the glutamate residues. 
One of the explanations for the earlier findings that AOXs were inhibited by SHAM, a metal chelator, led to their classification as metaloenzymes. ${ }^{117} \mathrm{~A}$ few years later, the presence of $\mathrm{Fe}$ was reported, based on spectroscopic analyses, ${ }^{45,1,173}$ bearing out the predictions of the presence of $\mathrm{Fe}$ based on the diiron binding motif of AOXs. ${ }^{173,174}$ Indeed, the structure of TAO revealed the presence of two ferric ions positioned about $3.3 \AA$ and bridged together by one hydroxo group, which together with the coordinating amino acids (four glutamate residues; Glu123, Glu162, Glu213, Glu266 and two histidine residues; His165 and His269) form the diiron center in the active site (Figure 22D) of each monomer. ${ }^{10}$

Remarkably, Shiba et al ${ }^{10}$ also successfully determined the structure of TAO in complex with AF derivative AF $27790 \mathrm{H}$. The inhibitor was bound in a cavity that is located near the membrane surface between $\alpha \mathrm{L} 1$ and $\alpha \mathrm{L} 4$, and coordinated by 16 highly conserved amino acids amongst which are Glu123 and Glu213, two of the glutamate residues that bind the $\mathrm{Fe}^{3+}$ cofactors and help form the catalytic diiron centre (Figure 23A). This implies that the inhibitor was bound close to the catalytic center, revealing the mechanism of inhibition. In fact, binding of the inhibitor affected the position of $\mathrm{Fe}$, causing its displacement towards His 165 by approximately $1.2 \AA$ (Figure 23A). It was proposed that AF27790H, a structural analogue of ubiquinone, ${ }^{1}$ was bound at the substrate binding site of the enzyme. The TAO-AF27790H structure (PDB ID: 3AAV) has been used for modeling, to infer the possible binding patterns of new series of 4-hydroxybenzoate and 4-alkoxybenzoate derivatives to TAO (Figure 23B). ${ }^{13,126}$ The model supported the enzymological inhibitory kinetics of the derivatives, which characterized a number of them as competitive inhibitors of TAO. ${ }^{13}$ Due to the availability of the crystal structure of TAO in the ligand-free and inhibitor-bound forms, there are renewed efforts towards utilizing the structure data for rational design of new inhibitors with improved potency and drug-like properties above AF and SHAM. ${ }^{13,18,62,126,159,160}$

Although TAO is the only alternative oxidase whose structure has been experimentally elucidated, this has allowed the comparative modelling of other AOX in the context of explaining differences in catalytic efficiency and inhibitor sensitivity. This has recently been expertly reviewed by May et al. ${ }^{7}$ They proposed that, although the active site and the structure of the hydrophobic cavity is highly conserved, the major differences in $\mathrm{V}_{\max }$ and, for instance, sensitivity to $\mathrm{AF}$, can be attributed to differences in the hydrophobic tunnel giving access to the central cavity. 

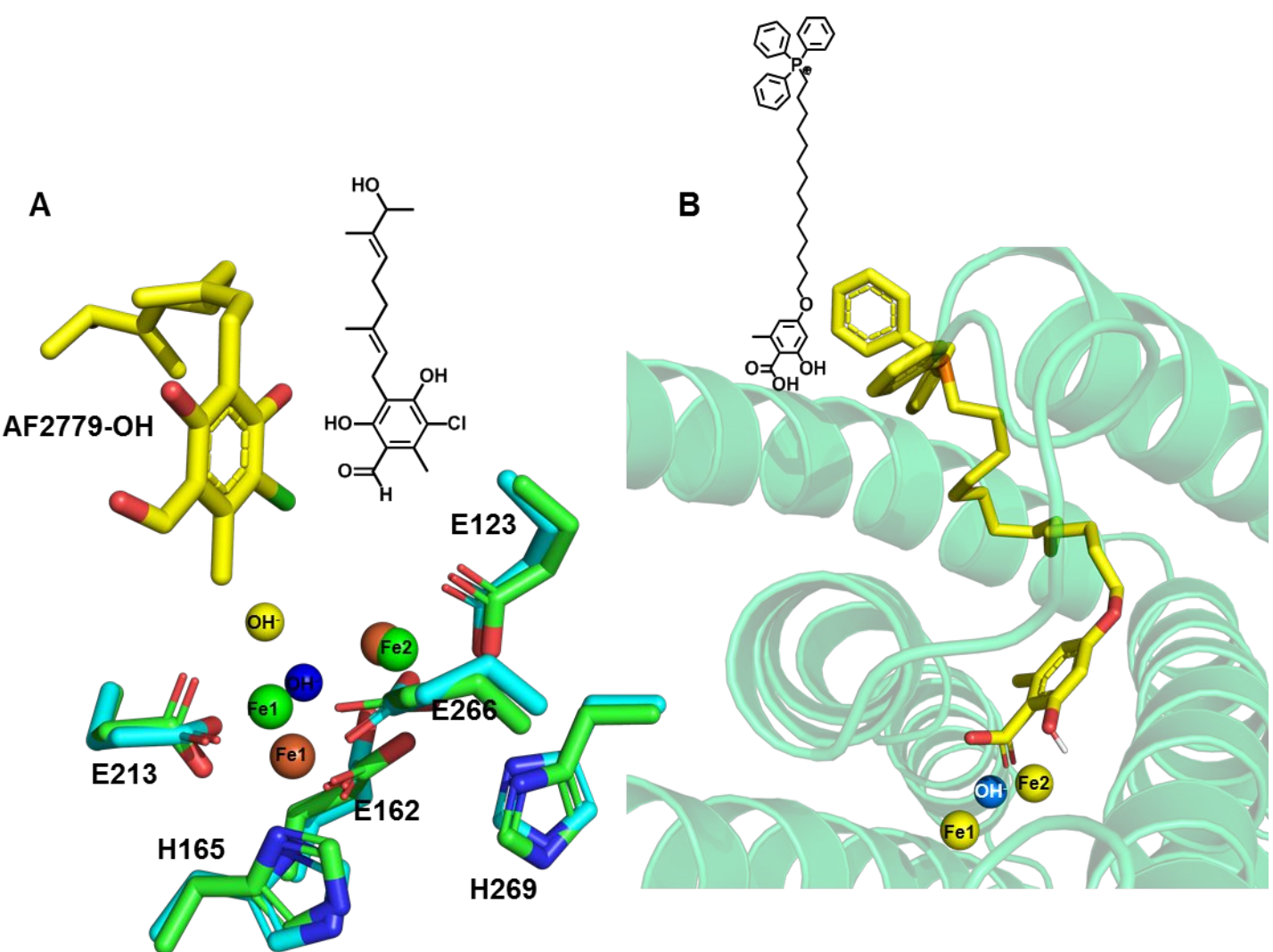

Figure 23. Structure of TAO-inhibitor complex. (A) Complex structure of TAO (cyan sticks) bound with ascofuranone derivative AF2779-OH (yellow stick); the structure is superposed with the diiron center of the uninhibited form (green sticks). The diiron and hydroxo of the inhibited form are brown and blue spheres, respectively. While the diiron and hydroxo of the uninhibited form are green and yellow spheres, respectively. The inhibitor is bound in the active site of TAO close to the diiron center. Binding of the inhibitor caused a displacement of the $\mathrm{Fe} 1$, the $\mathrm{Fe} 2$ is not affected. (B) Model structure of SHAM derivative $\mathbf{3 2 2}$. 


\subsection{Ascofuranone as template for inhibitor design}

\subsubsection{Ascofuranone pharmacophore}

The discovery by Minagawa et $a l^{113}$ of the inhibitory action of ascofuranone (AF) against the respiration and growth of bloodstream forms of $T$. b. brucei opened the path to a new class of highly potent AOX inhibitors. Ascofuranone is a prenylated phenol antibiotic, which was first isolated by Ando and co-workers ${ }^{175}$ from an organism that was initially described as the phytopathogenic fungus Ascochyta visiae but now re-identified as Acremonium sclerotigenum. ${ }^{176}$ The structure of ascofuranone comprises a chlorinated orsenilaldehyde and a furanone group in the extremities, connected through a prenyl linker (Figure 24A).

The exhaustive SAR studies of the ascofuranone scaffold by Kita and co-workers led to the construction of the AF pharmacophore for binding to the AOX substrate binding site (Figure 24B). ${ }^{59}$ The main characteristics were summarized by Saimoto et a ${ }^{59}$ as follows: 1) the hydrogenbonding capacity of the 1-formyl and 6-OH groups is responsible for potent inhibition of AOX. However, their role depends on the structure of the lipophilic tail; 2) the furanone ring is not essential for strong inhibition; 3) One isoprene group in proximity to the aromatic ring is recognized by the enzyme; 4) The 2-methyl and/or 3-chloro groups contribute to the enzymebound conformation of the molecule.

A

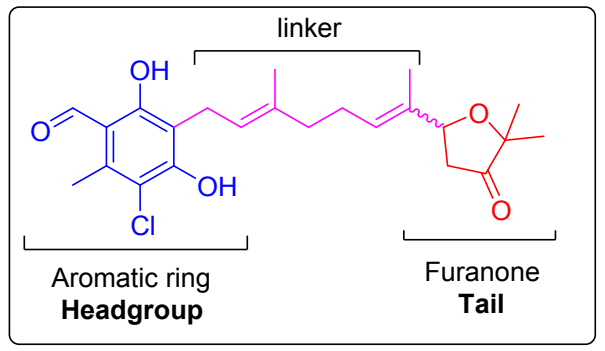

B

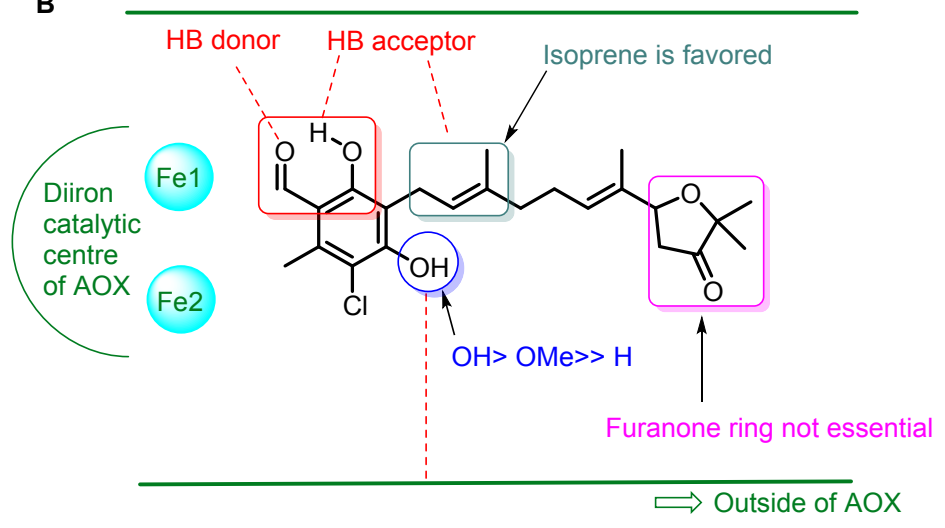

Figure 24. (A) Structural features of ascofuranone (188). (B) Ascofuranone pharmacophore: functional interaction between $\mathrm{AF}$ and AOX. ${ }^{59}$ Dash-lines represent $\mathrm{H}$-bonds with amino acids of the inhibitor binding site.

Despite the potent activity of AF against trypanosomes in vitro ${ }^{113}$ and in vivo, ${ }^{74,130,137}$ the development of AF-like inhibitors has been hampered by the less-than-optimum drug-like properties of this scaffold (e.g. high lipophilicity, low water solubility) due in part to the presence of an aldehyde group and a lipophilic side-chain. Moreover, the complex chemical structure of 
AF, which requires long multistep synthetic strategies resulting in high synthesis cost, has limited the access to synthetic analogues. The fact that the 3D-structure of TAO was unknown until $2013^{10}$ has further hindered strategies for the rational design of AOX inhibitors. Altogether, this can probably explain the apparent lack of interest from the scientific community in developing AF derivatives during almost 30 years (from the mid-1980's). In the next section, we illustrate these synthetic difficulties with an overview of the reported synthesis approaches to the ascofuranone scaffold.

\subsubsection{Synthetic strategies towards ascofuranone derivatives}

Over the years, several routes towards the synthesis of AF and its analogues have been reported in the literature. Indeed, most of the efforts were devoted to the modification of i) the substituents in the phenolic head group, aiming either to explore the structural-activity relationship or to improve chemical coupling efficiency, ${ }^{159,160}$ and ii) the linker structure and length. ${ }^{59}$ The first synthetic efforts (1970-2000) employed mainly two main strategies, based on an arene alkylation route (Scheme 1) or on non-aromatic alkylation/aromatization strategies (Scheme 2).

\subsubsection{Arene alkylation strategies}

In the $1970 \mathrm{~s}-80 \mathrm{~s}$, the typical synthesis route comprised the introduction of the vinyl group via aromatic $\mathrm{SN}_{2}$ substitution (Scheme 1a), usually leading to very low yields of the product. The prenyl chain grafting step was later improved by protecting the phenolic substrate introduced in a late stage of the synthesis (Scheme 1b). ${ }^{177}$

a) Ima-ye (1973), ${ }^{178}$ Mori (1984), ${ }^{179}$ Chen (1984), ${ }^{180}$ Ohta $(1988)^{181}$

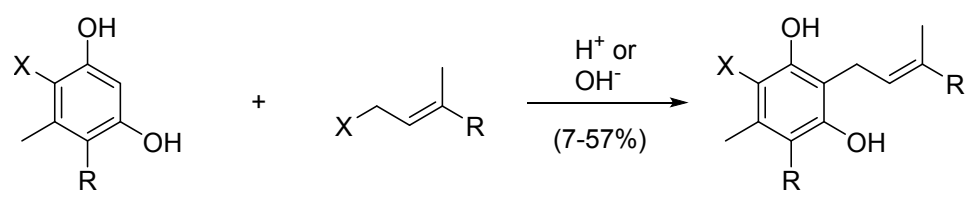

b) Saimoto $(1986)^{177}$<smiles>[R]COc1c(Cl)c(C)c(C(=O)O[M])c(O[R14])c1CC=C([R])C</smiles>

Scheme 1. Different synthetic strategies employing early stage aromatic head group functionalization. SEM: 2-(Trimethylsilyl)ethoxymethyl.

\subsubsection{Non-aromatic alkylation/aromatization strategies}


The first robust and general method of synthesis of AF was developed by Mori ${ }^{179,182}$ and featured tert-butyllithium-based alkylation of 1,5-dimethoxy-3-methyl-1,4-cyclohexadiene 268 with an halogenated geranyl tail as key step (Scheme 2). This method proved successful for the synthesis of $\mathrm{AF}(\mathbf{1 8 8})$ and illicicolin derivatives $(\mathbf{2 6 3}, \mathbf{2 6 6})$, but harsh conditions were needed and overall yields did not exceed $15 \% .{ }^{179,182}$

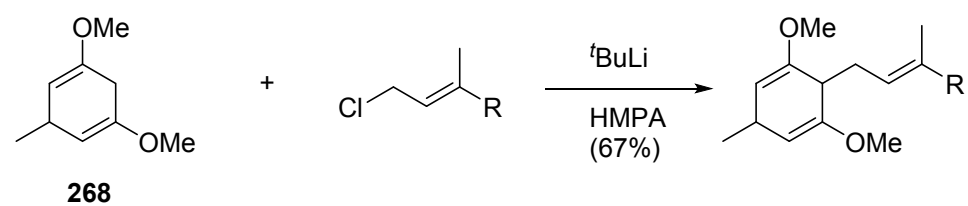

Scheme 2. Synthetic strategy employing early stage aromatic head group functionalization: Mori $(1983,1984)^{179,182}$

In the particular case of $\mathrm{AF}(\mathbf{1 8 8})$, precursor 268 was connected to 269 via $\mathrm{SN}_{2}$ displacement to yield 270 (Scheme 3). ${ }^{179}$ Another 5 synthetic steps lead to $( \pm$ )-AF which was obtained in very poor overall yield $(0.03 \%)$. The problems encountered in this route (i.e. high number of steps, poor yields, especially for the acetal deprotection and 268 grafting), were tackled in later years by pre-producing the suitable head group, and by developing alternatives in the protection/deprotection approaches for the phenolic $\mathrm{OH}$ groups. 
<smiles>CC(=O)OC/C=C(\C)CC/C=C(/C)C(=O)OC/C=C(\C)CC/C=C(\C)C=O</smiles><smiles>CC(C)(C)C(C)(C)O</smiles>

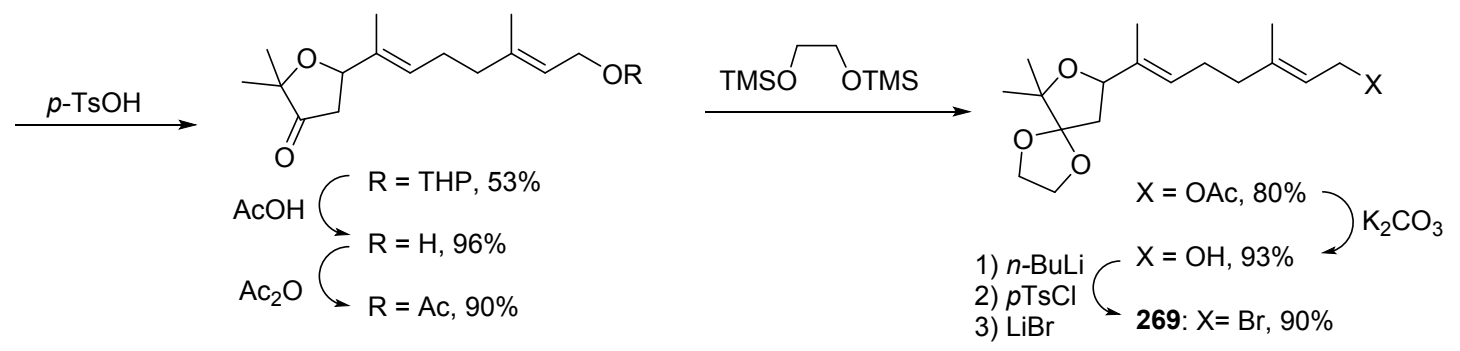<smiles>COC1=CC(C)C=C(CC(C)(C)C)C1</smiles><smiles>COC1=CC(C)C=C(OC)C1C/C=C(\C)CC/C=C(\C)C1CC2(OCCO2)C(C)(C)O1</smiles><smiles>C/C(=C\CC1C(=O)C(Cl)C(C)C(Cl)C1=O)CC/C=C(\C)C1CC2(OCCO2)C(C)(C)O1</smiles>

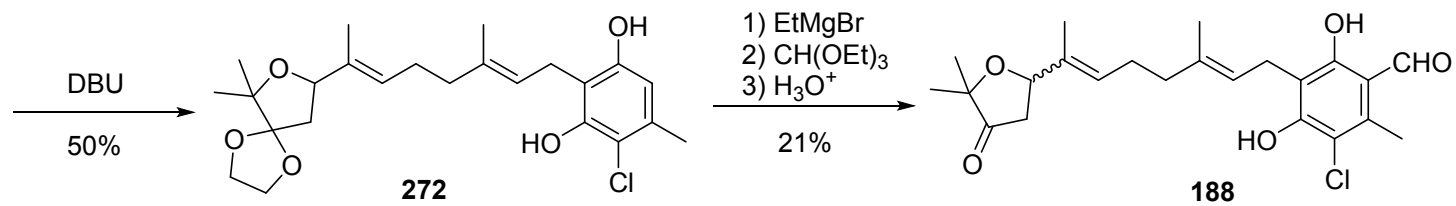

Scheme 3. Synthesis of $( \pm)$-ascofuranone employing early stage head group functionalization ${ }^{179}$

In the mid 1980's, Saimoto and co-wokers ${ }^{177}$ overcame the limitations observed in Mori's pathway and developed a more convergent synthesis of Colletochlorin B and D. In this approach, the fully protected aromatic head group was prepared separately and introduced at a later stage of the synthesis (Schemes 4 and 5). First, condensation of either dimethyl malonate with 3-penten2-one $\mathbf{2 7 4}$ or of methyl acetoacetate with methyl crotonate $\mathbf{2 7 3}$ gave the 4-oxocyclohex-2-ene adduct 275 in good yields. Dehydrobromination, followed by chlorination and alcohol protection either with $\mathrm{Me}_{2} \mathrm{SO}_{4}$ or SEM-Cl, led to the protected resorcinol-based analogues 279 and $\mathbf{2 8 0}$, respectively. Nevertheless, this step could lead to undesired by-products. ${ }^{183}$ 
6<smiles>CC=CC(C)=O</smiles><smiles></smiles>

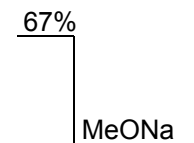<smiles>CC(=O)C1C(O)=CC(=O)CC1C</smiles>
$88 \%$

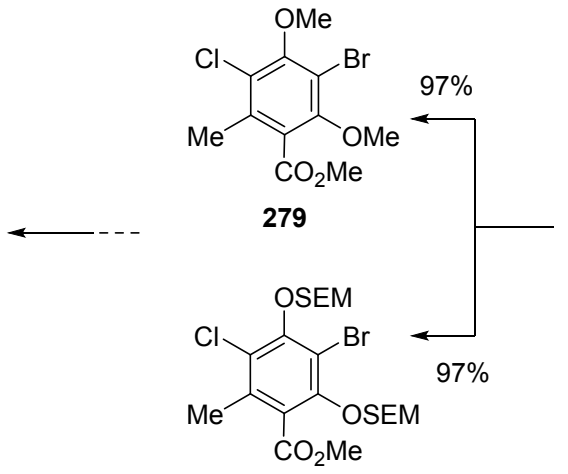
275 280<smiles>C[14CH3]</smiles><smiles>COC(=O)C1(Br)C(O)=C(Br)C(=O)CC1C</smiles>

276

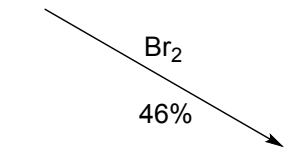

$42 \%$<smiles>CCCc1cc(O)c(Br)c(O)c1Cl</smiles>

278

Scheme 4. Synthesis of the fully-protected aromatic head group $(\mathbf{2 7 9}, \mathbf{2 8 0})$ of colletochlorin and ascofuranone from aliphatic starting materials. ${ }^{177}$

In the following step (Scheme 5), the aromatic head precursors 279 and $\mathbf{2 8 0}$ were coupled orthogonally with either geranyl or prenyl bromides via an organocuprate intermediate to give 281 and 282 in good yields. ${ }^{177}$ The early introduction of the electrophilic carbonyl in the synthetic pathway, did not seem to restrict posterior nucleophilic addition of the isoprenoid linker. Serious problems were encountered to deprotect the $\mathrm{OH}$ groups following the conditions of Guthrie et $a l^{183}$ (i.e. only one SEM group was removed), but removal of the SEM protecting groups was achieved successfully using TBAF in $\mathrm{HMPA}^{177}$ at $70^{\circ} \mathrm{C}$ for $2.5 \mathrm{~h}$ to give $\mathrm{CCB}(\mathbf{1 8 9})$ in $70 \%$ yield. In parallel, the deprotection of OMe groups was successfully achieved in harsh conditions by treatment with either EtSNa in HMPA, or EtSMgBr in DMF, leading to moderate yields of CCB (189) and CCD (285), respectively (Scheme 5). 
<smiles>[R]Oc1c(Cl)c(C)c(C(C)=O)c(O[R])c1Br</smiles>

279: $R=M e$

280: $R=S E M$
1) n-BuLi

2) $\mathrm{CuC} \equiv \mathrm{CC}(\mathrm{OMe}) \mathrm{Me}_{2}$

3) geranyl bromide or $\mathrm{BrCH}_{2} \mathrm{CH}=\mathrm{CMe}_{2}$<smiles>[R]CC(C)=CCc1c([R])c(Cl)c(C)c(C(=O)O)c1O[R]</smiles>

281: $R=M e, 70 \%$

282: $R=S E M, 91 \%$

$$
\text { 1) } \mathrm{LiAlH}_{4}
$$

2) $\mathrm{PyHClCrO}_{3}$<smiles>[R]CC(C)=CCc1c([R])c(Cl)c(C)c(C=O)c1[R]</smiles>

283: $R=M e, 97 \%$

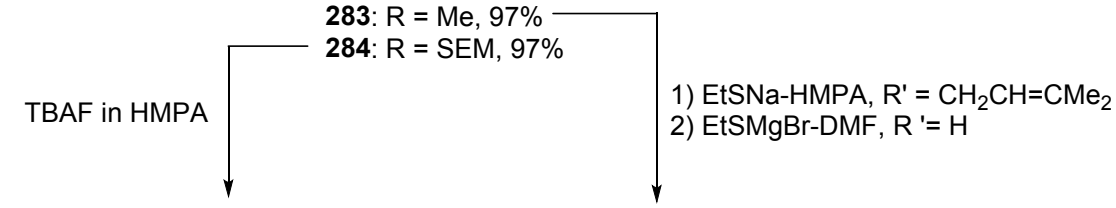<smiles>CC(C)=CCC/C(C)=C/Cc1c(O)c(Cl)c(C)c(C=O)c1O</smiles>

$189(70 \%)$<smiles>[R]CC(C)=CCc1c(O)c(Cl)c(C)c(C=O)c1O</smiles>

285 (CCD): $\mathrm{R}^{\prime}=\mathrm{H}(53 \%)$

189 (CCB): $\mathrm{R}^{\prime}=\mathrm{CH}_{2} \mathrm{CH}=\mathrm{CMe}_{2}(64 \%)$

Scheme 5. Colletochlorin B and D synthesis ${ }^{177}$

Mori reported the first synthesis of the natural enantiomers of ascochlorin and ascofuranone; ${ }^{184}$ (-)-ascochlorin was obtained in 22 steps $(0.035 \%$ overall yield) starting from (R)-(+)-pulegone whereas (-)-ascofuranone was synthesized in 17 steps from geraniol $(0.073 \%$ overall yield). Improved enantioselective synthesis of AF was achieved 10 years later, ${ }^{185}$ by replacing the acetate protecting group located in the 2,5-dihydrofuran heterocycle (287) with a bulkier pivaloyl ester (Scheme 6). More importantly, chirality transfer was shown to be quantitative, indicating that cyclization of $\mathbf{2 8 6}$ to $\mathbf{2 8 7}$ was more rapid than isomerization of the allene intermediate. The chirality was induced via asymmetric reduction of the starting alkynones with (S)-Alpine borane. ${ }^{185,186}$ 
<smiles>C/C(=C\CO[PH])CC/C=C(\C)C(=O)C#CC(C)(C)O</smiles>

$\underset{\text { 2) }}{\stackrel{\text { tBuCOCl, DMAP }}{\longrightarrow}}$ ee $84 \%$<smiles>CC(=CCO[PH])CCC=C(C)[C@@H](C#CC(C)(C)O)OC(=O)C(C)(C)C</smiles>

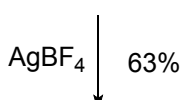<smiles>C/C(=C\Cc1c(O)c(Cl)c(C)c(C=O)c1O)CC/C=C(\C)[C@@H]1CC(=O)C(C)(C)O1</smiles>

(S)-(-)-188

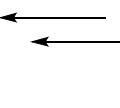

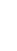<smiles>C1CCC1</smiles><smiles>C/C(=C\CO[PH])CC/C=C(\C)[C@@H]1C=C(OC(=O)C(C)(C)C)C(C)(C)O1</smiles>

Scheme 6. Asymmetric synthesis of (S)-(-)-ascofuranone (188)

In 2000, an original approach to the synthesis of (-)-ascochlorin (263) was reported by Dudley et al. ${ }^{187}$ In this route, an elegant cyclobutenone-based benzannulation is introduced as tool for assembling the aromatic core (Scheme 7). On the downside, this strategy requires a specifically designed alkynyl ether and long-time photoirradiation (>40 h) (Scheme 7).

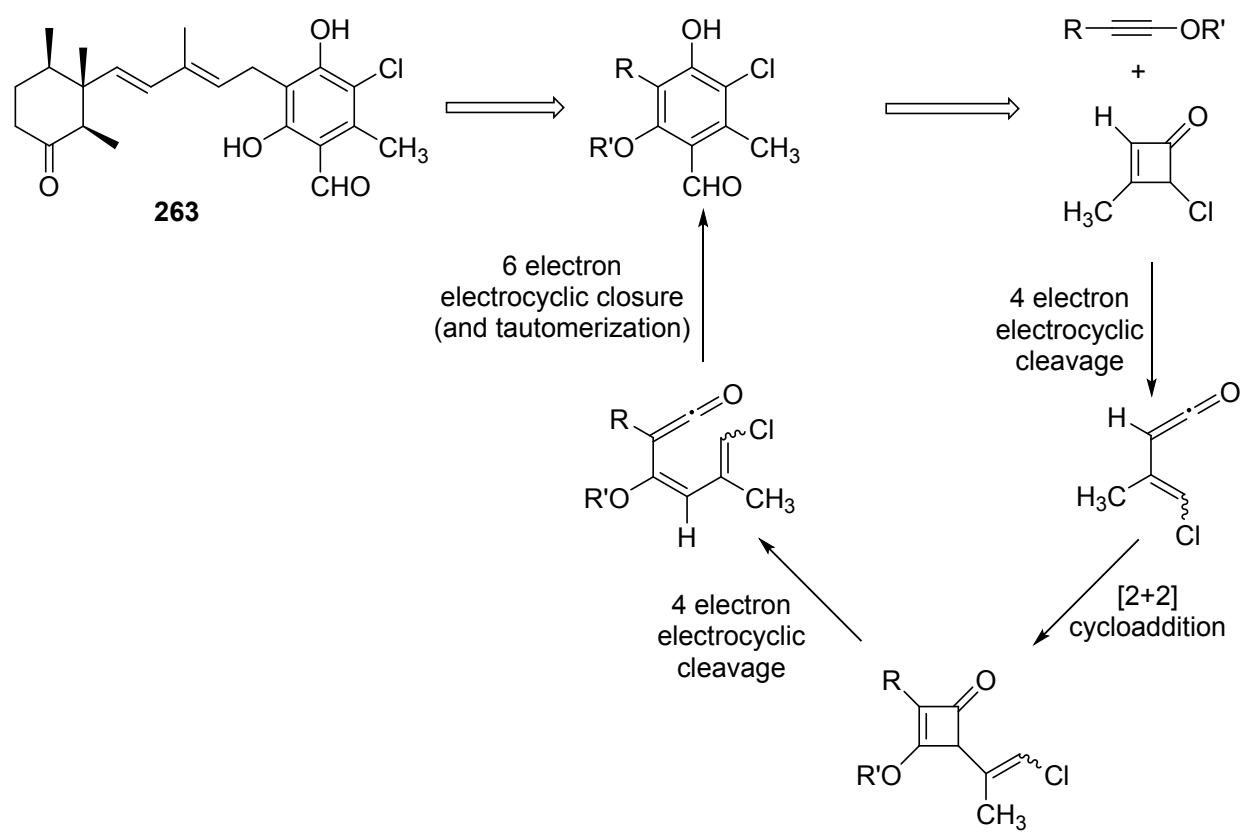

Scheme 7. Mechanistic course of the benzannulation key step: Dudley (2000)187

In summary, none of the synthetic approaches to AF derivatives described in the period 19702000 offer both generality and efficiency; yields tend to be low and harsh conditions are required. Since SAR studies have shown that structural modifications of the furanone tail have only minor 
influence on AOX activity, recent synthetic efforts have explored more accessible routes to structurally-simpler AF analogues.

\subsubsection{Recent strategies}

In the recent period (2010-2018), improved synthetic approaches based on the direct coupling of the functionalized tail group to the aromatic head (Scheme 8) or other routes allowing the structural diversification of the scaffold were reported (Scheme 9). These new synthetic routes are of particular interest because they dramatically decrease the number of synthetic steps and allow the introduction of diverse substituents, a key parameter when performing SAR studies.

\section{A. Direct coupling}

In 2010, a new synthetic approach to ( \pm ) ascofuranone in just 7 steps starting from geranyl acetate was reported by Haga et al. ${ }^{188}$ The chemical pathway involved the preparation of the brominated prenyl side-chain precursor bearing a furanone ring (288), and subsequent direct coupling with the non-protected aromatic moiety $\mathbf{2 8 9}$ under basic conditions, in the presence or absence of $\mathrm{CaCl}_{2}$ (Scheme 8). The presence of $\mathrm{CaCl}_{2}$, which acts as Lewis acid coordinating both molecules, resulted in higher yields (35-44\%) and the absence of by-products. This was the first ever route featuring direct coupling of $\mathbf{2 8 8}$ with the functionalized aromatic ring $\mathbf{2 8 9}$.<smiles>Cc1cc(O)c(O)cc1Cl</smiles>

289<smiles>CC(=CCBr)CCC=C(C)C1CC(=O)C(C)(C)O1</smiles>

288

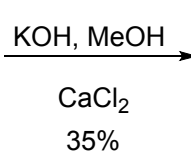

$35 \%$<smiles>CC(=CCc1c(O)c(Cl)c(C)c(C=O)c1O)CCC=C(C)C1CC(=O)C(C)(C)O1</smiles>

188

Scheme 8. Direct coupling in the absence of protecting groups: Haga (2010) ${ }^{188}$

\section{B. Diversifiable routes}

The focus in the last two years has shifted to the synthesis of diversifiable routes as it provides access to a wide number of natural product derivatives reducing the synthetic cost of production (Scheme 9).<smiles>[Y]c1c(O)c(CCC)c(O)c([X])c1CCCCC</smiles><smiles>[Y]c1c(C)c(O)c(CCC)c([X])c1O</smiles><smiles>[Y]c1c(C)c(O)c(CC=CC)c([X])c1O</smiles>
$(2017,2018)^{159,160}$ 
Grabovyi et al $^{189}$ discovered an alternative towards the total synthesis of polysubstituted phenolic natural products featuring terpenoid side chains (Scheme 10). This pathway, in which the phenolic head group is introduced early in the synthesis, is advantageous because it uses accessible protecting groups (e.g. MOM, Boc, and TBS) that are easily cleaved using $\mathrm{HCl}, \mathrm{ZnBr}$ and tetrabutylammonium fluoride (TBAF), respectively, and it allows the gram scale synthesis of the products in high overall yields $(>50 \%)$. The main drawback is the harsh conditions requested during the course of the divergent routes.

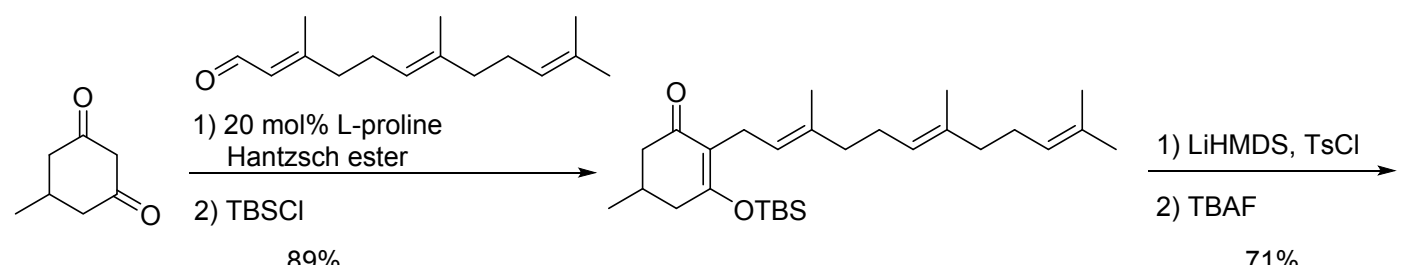

$89 \%$ $71 \%$

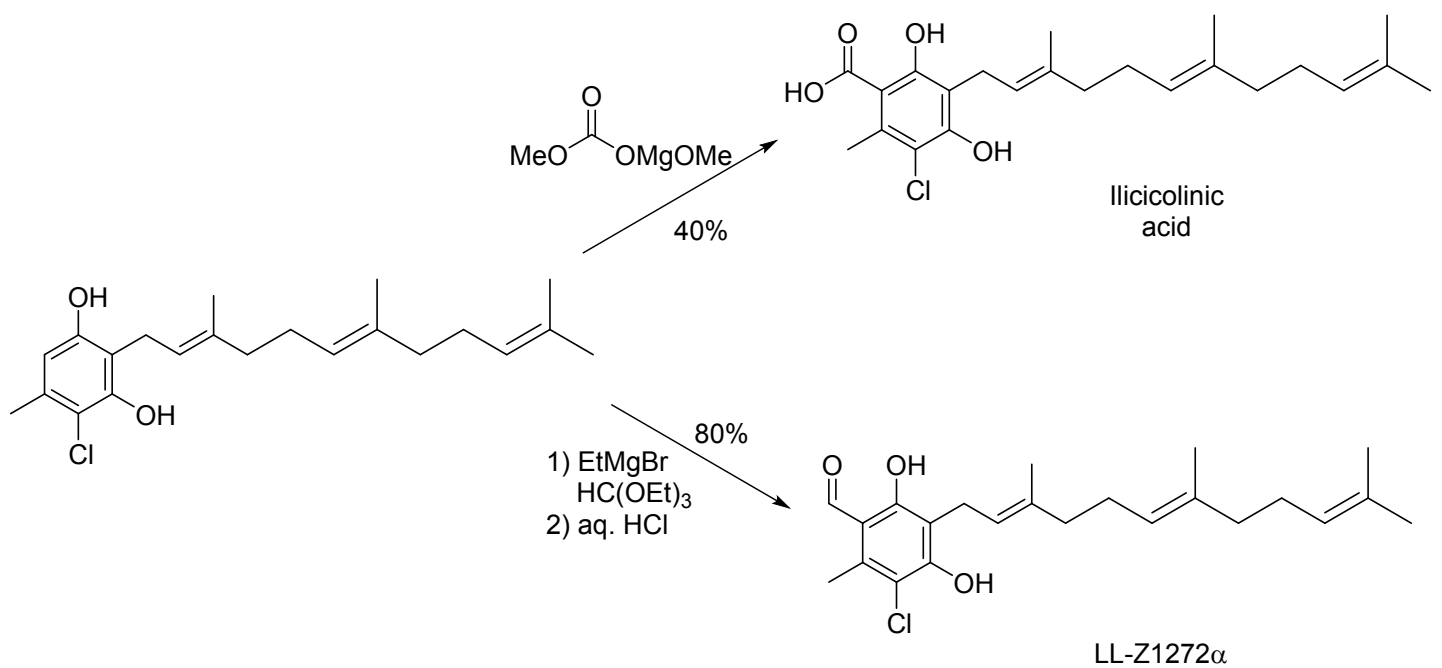

Scheme 10. Total synthesis scheme of natural products LL-Z1272 $\alpha$ and ilicicolinic acid

Recently, West et al ${ }^{159,160}$ studied the key step in the synthesis of AF-like compounds consisting in the installation of the prenyl chain in the aromatic ring. The reaction between alkyl or geranyl bromides via lithiation and subsequent electrophilic aromatic substitution (Scheme 11), led to 290 in excellent yields. However, once again, removal of the protecting groups was challenging and afforded a poor yield (15\%) of the product 291. 


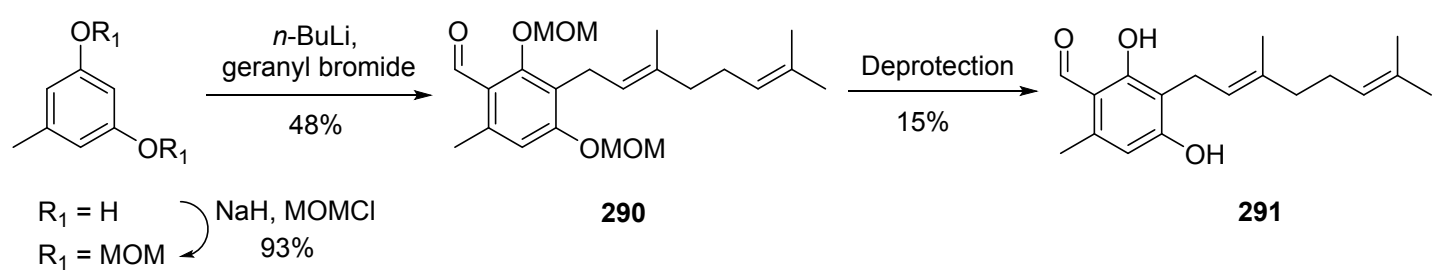

Scheme 11. Alkylation of protected resorcinol-like analogue

Deprotection of the phenolic groups in the course of AF synthesis has been a major problem over the years. Saimoto's attempts ${ }^{177}$ to reproduce Chen's procedure ${ }^{180}$ for the deprotection of Meethers (i.e. trimethylsilyl iodide in $\mathrm{CHCl}_{3}$ /pyridine for 4 days) was not successful. Hence, an alternative using $\mathrm{P}_{2} \mathrm{I}_{4}$ under neutral conditions was proposed to cleave the 1-alkoxymethyl aryl ether under mild conditions (Scheme 12). ${ }^{190}$

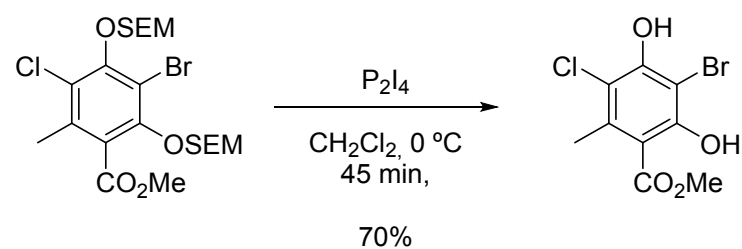

Scheme 12. Example of SEM ether deprotection using $\mathrm{P}_{2} \mathrm{I}_{4}{ }^{190}$

However, this protocol is also under debate as Fürstner et al ${ }^{191}$ and Marsico and co-workers, ${ }^{192}$ in further attempts, found complications (e.g. decomposition of the starting material) in the deprotection of SEM ethers using $\mathrm{P}_{2} \mathrm{I}_{4}$. In both cases, these problems were avoided using TBAF in hexamethylphosphoramide (HMPA). ${ }^{193}$ Thus, the availability of deprotection methods for the phenolic $\mathrm{OH}$ groups remains a critical issue when developing alternative routes to AF-like compounds.

Another route developed by West et al, ${ }^{159}$ based on non-aromatic alkylation/aromatization strategy, allowed facile diversification of the phenolic moiety through lithiation chemistry. This improved structural diversity and overall yields (Scheme 13). 


\subsection{Mitochondrial targeting strategy using lipophilic cations}

Notwithstanding all the recent methodological progress in the synthesis of AF derivatives, it is clear that the development of ascofuranone-like inhibitors remains somewhat limited, from a medicinal chemistry point of view, by the synthetic challenges associated with the modification of this scaffold.

Over the last several years, our group has developed an innovative strategy to boost the antiparasite activity of structurally simple AOX inhibitors derived from the 2,4-dihydroxybenzoic acid scaffold (80). The localization of AOX to the inner surface (matrix side) of the inner membrane of mitochondria ${ }^{1,162}$ has inspired us to use mitochondrion-targeting strategies for AOX inhibitors. Recent reports by our group ${ }^{13,28,62,194,195}$ and others ${ }^{196,197}$ have shown that coupling antiparasitic agents with lipophilic cations is an effective chemotherapeutic approach to deliver compounds specifically to the mitochondrion of protozoan parasites. In particular, the triphenylphosphonium (TPP) cation, which holds a charge that is delocalized over a large and hydrophobic surface area, can cross lipid bilayers by non-carrier mediated transport electrophoretically driven by the plasma and mitochondrial transmembrane potentials (Figure 25). ${ }^{198}$ Other cations such as quinolinium salts are also effective mitochondrion-targeting groups. ${ }^{62,199}$ 


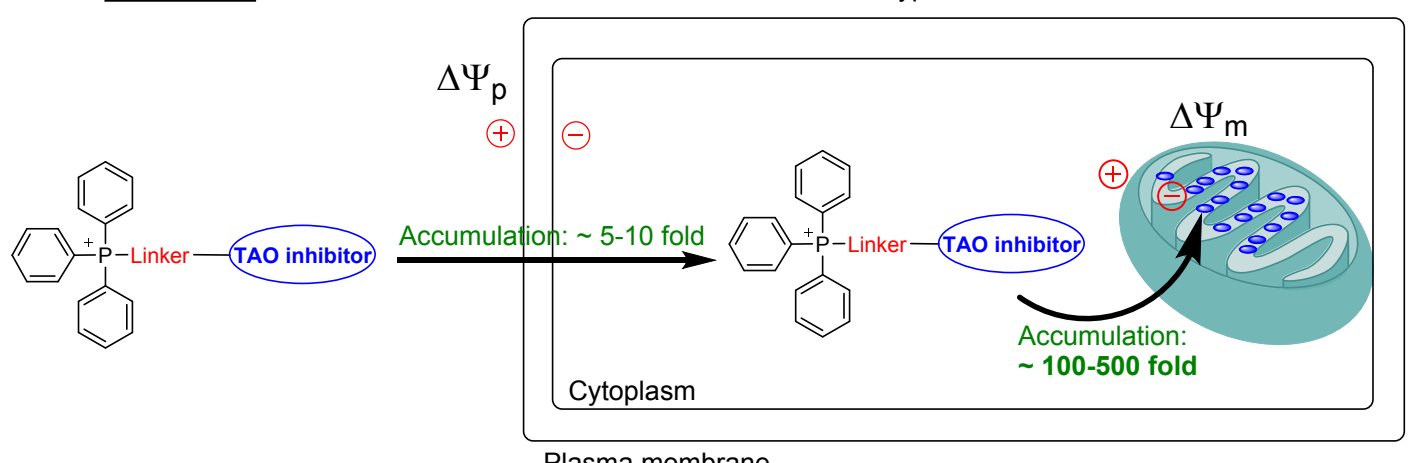

Plasma membrane

Figure 25. Schematic representation of uptake and accumulation of mitochondria-targeted triphenylphosphonium (TPP) TAO-inhibitor conjugates within BSF trypanosomes. $\Delta \Psi_{\mathrm{p}}$, plasma membrane potential; $\Delta \Psi_{\mathrm{m}}$, mitochondrial membrane potential.

The SAR of the different series of AOX inhibitors reported to date has shown that a certain level of lipophilicity, and a minimum length, is required in the tail region of the molecule to exhibit potent inhibition (see section 4). In particular, compounds holding a C12 or C14 chain are more inhibitory than shorter analogues. Hence, a series of 4-alkoxybenzoate derivatives (292-305) conjugated to a TPP or 1-quinolinium lipophilic cation via a methylene linker were synthesized (Figure 26). ${ }^{13}$ We found, consistent with previous reports and other series of benzhydroxamates and 4-hydroxybenzoates (Figures 6 and 13, respectively), that a linker length of 14 carbons was preferred $(297,299,301-305)$ while shorter or longer linkers were detrimental to TAO inhibition. ${ }^{13,62}$ For compounds 301-305, the introduction of the mitochondrion-targeting LC in the structure of inhibitors $\mathbf{1 5 9}, \mathbf{1 6 0}$, and $\mathbf{1 6 2}$ hardly affected their inhibitory potency against rTAO, indicating that the $\mathrm{LC}$ does not interfere with binding to TAO when a tetradecane linker is used.

As expected, mitochondrial targeting increased the potency of the compounds against wild type and drug-resistant strains of $T$. brucei and $T$. congolense by up to 3 orders of magnitude $\left(\mathrm{EC}_{50}\right.$ values from 0.6 to $210 \mathrm{nM}$ ), reflecting a similar improvement in mitochondrial accumulation. Selectivity of the LC-conjugates over human cells was also greatly improved vs non-cationic inhibitors. ${ }^{13}$ In general, the TPP cation was a more efficient mitochondrion-targeting moiety than the 1-quinolinium salt. Within this 4-hydroxybenzoate series, compounds $\mathbf{3 0 2}$ and 303, featuring $\mathrm{OH}$ and $\mathrm{Me}$ groups in ortho to the ester bond were metabolically stable in mouse serum and human microsomal fractions. In vivo, both compounds reduced the parasite load of mice infected with $T$. $b$. rhodesiense by $95 \% 24 \mathrm{~h}$ post-treatment by intraperitoneal administration $(4 \times 10$ $\mathrm{mg} / \mathrm{kg}$ ), without co-administration of glycerol. ${ }^{13}$

The 4-hydroxybenzaldehyde-LC conjugates $\mathbf{3 0 6}$ and $\mathbf{3 0 7}$ inhibited $\mathrm{TAO}\left(\mathrm{IC}_{50}=0.22\right.$ and 1.23 $\mu \mathrm{M})$ and $T$. brucei growth with $\mathrm{EC}_{50}$ values in the same concentration range $(0.133$ and $1.75 \mu \mathrm{M}$, 
respectively). ${ }^{13}$ SAR studies showed that the methyl ester analogues $\mathbf{3 0 9}$ and $\mathbf{3 1 0}$ were 10-times more potent whereas the free carboxylic acid derivative (317-321) were less effective $(>5 \mu \mathrm{M})$. Within this series, the 2-hydroxy-6-methyl carboxylate derivative $\mathbf{3 2 2}$ was the most potent (low nanomolar) inhibitor of the enzyme and of T. brucei growth. ${ }^{126}$

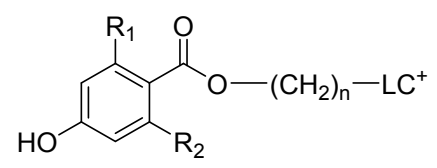

\begin{tabular}{|c|c|c|c|c|c|c|}
\hline & & & & & rTAO & T. brucei \\
\hline Cpd & $\mathrm{R}_{1}$ & $\mathrm{R}_{2}$ & $\mathrm{n}$ & $\mathrm{LC}^{+}$ & $\mathrm{IC}_{50}(\mu \mathrm{M})$ & $\mathrm{EC}_{50}(\mu \mathrm{M})$ \\
\hline 292 & $\mathrm{OH}$ & & 8 & TPP & $>50$ & 0.073 \\
\hline 293 & $\mathrm{OH}$ & & 9 & TPP & $>50$ & 0.0059 \\
\hline 294 & $\mathrm{OH}$ & & 10 & TPP & $>50$ & 0.0013 \\
\hline 295 & $\mathrm{OH}$ & & 12 & TPP & $>5$ & 0.0012 \\
\hline 296 & $\mathrm{OH}$ & & 12 & Quin & $>5$ & 0.33 \\
\hline 297 & $\mathrm{OH}$ & & 14 & TPP & 1.46 & 0.0015 \\
\hline 298 & $\mathrm{OH}$ & & 16 & TPP & $>5$ & 0.009 \\
\hline 299 & $\mathrm{OH}$ & & 14 & Quin & 1.36 & 0.10 \\
\hline 300 & $\mathrm{OH}$ & & 16 & Quin & $>5$ & 0.14 \\
\hline 301 & $\mathrm{~F}$ & & 14 & TPP & 0.030 & 0.0006 \\
\hline 302 & $\mathrm{OH}$ & $\mathrm{Me}$ & 14 & TPP & 0.088 & 0.0016 \\
\hline 303 & $\mathrm{OH}$ & $\mathrm{Me}$ & 14 & Quin & 0.104 & 0.032 \\
\hline 304 & $\mathrm{Me}$ & & 14 & TPP & 0.081 & 0.0024 \\
\hline 305 & $\mathrm{Me}$ & & 14 & Quin & 0.030 & 0.21 \\
\hline
\end{tabular}<smiles>[R]C(=O)c1c([R])cc(OCCCCC)cc1Br</smiles>

\begin{tabular}{|c|c|c|c|c|c|c|c|c|}
\hline & & & & & & & rTAO & T. brucei \\
\hline Cpd & $\mathrm{R}_{1}$ & $\mathrm{R}_{2}$ & $\mathrm{R}_{3}$ & $\mathrm{n}$ & Subst. & $\mathrm{LC}^{+}$ & $\mathrm{IC}_{50}(\mu \mathrm{M})$ & $\mathrm{EC}_{50}(\mu \mathrm{M})$ \\
\hline 306 & $\mathrm{OH}$ & & & 14 & 4- & TPP & 0.22 & 0.133 \\
\hline 307 & $\mathrm{OH}$ & & & 14 & 4- & Quin & 1.23 & 1.75 \\
\hline 308 & $\mathrm{OH}$ & & $\mathrm{OMe}$ & 10 & 4- & TPP & $>5$ & 0.002 \\
\hline 309 & $\mathrm{OH}$ & & $\mathrm{OMe}$ & 14 & 4- & TPP & 0.015 & 0.018 \\
\hline 310 & $\mathrm{OH}$ & & $\mathrm{OMe}$ & 14 & $3-$ & TPP & 0.012 & 0.028 \\
\hline 311 & $F$ & & $\mathrm{OMe}$ & 14 & 4- & TPP & 0.74 & 0.05 \\
\hline 312 & $F$ & & $\mathrm{OMe}$ & 14 & 4- & Quin & $>5$ & 2.4 \\
\hline 313 & $\mathrm{Me}$ & & $\mathrm{OMe}$ & 14 & 4- & TPP & $>5$ & 0.018 \\
\hline 314 & $\mathrm{Me}$ & & $\mathrm{OMe}$ & 14 & 4- & Quin & $>5$ & 0.16 \\
\hline 315 & $\mathrm{OH}$ & $\mathrm{Me}$ & OEt & 14 & 4- & TPP & 0.25 & 0.05 \\
\hline 316 & $\mathrm{OH}$ & $\mathrm{Me}$ & OEt & 14 & 4- & Quin & $>5$ & 0.29 \\
\hline 317 & $\mathrm{OH}$ & & $\mathrm{OH}$ & 10 & $4-$ & TPP & $>5$ & 0.73 \\
\hline 318 & $\mathrm{OH}$ & & $\mathrm{OH}$ & 14 & 4- & TPP & $>5$ & 0.086 \\
\hline 319 & $F$ & & $\mathrm{OH}$ & 14 & 4- & TPP & $>5$ & 0.037 \\
\hline 320 & $\mathrm{Me}$ & & $\mathrm{OH}$ & 14 & 4- & TPP & $>5$ & 0.19 \\
\hline 321 & $\mathrm{Me}$ & & $\mathrm{OH}$ & 14 & 4- & Quin & $>5$ & 10.6 \\
\hline 322 & $\mathrm{OH}$ & $\mathrm{Me}$ & $\mathrm{OH}$ & 14 & 4- & TPP & 0.0042 & 0.013 \\
\hline
\end{tabular}

Figure 26. $\mathrm{IC}_{50}$ values for inhibition of purified $\triangle \mathrm{MTS}-\mathrm{TAO}$ and $\mathrm{EC}_{50}$ values against $T$. $b$. brucei (WT) by 4-hydroxybenzoate-lipocation (LC) conjugates (292-305), 4-alkoxybenzaldehyde-LC conjugates $(\mathbf{3 0 6}, \mathbf{3 0 7})$, and (3)4-alkoxybenzoate-LC conjugates (308-322). The $\mathrm{IC}_{50}$ of SHAM (2) is $5.93 \mu \mathrm{M}$ in this assay. ${ }^{13,62,126} \mathrm{TPP}$ : triphenylphosphonium. Quin: 1-quinolinium.

\section{OUTLOOK AND CLINICAL PERSPECTIVE}

The first mention of alternative oxidases can be traced to the $1920 \mathrm{~s}^{35}$ and are now known to have important functions in many different organisms. In plants, the principal functions of AOX appear to be related to growth under adverse or stress conditions including drought ${ }^{84,200}$ - a topic of intense interest in relation to agriculture and food security. The role of AOX was also investigated in many fungi of agricultural or medical importance and it was similarly found to be important in their stress response, and to contribute to pathogenicity and virulence. Yet, the enzyme is not believed to be essential to most fungi and is not considered a target for drugs against fungal infection, at least not as monotherapy. 
The main pharmacological focus has been on the trypanosome alternative oxidase, which is a well-validated target. Several major challenges slowed progress for a considerable time: (1) the early inhibitors including SHAM were of low potency and required co-administration of large quantities of glycerol in vivo; (2) the ab initio synthesis of derivatives of the best available early inhibitor, ascofuranone, was chemically poorly accessible; (3) the enzyme proved very difficult to produce and purify in large enough yield to obtain structural information through crystallization and X-ray diffraction; (4) improved potency of the enzyme inhibitors ( $K_{\mathrm{i}}$ values) did not translate in similar potencies against the parasites in vitro or in vivo. However, over the last few years, each of these hurdles has been successfully taken.

(1) SHAM remained the standard TAO inhibitor for a long time, despite its low efficacy and the need for huge doses in vivo, in combination with even larger amounts of glycerol. The discovery of ascofuranone for the first time allowed the cure of infected animals with moderate doses and no glycerol co-administration. This breakthrough demonstrated that further improvements in trypanocidal potency and/or pharmacokinetics could deliver a genuine preclinical candidate.

(2) Multiple important improvements have been made to the synthetic routes to structurallysimpler ascofuranone analogues, allowing the construction of chemical library for SAR studies and the optimization of lead compounds.

(3) The production of TAO in bacteria suffered from the presence of prokaryotic cytochromes performing essentially the same reaction. The construction of an E. coli strain lacking the first step in heme synthesis, but able to grow when complemented by an intermediate metabolite (5aminolevulinic acid) or the expression of TAO, literally an alternative oxidase, was a major step in solving this problem, as was the painstaking optimization of solubilization detergents and purification protocols. The outlook has further improved with the shift to $\triangle \mathrm{MTS}-\mathrm{TAO}$, which, lacking the functionally redundant N-terminal sequence, is better soluble and displays greater yield, stability, and specific activity.

(4) Optimization of inhibitors, particularly when driven by structure-aided design, necessarily focus on the primary aim of improving interaction with the target, measured as binding affinity or inhibition constants. However, the optimized inhibitors do not necessarily display improved anti-parasite activity as there is no presumption of a correlation between inhibition of a target and the ability to reach that intracellular target. ${ }^{201,202}$ In the case of TAO, it is only the concentration of the inhibitor locally, inside the T. brucei mitochondrion that determines the antiparasite efficacy. This requires efficient uptake of the drug by the parasite into the cytosol and its further translocation into the mitochondrion. Both the plasma membrane and the inner mitochondrial membrane are inside-negative, with a strong membrane potential providing a driving force for the accumulation of cations that can actively or passively cross the lipid bilayer. This, essentially, 
forms the basis of the effectiveness of the cationic trypanocides including pentamidine, ${ }^{203}$ diminazene, ${ }^{204}$ furamidine ${ }^{205}$ and isometamidium. ${ }^{65}$ Since all classical TAO inhibitors including SHAM and ascofuranone are uncharged at physiological $\mathrm{pH}$, uptake was neither efficient nor concentrative. This problem was overcome by the coupling of lipophilic cations via long (C12 or C14) linkers to the inhibitors, allowing the intra-mitochondrial concentration to increase by several hundred-fold for the same extracellular concentration or dose. This has reversed the paradigm by creating molecules with a much lower anti-parasite $\mathrm{EC}_{50}$ than enzyme inhibition $\mathrm{IC}_{50 \cdot}{ }^{13,62}$

Altogether, the potency observed with the TAO inhibitor-LC conjugates shows that mitochondrial targeting with lipophilic cations is a promising strategy to boost the trypanocidal efficacy of AOX inhibitors, and that it can work in vivo. At least some of these molecules were stable in serum and when challenged by Phase I or Phase II metabolism in pharmacokinetic tests. In preliminary in vivo studies with these inhibitors $T$. b. rhodesiense parasitemia was reduced $95 \%$ with 4 daily doses of $10 \mathrm{mg} / \mathrm{kg} .{ }^{13}$ However, an improvement of the drug-like properties of these conjugates, and a much more thorough evaluation of in vivo behavior will be required if they are to be used as anti-parasite drugs. The initial argument that TAO is a druggable and essential trypanosome enzyme without a mammalian counterpart is still valid and the breakthroughs of the last few years give every reason for optimism.

\section{ACKNOWLEDGEMENTS}

Funding from the Spanish Ministerio de Economia y Competitividad (grant SAF2015-66690-R) and the Japan Society for the promotion of Science (JSPS grant-17F17420) is gratefully acknowledged. 


\section{REFERENCES}

1. Moore AL, Shiba T, Young L, Harada S, Kita K, Ito K. Unraveling the Heater: New Insights into the Structure of the Alternative Oxidase. Annu Rev Plant Biol. 2013;64(1):637-663.

2. Moore AL, Albury MS. Further insights into the structure of the alternative oxidase: from plants to parasites. Biochem Soc Trans. 2008;36(Pt 5):1022-1026.

3. McDonald AE, Vanlerberghe GC. Origins, evolutionary history, and taxonomic distribution of alternative oxidase and plastoquinol terminal oxidase. Comp Biochem, Physiol Part D, Genomics \& proteomics. 2006;1(3):357-364.

4. Barrett MP, Burchmore RJ, Stich A, et al. The trypanosomiases. Lancet. 2003;362(9394):1469-1480.

5. Williams BAP, Elliot C, Burri L, et al. A Broad Distribution of the Alternative Oxidase in Microsporidian Parasites. PLoS Pathogens. 2010;6(2):e1000761.

6. Roberts $\mathrm{CW}$, Roberts F, Henriquez FL, et al. Evidence for mitochondrial-derived alternative oxidase in the apicomplexan parasite Cryptosporidium parvum: A potential anti-microbial agent target. Int J Parasitol. 2004;34(3):297-308.

7. May B, Young L, Moore AL. Structural insights into the alternative oxidases: Are all oxidases made equal? Biochem Soc Trans. 2017;45(3):731-740.

8. Young L, Shiba T, Harada S, Kita K, Albury MS, Moore AL. The alternative oxidases: Simple oxidoreductase proteins with complex functions. Biochem Soc Trans. 2013;41(5):1305-1311.

9. Yan L, Li M, Cao Y, et al. The alternative oxidase of Candida albicans causes reduced fluconazole susceptibility. J Antimicrob Chemother. 2009;64(4):764-773.

10. Shiba T, Kido Y, Sakamoto K, et al. Structure of the trypanosome cyanide-insensitive alternative oxidase. Proc Nat Acad Sci 2013;110(12):4580-4585.

11. Vanlerberghe GC. Alternative Oxidase: A Mitochondrial Respiratory Pathway to Maintain Metabolic and Signaling Homeostasis during Abiotic and Biotic Stress in Plants. Int J Mol Sci. 2013;14(4):6805-6847.

12. Giordani F, Morrison LJ, Rowan T, De Koning HP, Barrett MP. The animal trypanosomiases and their chemotherapy - a review. Parasitol Int. 2016;143(14):18621889.

13. Ebiloma GU, Díaz-Ayuga T, Balogun EO, et al. Inhibition of trypanosome alternative oxidase without its $\mathrm{N}$-terminal mitochondrial targeting signal ( $\triangle \mathrm{MTS}-\mathrm{TAO}$ ) by cationic and non-cationic 4-hydroxybenzoate and 4-alkoxybenzaldehyde derivatives active against T. brucei and T. congolense. Eur J Med Chem. 2018;150:385-402. 
14. Chaudhuri M, Ott RD, Hill GC. Trypanosome alternative oxidase: from molecule to function. Trends Parasitol. 2006;22(10):484-491.

15. Nihei C, Fukai Y, Kita K. Trypanosome alternative oxidase as a target of chemotherapy. Biochim Biophys Acta. 2002;1587(2-3):234-239.

16. Chaudhuri M, Ajayi W, Hill GC. Biochemical and molecular properties of the Trypanosoma brucei alternative oxidase. Mol Biochem Parasitol. 1998;95(1):53-68.

17. Clarkson AB, Jr., Bienen EJ, Pollakis G, Grady RW. Respiration of bloodstream forms of the parasite Trypanosoma brucei brucei is dependent on a plant-like alternative oxidase. J Biol Chem. 1989;264(30):17770-17776.

18. Menzies SK, Tulloch LB, Florence GJ, Smith TK. The trypanosome alternative oxidase: a potential drug target? Parasitology. 2016;145(2):175-183.

19. Murphy AD, Lang-Unnasch N. Alternative Oxidase Inhibitors Potentiate the Activity of Atovaquone against Plasmodium falciparum. Antimicrob Agents Chemother. 1999;43(3):651-654.

20. Murphy AD, Doeller JE, Hearn B, Lang-Unnasch N. Plasmodium falciparum: CyanideResistant Oxygen Consumption. Exp Parasitol. 1997;87(2):112-120.

21. Kissinger JC, Gajria B, Li L, Paulsen IT, Roos DS. ToxoDB: accessing the Toxoplasma gondii genome. Nucl Acids Res. 2003;31(1):234-236.

22. Gardner MJ, Hall N, Fung E, et al. Genome sequence of the human malaria parasite Plasmodium falciparum. Nature. 2002;419:498-511.

23. Suzuki T, Hashimoto T, Yabu Y, et al. Direct evidence for cyanide-insensitive quinol oxidase (alternative oxidase) in apicomplexan parasite Cryptosporidium parvum: Phylogenetic and therapeutic implications. Biochem Biophys Res Commun. 2004;313(4):1044-1052.

24. King P, Robinson G, Elwin K, Tyler KM, Hunter PR, Chalmers RM. Prevalence and epidemiology of human Cryptosporidium parvum IIc infections in England and Wales. Lancet. 2017;389:S56.

25. Hunter PR, Nichols G. Epidemiology and Clinical Features of Cryptosporidium Infection in Immunocompromised Patients. Clin Microbiol Rev. 2002;15(1):145-154.

26. Müller M, Mentel M, van Hellemond JJ, et al. Biochemistry and Evolution of Anaerobic Energy Metabolism in Eukaryotes. Microbiol Mol Biol Rev. 2012;76(2):444-495.

27. Suzuki T, Nihei C, Yabu Y, et al. Molecular cloning and characterization of Trypanosoma vivax alternative oxidase (AOX) gene, a target of the trypanocide ascofuranone. Parasitology international. 2004;53(3):235-245.

28. Alkhaldi AAM, Martinek J, Panicucci B, Dardonville C, Zíková A, de Koning HP. Trypanocidal action of bisphosphonium salts through a mitochondrial target in 
bloodstream form Trypanosoma brucei. Int J Parasitol Drugs Drug Resist. 2016;6(1):2334.

29. Rodenko B, Wanner MJ, Alkhaldi AAM, et al. Targeting the Parasite's DNA with Methyltriazenyl Purine Analogs Is a Safe, Selective, and Efficacious Antitrypanosomal Strategy. Antimicrob Agents Chemother. 2015;59(11):6708-6716.

30. Jamonneau V, Ilboudo H, Kaboré J, et al. Untreated Human Infections by Trypanosoma brucei gambiense Are Not 100\% Fatal. PLOS Negl Trop Dis. 2012;6(6):e1691.

31. Deborggraeve S, Koffi M, Jamonneau V, et al. Molecular analysis of archived blood slides reveals an atypical human Trypanosoma infection. Diagnostic Microbiol Infect Dis. 2008;61(4):428-433.

32. Wolf T, Wichelhaus T, Göttig S, Kleine C, Brodt H, Just-Nuebling G. Trypanosoma brucei rhodesiense infection in a German traveller returning from the Masai Mara area, Kenya. Euro Surveill 2012;17(10):20114.

33. Gautret P, Clerinx J, Caumes E, et al. Imported human African trypanosomiasis in Europe, 2005-2009. Eurosurveillance. 2009;14(36):19327.

34. Moore AL, Siedow JN. The regulation and nature of the cyanide-resistant alternative oxidase of plant mitochondria. Biochim Biophys Acta (BBA) - Bioenergetics. 1991;1059(2):121-140.

35. Schmucker T. Beiträge zur Biologie und Physiologie von Arum maculatum. Flora 1925;118: 460-475

36. Miller RE, Grant NM, Giles L, et al. In the heat of the night - alternative pathway respiration drives thermogenesis in Philodendron bipinnatifidum. New Phytol. 2011;189:1013-1026.

37. Wagner AM, Krab K, Wagner MJ, Moore AL. Regulation of thermogenesis in flowering Araceae: The role of the alternative oxidase. Biochim Biophys Acta (BBA) Bioenergetics. 2008;1777(7):993-1000.

38. Watling JR, Robinson SA, Seymour RS. Contribution of the Alternative Pathway to Respiration during Thermogenesis in Flowers of the Sacred Lotus. Plant Physiol. 2006;140(4):1367-1373.

39. Gardeström P, Igamberdiev AU, Raghavendra AS. Mitochondrial functions in the light and significance to carbon-nitrogen interactions. . In: Photosynthetic nitrogen assimilation and associated carbon and respiratory metabolism. Dordrecht: Springer; 2002: 151-172.

40. Royo B, Moran JF, Ratcliffe RG, Gupta KJ. Nitric oxide induces the alternative oxidase pathway in Arabidopsis seedlings deprived of inorganic phosphate. $J$ Exp Botany. 2015;66(20):6273-6280. 
41. Maxwell DP, Wang Y, McIntosh L. The alternative oxidase lowers mitochondrial reactive oxygen production in plant cells. Proc Nat Acad Sci USA. 1999;96(14):82718276.

42. Millar AH, Day DA. Nitric oxide inhibits the cytochrome oxidase but not the alternative oxidase of plant mitochondria. FEBS Lett. 1996;398(2-3):155-158.

43. Millenaar FF, Lambers H. The Alternative Oxidase: in vivo Regulation and Function. Plant Biol. 2008;5(1):2-15.

44. Rychter AM, Szal B. Alternative pathways and phosphate and nitrogen nutrition. In: Wiley-Blackwell, ed. Alternative Respiratory Pathways in Higher Plants.2015:53.

45. Kido Y, Sakamoto K, Nakamura K, et al. Purification and kinetic characterization of recombinant alternative oxidase from Trypanosoma brucei brucei. Biochim Biophys Acta, Bioenerg. 2010;1797(4):443-450.

46. McDonald AE, Vanlerberghe GC, Staples JF. Alternative oxidase in animals: unique characteristics and taxonomic distribution. J Exp Biol. 2009;212(16):2627-2634.

47. Bruce D. Preliminary report on the tsetse fly disease or nagana, in Zululand. Bennett \& Davis; 1895.

48. Steverding D. The history of African trypanosomiasis. Parasit Vectors. 2008;1(1):3.

49. Smith T, Bringaud F, Nolan D, Figueiredo L. Metabolic reprogramming during the Trypanosoma brucei life cycle. F1000Research. 2017;6(683).

50. Hill GC. Electron transport systems in kinetoplastida. Biochim Biophys Acta (BBA) - Rev Bioenerg. 1976;456(2):149-193.

51. Grant PT, Sargent JR. Properties of L-alpha-glycerophosphate oxidase and its role in the respiration of Trypanosoma rhodesiense. Biochem J. 1960;76:229-237.

52. Opperdoes FR, Borst P, Bakker S, Leene W. Localization of glycerol-3-phosphate oxidase in the mitochondrion and particulate NAD+-linked glycerol-3-phosphate dehydrogenase in the microbodies of the bloodstream form to Trypanosoma brucei. Eur J Biochem. 1977;76(1):29-39.

53. Fairlamb AH, Bowman IBR. The isolation and characterisation of particulate sn-glycerol3-phosphate oxidase from Trypanosoma brucei. Int J Biochem. 1977;8(9):659-668.

54. Minagawa N, Yabu Y, Kita K, et al. An antibiotic, ascofuranone, specifically inhibits respiration and in vitro growth of long slender bloodstream forms of Trypanosoma brucei brucei. Mol Biochem Parasitol. 1996;81(2):127-136.

55. Evans DA, Brown RC. The inhibitory effects of aromatic hydroxamic acids on the cyanide-insensitive terminal oxidase of Trypanosoma brucei. Trans R Soc Trop Med Hyg. 1973;67(2):258.

56. Chaudhuri M, Ajayi W, Temple S, Hill GC. Identification and partial purification of a stage-specific $33 \mathrm{kDa}$ mitochondrial protein as the alternative oxidase of the 
Trypanosoma brucei brucei bloodstream trypomastigotes. J Eukaryot Microbiol. 1995;42(5):467-472.

57. Chaudhuri M, Hill GC. Cloning, sequencing, and functional activity of the Trypanosoma brucei brucei alternative oxidase. Mol Biochem Parasitol. 1996;83(1):125-129.

58. Hamilton V, Singha UK, Smith JT, Weems E, Chaudhuri M. Trypanosome Alternative Oxidase Possesses both an N-Terminal and Internal Mitochondrial Targeting Signal. Eukaryot Cell. 2014;13(4):539-547.

59. Saimoto H, Kido Y, Haga Y, Sakamoto K, Kita K. Pharmacophore identification of ascofuranone, potent inhibitor of cyanide-insensitive alternative oxidase of Trypanosoma brucei. J Biochem. 2013;153(3):267-273.

60. Shiba T, Kido Y, Sakamoto K, et al. Crystal structure of the alternative oxidases: New insights into the catalytic cycle. Biochim Biophys Acta (BBA) - Bioenergetics. 2012;1817, Supplement(0):S102-S103.

61. Kido Y, Shiba T, Inaoka DK, et al. Crystallization and preliminary crystallographic analysis of cyanide-insensitive alternative oxidase from Trypanosoma brucei brucei. Acta Cryst F. 2010;66(Pt 3):275-278.

62. Fueyo González FJ, Ebiloma GU, Izquierdo García C, et al. Conjugates of 2,4Dihydroxybenzoate and Salicylhydroxamate and Lipocations Display Potent Antiparasite Effects by Efficiently Targeting the Trypanosoma brucei and Trypanosoma congolense Mitochondrion. J Med Chem. 2017;60:1509-1522.

63. Siedow JN, Umbach AL. The mitochondrial cyanide-resistant oxidase: structural conservation amid regulatory diversity. Biochim Biophys Acta - Bioenergetics. 2000;1459(2):432-439.

64. Tielens AG, van Hellemond JJ. Surprising variety in energy metabolism within Trypanosomatidae. Trends Parasitol. 2009;25(10):482-490.

65. Eze AA, Gould MK, Munday JC, et al. Reduced Mitochondrial Membrane Potential Is a Late Adaptation of Trypanosoma brucei brucei to Isometamidium Preceded by Mutations in the gamma Subunit of the F1Fo-ATPase. PLoS Negl Trop Dis. 2016;10(8):e0004791.

66. Schnaufer A, Clark-Walker GD, Steinberg AG, Stuart K. The F1-ATP synthase complex in bloodstream stage trypanosomes has an unusual and essential function. The EMBO journal. 2005;24(23):4029-4040.

67. Chaudhuri M, Sharan R, Hill GC. Trypanosome alternative oxidase is regulated posttranscriptionally at the level of RNA stability. J Eukaryot Microbiol. 2002;49(4):263269.

68. Tetaud E, Barrett MP, Bringaud F, Baltz T. Kinetoplastid glucose transporters. Biochem J. 1997;325 ( Pt 3):569-580. 
69. Michels PA, Bringaud F, Herman M, Hannaert V. Metabolic functions of glycosomes in trypanosomatids. Biochim Biophys Acta. 2006;1763(12):1463-1477.

70. Sanchez MA. Molecular identification and characterization of an essential pyruvate transporter from Trypanosoma brucei. J Biol Chem. 2013;288(20):14428-14437.

71. Opperdoes FR. Compartmentation of Carbohydrate Metabolism in Trypanosomes. Ann Rev Microbiol. 1987;41(1):127-151.

72. Helfert S, Estevez AM, Bakker B, Michels P, Clayton C. Roles of triosephosphate isomerase and aerobic metabolism in Trypanosoma brucei. Biochem J. 2001;357(Pt 1):117-125.

73. Balogun EO, Inaoka DK, Shiba T, et al. Glycerol kinase of African trypanosomes possesses an intrinsic phosphatase activity. Biochim Biophys Acta. 2017;1861(11, Part A):2830-2842.

74. Yabu Y, Suzuki T, Nihei C, et al. Chemotherapeutic efficacy of ascofuranone in Trypanosoma vivax-infected mice without glycerol. Parasitol Int. 2006;55(1):39-43.

75. Walker R, Saha L, Hill GC, Chaudhuri M. The effect of over-expression of the alternative oxidase in the procyclic forms of Trypanosoma brucei. Mol Biochem Parasitol. 2005;139(2):153-162.

76. Fang J, Beattie DS. Alternative oxidase present in procyclic Trypanosoma brucei may act to lower the mitochondrial production of superoxide. Arch Biochem Biophys. 2003;414(2):294-302.

77. Tsuda A, Witola WH, Ohashi K, Onuma M. Expression of alternative oxidase inhibits programmed cell death-like phenomenon in bloodstream form of Trypanosoma brucei rhodesiense. Parasitol Int. 2005;54(4):243-251.

78. Vassella E, Oberle M, Urwyler S, et al. Major Surface Glycoproteins of Insect Forms of Trypanosoma brucei Are Not Essential for Cyclical Transmission by Tsetse. PLoS ONE. 2009;4(2):e4493.

79. Bütikofer P, Ruepp S, Boschung M, Roditi I. 'GPEET' procyclin is the major surface protein of procyclic culture forms of Trypanosoma brucei brucei strain 427. Biochem J. 1997;326(2):415.

80. Vassella E, Den Abbeele JV, Bütikofer P, et al. A major surface glycoprotein of Trypanosoma brucei is expressed transiently during development and can be regulated post-transcriptionally by glycerol or hypoxia. Genes Develop. 2000;14(5):615-626.

81. Vassella E, Probst M, Schneider A, Studer E, Renggli CK, Roditi I. Expression of a Major Surface Protein of Trypanosoma brucei Insect Forms Is Controlled by the Activity of Mitochondrial Enzymes. Mol Biol Cell. 2004;15(9):3986-3993. 
82. Pennisi R, Salvi D, Brandi V, Angelini R, Ascenzi P, Polticelli F. Molecular Evolution of Alternative Oxidase Proteins: A Phylogenetic and Structure Modeling Approach. $J$ Mol Evol. 2016;DOI 10.1007/s00239-016-9738-8:1-12.

83. Stechmann A, Hamblin K, Pérez-Brocal V, et al. Organelles in Blastocystis that Blur the Distinction between Mitochondria and Hydrogenosomes. Curr Biol. 2008;18(8):580585 .

84. Selinski J, Scheibe R, Day DA, Whelan J. Alternative Oxidase Is Positive for Plant Performance. Trends Plant Sci. 2018;23(7):588-597.

85. Stenmark P, Nordlund P. A prokaryotic alternative oxidase present in the bacterium Novosphingobium aromaticivorans. FEBS Lett. 2003;552(2):189-192.

86. Moore AL, Albury MS, Crichton PG, Affourtit C. Function of the alternative oxidase: is it still a scavenger? Trends Plant Sci. 2002;7(11):478-481.

87. Mizutani A, Yukioka H, Tamura H, Miki N, Masuko M, Takeda R. Respiratory characteristics of Pyricularia oryzae exposed to a novel alkoxyiminoacetamide. Physiopathol. 1995;85(2):271-280.

88. Yukioka $\mathrm{H}$, Inagaki $\mathrm{S}$, Tanaka $\mathrm{R}$, et al. Transcriptional activation of the alternative oxidase gene of the fungus Magnaporthe grisea by a respiratory-inhibiting fungicide and hydrogen peroxide. Biochim Biophys Acta (BBA) - Gene Structure and Expression. 1998;1442(2):161-169.

89. Honda Y, Hattori T, Kirimura K. Visual expression analysis of the responses of the alternative oxidase gene (aox1) to heat shock, oxidative, and osmotic stresses in conidia of citric acid-producing Aspergillus niger. J Biosci Bioeng. 2012;113(3):338-342.

90. Magnani T, Soriani FM, Martins VP, et al. Cloning and functional expression of the mitochondrial alternative oxidase of Aspergillus fumigatus and its induction by oxidative stress. FEMS Microbiol Lett. 2007;271(2):230-238.

91. Minagawa N, Koga S, Nakano M, Sakajo S, Yoshimoto A. Possible involvement of superoxide anion in the induction of cyanide-resistant respiration in Hansenula anomala. FEBS Lett. 1992;302(3):217-219.

92. Martins VP, Dinamarco TM, Soriani FM, et al. Involvement of an Alternative Oxidase in Oxidative Stress and Mycelium-to-Yeast Differentiation in Paracoccidioides brasiliensis. Eukaryot Cell. 2011;10(2):237-248.

93. Biryukova EN, Medentsev AG, Arinbasarova AY, Akimenko VK. Respiratory activity of yeast Yarrowia lipolytica under oxidative stress and heat shock. Microbiol. 2008;77(4):395-399.

94. Hernández Ruiz O, Gonzalez A, Almeida AJ, et al. Alternative Oxidase Mediates Pathogen Resistance in Paracoccidioides brasiliensis Infection. PLOS Negl Trop Dis. 2011;5(10):e1353. 
95. Akhter S, McDade HC, Gorlach JM, Heinrich G, Cox GM, Perfect JR. Role of alternative oxidase gene in pathogenesis of Cryptococcus neoformans. Infect Immun. 2003;71(10):5794-5802.

96. Dean R, Van Kan JAL, Pretorius ZA, et al. The Top 10 fungal pathogens in molecular plant pathology. Mol Plant Pathol. 2012;13(4):414-430.

97. Brefort T, Doehlemann G, Mendoza-Mendoza A, Reissmann S, Djamei A, Kahmann R. Ustilago maydis as a Pathogen. Ann Rev Phytopathol. 2009;47(1):423-445.

98. Guerrero-Castillo S, Cabrera-Orefice A, Vázquez-Acevedo M, González-Halphen D, Uribe-Carvajal S. During the stationary growth phase, Yarrowia lipolytica prevents the overproduction of reactive oxygen species by activating an uncoupled mitochondrial respiratory pathway. Biochim Biophys Acta (BBA) - Bioenergetics. 2012;1817(2):353362.

99. Juárez O, Guerra G, Velázquez I, Flores-Herrera O, Rivera-Pérez RE, Pardo JP. The physiologic role of alternative oxidase in Ustilago maydis. FEBS J. 2006;273(20):46034615 .

100. Cárdenas-Monroy CA, Pohlmann T, Piñón-Zárate G, et al. The mitochondrial alternative oxidase Aox1 is needed to cope with respiratory stress but dispensable for pathogenic development in Ustilago maydis. PloS ONE. 2017;12(3):e0173389.

101. Gashaw I, Ellinghaus P, Sommer A, Asadullah K. What makes a good drug target? Drug Discov Today. 2011;16(23-24):1037-1043.

102. Jones LH. An industry perspective on drug target validation. Expert opinion on drug discovery. 2016;11(7):623-625.

103. Ohashi-Suzuki M, Yabu Y, Ohshima S, et al. Differential kinetic activities of glycerol kinase among African trypanosome species: phylogenetic and therapeutic implications. $J$ Vet Med Sci. 2011;73(5):615-621.

104. Takumi S, Tomioka M, Eto K, Naydenov N, Nakamura C. Characterization of two nonhomoeologous nuclear genes encoding mitochondrial alternative oxidase in common wheat. Genes \& genetic systems. 2002;77(2):81-88.

105. Zalutskaya Z, Filina V, Ostroukhova M, Ermilova E. Regulation of alternative oxidase 1 in Chlamydomonas reinhardtii during sulfur starvation. Eur J Protistol. 2018;63:26-33.

106. Brew-Appiah RAT, York ZB, Krishnan V, Roalson EH, Sanguinet KA. Genome-wide identification and analysis of the ALTERNATIVE OXIDASE gene family in diploid and hexaploid wheat. PLoS One. 2018;13(8):e201439.

107. Kita K, Konishi K, Anraku Y. Terminal oxidases of Escherichia coli aerobic respiratory chain. II. Purification and properties of cytochrome b558-d complex from cells grown with limited oxygen and evidence of branched electron-carrying systems. $J$ Biol Chem. 1984;259(5):3375-3381. 
108. Tsubaki M, Hori H, Mogi T. Glutamate-286 mutants of cytochrome bo-type ubiquinol oxidase from Escherichia coli: influence of mutations on the binuclear center structure revealed by FT-IR and EPR spectroscopies. FEBS letters. 1997;416(3):247-250.

109. Fukai Y, Amino H, Hirawake H, et al. Functional expression of the ascofuranonesensitive Trypanosoma brucei brucei alternative oxidase in the cytoplasmic membrane of Escherichia coli. Comp Biochem Physiol C Pharmacol Toxicol Endocrinol. 1999;124(2):141-148.

110. Ajayi WU, Chaudhuri M, Hill GC. Site-directed mutagenesis reveals the essentiality of the conserved residues in the putative diiron active site of the trypanosome alternative oxidase. J Biol Chem. 2002;277(10):8187-8193.

111. Tobie EJ, Von Brand T, Mehlman B. Cultural and physiological observations on Trypanosoma rhodesiense and Trypanosoma gambiense. J Parasitol. 1950;36(1):48-54.

112. Nihashi N, Inaoka DK, Tsuge C, et al. Siccanin Is a Novel Selective Inhibitor of Trypanosomatid Complex II (Succinate-Ubiquinone Reductase) and a Potent BroadSpectrum Anti-trypanosomatid Drug Candidate. In: Noiri E, Jha TK, eds. Kala Azar in South Asia: Current Status and Sustainable Challenges. Cham: Springer International Publishing; 2016:101-122.

113. Minagawa N, Yabu Y, Kita K, et al. An antibiotic, ascofuranone, specifically inhibits respiration and in vitro growth of long slender bloodstream forms of Trypanosoma brucei brucei. Mol Biochem Parasitol. 1997;84(2):271-280.

114. Yang G, Zhu W, Kim K, et al. In Vitro and In Vivo Investigation of the Inhibition of Trypanosoma brucei Cell Growth by Lipophilic Bisphosphonates. Antimicrob Agents Chemother. 2015;59(12):7530-7539.

115. Gould MK, Vu XL, Seebeck T, de Koning HP. Propidium iodide-based methods for monitoring drug action in the kinetoplastidae: Comparison with the Alamar Blue assay. Anal Biochem. 2008;382(2):87-93.

116. Räz B, Iten M, Grether-Bühler Y, Kaminsky R, Brun R. The Alamar Blue assay to determine drug sensitivity of African trypanosomes (T. b. rhodesiense and $T . b$. gambiense) in vitro. Acta Trop. 1997;68(2):139-147.

117. Schonbaum GR, Bonner WD, Storey BT, Bahr JT. Specific Inhibition of the Cyanideinsensitive Respiratory Pathway in Plant Mitochondria by Hydroxamic Acids. Plant Physiology. 1971;47(1):124-128.

118. Tyler KM, Matthews KR, Gull K. The bloodstream differentiation-division of Trypanosoma brucei studied using mitochondrial markers. Proc Biol Sci. 1997;264(1387):1481-1490.

119. Opperdoes FR, Aarsen PN, van der Meer C, Borst P. Trypanosoma brucei: an evaluation of salicylhydroxamic acid as a trypanocidal drug. Exp Parasitol. 1976;40(2):198-205. 
120. Fairlamb AH, Opperdoes FR, Borst P. New approach to screening drugs for activity against African trypanosomes. Nature. 1977;265(5591):270-271.

121. Van Der Meer C, Versluijs-Broers JA. Trypanosoma brucei: trypanocidal effect of salicylhydroxamic acid plus glycerol in infected rats. Exp Parasitol. 1979;48(1):126-134.

122. Njogu RM, Whittaker CJ, Hill GC. Evidence for a branched electron transport chain in Trypanosoma brucei. Mol Biochem Parasitol. 1980;1(1):13-29.

123. Grady RW, Bienen EJ, Clarkson AB, Jr. p-Alkyloxybenzhydroxamic acids, effective inhibitors of the trypanosome glycerol-3-phosphate oxidase. Mol Biochem Parasitol. 1986;19(3):231-240.

124. Clarkson AB, Jr., Grady RW, Grossman SA, McCallum RJ, Brohn FH. Trypanosoma brucei brucei: a systematic screening for alternatives to the salicylhydroxamic acidglycerol combination. Mol Biochem Parasitol. 1981;3(5):271-291.

125. Grady RW, Bienen EJ, Clarkson AB, Jr. Esters of 3,4-dihydroxybenzoic acid, highly effective inhibitors of the sn-glycerol-3-phosphate oxidase of Trypanosoma brucei brucei. Mol Biochem Parasitol. 1986;21(1):55-63.

126. Meco-Navas A, Ebiloma GU, Martín-Domínguez A, et al. SAR of 4-Alkoxybenzoic Acid Inhibitors of the Trypanosome Alternative Oxidase. ACS Med Chem Lett. 2018;9(9):923928.

127. Clarkson AB, Jr., Brohn FH. Trypanosomiasis: an approach to chemotherapy by the inhibition of carbohydrate catabolism. Science (New York, NY. 1976;194(4261):204-206.

128. Brohn FH, Clarkson AB, Jr. Quantitative effects of salycylhydroxamic acid and glycerol on Trypanosoma brucei glycolysis in vitro and in vivo. Acta Trop. 1978;35(1):23-33.

129. Yabu Y, Nose M, Koide T, Ohta N, Ogihara Y. Antitrypanosomal effects of traditional Chinese herbal medicines on bloodstream forms of Trypanosoma brucei rhodesiense in vitro. Southeast Asian J Trop Med Public Health. 1998;29(3):599-604.

130. Yabu Y, Yoshida A, Suzuki T, et al. The efficacy of ascofuranone in a consecutive treatment on Trypanosoma brucei brucei in mice. Parasitol Int. 2003;52(2):155-164.

131. Giroud C, Ottones F, Coustou V, et al. Murine Models for Trypanosoma brucei gambiense disease progression--from silent to chronic infections and early brain tropism. PLoS Negl Trop Dis. 2009;3(9):e509.

132. Trindade S, Rijo-Ferreira F, Carvalho T, et al. Trypanosoma brucei Parasites Occupy and Functionally Adapt to the Adipose Tissue in Mice. Cell Host Microbe. 2016;19(6):837848.

133. Carvalho T, Trindade S, Pimenta S, Santos AB, Rijo-Ferreira F, Figueiredo LM. Trypanosoma brucei triggers a marked immune response in male reproductive organs. PLoS Negl Trop Dis. 2018;12(8):e0006690. 
134. van der Meer C, Versluys-Broers JA, van Duin CT, van den Ingh TS, Nieuwenhuijs J, Zwart D. Pitfalls of salicylhydroxamic acid plus glycerol treatment of $T$. vivax infected goats. Tropenmedizin und Parasitologie. 1980;31(3):275-282.

135. Evans DA, Brightman CJ, Holland MF. Salicylhydroxamic-acid/glycerol in experimental trypanosomiasis. Lancet. 1977;2(8041):769.

136. Evans DA, Brightman CA. Pleomorphism and the problem of recrudescent parasitaemia following treatment with salicylhydroxamic acid (SHAM) in African trypanosomiasis. Trans R Soc Trop Med Hyg. 1980;74(5):601-604.

137. Yabu Y, Minagawa N, Kita K, et al. Oral and intraperitoneal treatment of Trypanosoma brucei brucei with a combination of ascofuranone and glycerol in mice. Parasitol Int. 1998;47(2):131-137.

138. Jackson DA, Symons RH, Berg P. Biochemical method for inserting new genetic information into DNA of Simian Virus 40: circular SV40 DNA molecules containing lambda phage genes and the galactose operon of Escherichia coli. Proc. Natl Acad Sci USA. 1972;69(10):2904-2909.

139. Cohen SN, Chang AC, Boyer HW, Helling RB. Construction of biologically functional bacterial plasmids in vitro. Proc. Natl Acad Sci USA. 1973;70(11):3240-3244.

140. Chang AC, Cohen SN. Genome construction between bacterial species in vitro: replication and expression of Staphylococcus plasmid genes in Escherichia coli. Proc. Natl Acad Sci USA. 1974;71(4):1030-1034.

141. Acestor N, Panigrahi AK, Ogata Y, Anupama A, Stuart KD. Protein composition of Trypanosoma brucei mitochondrial membranes. Proteomics. 2009;9(24):5497-5508.

142. Jakob M, Hoffmann A, Amodeo S, Peitsch C, Zuber B, Ochsenreiter T. Mitochondrial growth during the cell cycle of Trypanosoma brucei bloodstream forms. Sci Rep. 2016;6:36565.

143. Fukai Y, Nihei C, Kawai K, et al. Overproduction of highly active trypanosome alternative oxidase in Escherichia coli heme-deficient mutant. Parasitol Int. 2003;52(3):237-241.

144. Nihei C, Fukai Y, Kawai K, et al. Purification of active recombinant trypanosome alternative oxidase. FEBS letters. 2003;538(1-3):35-40.

145. Nihei C, Nakayashiki T, Nakamura K, et al. Abortive assembly of succinate-ubiquinone reductase (complex II) in a ferrochelatase-deficient mutant of Escherichia coli. Mol. Genet Genomics. 2001;265(3):394-404.

146. Nakamura K, Fujioka S, Fukumoto S, et al. Trypanosome alternative oxidase, a potential therapeutic target for sleeping sickness, is conserved among Trypanosoma brucei subspecies. Parasitol Int. 2010;59(4):560-564. 
147. Sharpless TK, Butow RA. An inducible alternate terminal oxidase in Euglena gracilis mitochondria. J Biol Chem. 1970;245(1):58-70.

148. Baker JE. Diphenylamine Inhibition of Electron Transport in Plant Mitochondria. Arch Biochem Biophys. 1963;103:148-155.

149. Evans DA, Brown RC. The effect of diphenylamine on terminal respiration in bloodstream and culture forms of Trypanosoma brucei. J Protozool. 1972;19(2):365-369.

150. Evans DA, Brown RC. $m$-Chlorobenzhydroxyamic acid--an inhibitor of cyanideinsensitive respiration in Trypanosoma brucei. J Protozool. 1973;20(1):157-160.

151. Opperdoes FR, Borst P, Fonck K. The potential use of inhibitors of glycerol-3-phosphate oxidase for chemotherapy of African trypanosomiasis. FEBS letters. 1976;62(2):169172.

152. Kunze B, Hofle G, Reichenbach H. The aurachins, new quinoline antibiotics from myxobacteria: production, physico-chemical and biological properties. J Antibiot. 1987;40(3):258-265.

153. Hoefnagel MHN, Wiskich JT, Madgwick SA, Patterson Z, Oettmeier W, Rich PR. New Inhibitors of the Ubiquinol Oxidase of Higher Plant Mitochondria. Eur J Biochem. 1995;233(2):531-537.

154. Miyoshi H, Takegami K, Sakamoto K, Mogi T, Iwamura H. Characterization of the Ubiquinol Oxidation Sites in Cytochromes $b_{o}$ and $b_{d}$ from Escherichia coli using Aurachin C Analogues. J Biochem. 1999;125(1):138-142.

155. Mogi T, Ui H, Shiomi K, Ōmura S, Miyoshi H, Kita K. Antibiotics LL-Z1272 identified as novel inhibitors discriminating bacterial and mitochondrial quinol oxidases. Biochim Biophys Acta - Bioenergetics. 2009;1787(2):129-133.

156. Siedow JN, Bickett DM. Structural features required for inhibition of cyanide-insensitive electron transfer by propyl gallate. Archiv Biochem Biophys. 1981;207(1):32-39.

157. Ott R, Chibale K, Anderson S, et al. Novel inhibitors of the trypanosome alternative oxidase inhibit Trypanosoma brucei brucei growth and respiration. Acta Trop. 2006;100(3):172-184.

158. Grady RW, Bienen EJ, Dieck HA, Saric M, Clarkson AB, Jr. N-n-alkyl-3,4dihydroxybenzamides as inhibitors of the trypanosome alternative oxidase: activity in vitro and in vivo. Antimicrob Agents Chemother. 1993;37(5):1082-1085.

159. West RA, O'Doherty OG, Askwith T, et al. African trypanosomiasis: Synthesis \& SAR enabling novel drug discovery of ubiquinol mimics for trypanosome alternative oxidase. Eur J Med Chem. 2017;141(Supplement C):676-689.

160. West RA, Cunningham T, Pennicott LE, Rao SPS, Ward SE. Toward More Drug Like Inhibitors of Trypanosome Alternative Oxidase. ACS Infect Dis. 2018;4(4):592-604. 
161. Wager TT, Hou X, Verhoest PR, Villalobos A. Moving beyond Rules: The Development of a Central Nervous System Multiparameter Optimization (CNS MPO) Approach To Enable Alignment of Druglike Properties. ACS Chem Neurosci. 2010;1(6):435-449.

162. Rogov AG, Sukhanova EI, Uralskaya LA, Aliverdieva DA, Zvyagilskaya RA. Alternative oxidase: Distribution, induction, properties, structure, regulation, and functions. Biochem (Moscow). 2014;79(13):1615-1634.

163. Charles A, G. WD, L. MA. Maesaquinone: A Novel Inhibitor of Plant Mitochondrial Respiratory Enzymes That React with Ubiquinone. IUBMB Life. 2000;49(6):533-537.

164. Turrens JF, Bickar D, Lehninger AL. Inhibitors of the mitochondrial cytochrome b-c1 complex inhibit the cyanide-insensitive respiration of Trypanosoma brucei. Mol Biochem Parasitol. 1986;19(3):259-264.

165. Carboni S, Malaguzzi V, Marsili A. Ferulenol a new coumarin derivative from Ferula communis. Tetrahedron Lett. 1964;5(38):2783-2786.

166. Appendino G, Mercalli E, Fuzzati N, et al. Antimycobacterial Coumarins from the Sardinian Giant Fennel (Ferula communis). J Nat Prod. 2004;67(12):2108-2110.

167. Hartuti ED, Inaoka DK, Komatsuya K, et al. Biochemical studies of membrane bound Plasmodium falciparum mitochondrial L-malate:quinone oxidoreductase, a potential drug target. Biochim Biophys Acta - Bioenergetics. 2018;1859(3):191-200.

168. Kosuge Y, Suzuki A, Tamura S. Structures of Colletochlorin C, Colletorin A and Colletorin C from Colletotrichum nicotianae. Agr Biol Chem. 1974;38(6):1265-1267.

169. Takamatsu S, Rho M-C, Masuma R, et al. A Novel Testosterone 5a-Reductase Inhibitor, 8',9'-Dehydroascochlorin Produced by Verticillium sp. FO-2787. Chem Pharm Bull. 1994;42(4):953-956.

170. Andersson ME, Nordlund P. A revised model of the active site of alternative oxidase. FEBS letters. 1999;449(1):17-22.

171. Picot D, Loll PJ, Garavito RM. The X-ray crystal structure of the membrane protein prostaglandin H2 synthase-1. Nature. 1994;367(6460):243-249.

172. Gupta K, Selinsky BS, Kaub CJ, Katz AK, Loll PJ. The 2.0 A resolution crystal structure of prostaglandin $\mathrm{H} 2$ synthase-1: structural insights into an unusual peroxidase. J. Mol. Biol. 2004;335(2):503-518.

173. Berthold DA, Voevodskaya N, Stenmark P, Graslund A, Nordlund P. EPR studies of the mitochondrial alternative oxidase. Evidence for a diiron carboxylate center. J Biol Chem. 2002;277(46):43608-43614.

174. Nordlund P, Eklund H. Di-iron-carboxylate proteins. Curr Opin Struct. Biol. 1995;5(6):758-766.

175. Sasaki H, Okutomi T, Hosokawa T, Nawata Y, Ando K. Ascofuranone, a new antibiotic from Ascochyta viciae. Tetrahedron Lett. 1972;13(25):2541-2544. 
176. Hijikawa Y, Matsuzaki M, Suzuki S, et al. Re-identification of the ascofuranoneproducing fungus Ascochyta viciae as Acremonium sclerotigenum. $J$ Antibiot. 2016;70:304.

177. Saimoto H, Hiyama T. A general highly efficient access to prenylated phenolic natural products. Synthesis of colletochlorins B and D. Tetrahedron Lett. 1986;27(5):597-600.

178. Ima-ye K, Kakisawa H. Synthesis of grifolin and dihydrodeoxytauranin. J Chem Soc, Perkin Trans 1. 1973(0):2591-2595.

179. Mori K, Fujioka T. Synthesis of $( \pm)$-ascochlorin, ( \pm )-ascofuranone and LL-Z1272. Tetrahedron. 1984;40(14):2711-2720.

180. Chen K-M, Joullié MM. A simple total synthesis of $( \pm)$-ascofuranone. Tetrahedron Lett. 1984;25(35):3795-3796.

181. Ohta S, Nozaki A, Ohashi N, Matsukawa M, Okamoto M. A Total Synthesis of Grifolin. Chem Pharm Bull. 1988;36(6):2239-2243.

182. Mori K, Fujioka T. Synthesis of $( \pm)$-ascofuranone, in antibiotic with hypolipidemic and antitumor protective properties. Tetrahedron Lett. 1983;24(14):1547-1548.

183. Guthrie AA, Semple JE, Joullie MM. Synthetic studies of fungal metabolites: ascofuranone and colletochlorin D. J Org Chem. 1982;47(12):2369-2376.

184. Mori K, Takechi S. Synthesis of the natural enantiomers of ascochlorin, ascofuranone and ascofuranol. Tetrahedron. 1985;41(15):3049-3062.

185. Saimoto H, Ohrai S-i, Sashiwa H, Shigemasa Y, Hiyama T. Total Synthesis of dlAscofuranone and Related Compounds. Bull Chem Soc Jap. 1995;68(9):2727-2734.

186. Shigemasa Y, Yasui M, Ohrai S, Sasaki M, Sashiwa H, Saimoto H. Enantioselective transformation of propargyl esters to dihydrofurans. J Org Chem. 1991;56(3):910-912.

187. Dudley GB, Takaki KS, Cha DD, Danheiser RL. Total Synthesis of (-)-Ascochlorin via a Cyclobutenone-Based Benzannulation Strategy. Org Lett. 2000;2(21):3407-3410.

188. Haga Y, Tonoi T, Anbiru Y, et al. A short and efficient total synthesis of $( \pm)$ ascofuranone. Chem Lett. 2010;39(6):622-623.

189. Grabovyi GA, Mohr JT. Total Synthesis of Grifolin, Grifolic Acid, LL-Z1272 $\alpha$, LLZ1272ß, and Ilicicolinic Acid A. Org Lett. 2016;18(19):5010-5013.

190. Saimoto H, Kusano Y, Hiyama T. A mild procedure for hydrolysis of alkoxymethyl aryl ethers to give hydroxyarenes. A rational synthesis of ascofuranone. Tetrahedron Lett. 1986;27(14):1607-1610.

191. Fürstner A, Gastner T. Total Synthesis of Cristatic Acid. Org Lett. 2000;2(16):24672470.

192. Marsico G, Pignataro BA, Masi M, et al. Asymmetric synthesis and structure-activity studies of the fungal metabolites colletorin A, colletochlorin A and their halogenates analogues. Tetrahedron. 2018;74(28):3912-3923. 
193. Kan T, Hashimoto M, Yanagiya M, Shirahama H. Effective deprotection of 2(trimethylsilylethoxy)methylated alcohols (SEM ethers). Synthesis of thyrsiferyl-23 acetate. Tetrahedron Lett. 1988;29(42):5417-5418.

194. Luque-Ortega JR, Reuther P, Rivas L, Dardonville C. New benzophenone-derived bisphosphonium salts as leishmanicidal leads targeting mitochondria through inhibition of respiratory complex II. J Med Chem 2010;53:1788-1798.

195. Taladriz A, Healy A, Flores Pérez EJ, et al. Synthesis and structure-activity analysis of new phosphonium salts with potent activity against African trypanosomes. $J$ Med Chem. 2012;55(6):2606-2622.

196. Cortes LA, Castro L, Pesce Br, et al. Novel Gallate Triphenylphosphonium Derivatives with Potent Antichagasic Activity. PloS one. 2015;10(8):e0136852.

197. Long TE, Lu X, Galizzi M, Docampo R, Gut J, Rosenthal PJ. Phosphonium lipocations as antiparasitic agents. Bioorg Med Chem Lett. 2012;22(8):2976-2979.

198. Ross MF, Da Ros T, Blaikie FH, et al. Accumulation of lipophilic dications by mitochondria and cells. Biochem J. 2006;400(1):199-208.

199. Dardonville C, Alkhaldi AAM, De Koning HP. SAR Studies of Diphenyl Cationic Trypanocides: Superior Activity of Phosphonium over Ammonium Salts. ACS Med Chem Lett. 2015;6(2):151-155.

200. Dahal K, Martyn GD, Alber NA, Vanlerberghe GC. Coordinated regulation of photosynthetic and respiratory components is necessary to maintain chloroplast energy balance in varied growth conditions. J Exp Bot. 2017;68(3):657-671.

201. Munday JC, Settimo L, de Koning HP. Transport proteins determine drug sensitivity and resistance in a protozoan parasite, Trypanosoma brucei. Front Pharmacol. 2015;6:32.

202. Lüscher A, de Koning HP, Mäser P. Chemotherapeutic strategies against Trypanosoma brucei: Drug targets vs. drug targeting. Curr Pharm Design. 2007;13(6):555-567.

203. De Koning HP. Uptake of Pentamidine in Trypanosoma brucei brucei is Mediated by Three Distinct Transporters: Implications for Cross-Resistance with Arsenicals. Mol Pharmacol. 2001;59(3):586-592.

204. de Koning HP, Anderson LF, Stewart M, Burchmore RJ, Wallace LJ, Barrett MP. The trypanocide diminazene aceturate is accumulated predominantly through the TbAT1 purine transporter: additional insights on diamidine resistance in african trypanosomes. Antimicrob Agents Chemother. 2004;48(5):1515-1519.

205. Ward CP, Wong PE, Burchmore RJ, de Koning HP, Barrett MP. Trypanocidal Furamidine Analogues: Influence of Pyridine Nitrogens on Trypanocidal Activity, Transport Kinetics, and Resistance Patterns. Antimicrob Agents Chemother. 2011;55(5):2352-2361. 


\section{Biosketches}

Christophe Dardonville graduated in Chemistry (1993) at the Université Pierre et Marie Curie (UPMC, Paris VI) and obtained his Master Degree in Chemistry (D.E.A.) at the University of Montpellier, France, in 1994. He moved to Spain with a Marie Curie Fellowship and obtained his $\mathrm{PhD}$ degree in Chemistry (2000) from the Complutense University of Madrid. He was a postdoctoral fellow with Dr. Ian Gilbert (Welsh School of Pharmacy, Cardiff University, UK, 2000-2003) and Dr. Nadine Jagerovic (IQM-CSIC, Madrid, 2003-2004). In 2004, he was appointed Senior scientist at the mixed research unit Lilly-Barcelona Science Park (2004-2005). Since 2006, he is appointed to the staff at the Medicinal Chemistry Institute (IQM) from the Spanish Council for Scientific Research (CSIC) in Madrid. As member of the group "Antiparasitic Chemotherapy", his current research focuses on the design and synthesis of new drugs for parasitic neglected tropical diseases (trypanosomiases, leishmaniasis, malaria). In particular, his group is interested in the development of antiparasitic compounds targeting the unique mitochondrion of protozoan parasites.

Harry de Koning is the Professor of Parasite Biochemistry and Pharmacology at the University of Glasgow and has been a Principal Investigator there since 1999, following a lectureship at the University of Glasgow and postdoctoral research positions at the University of Kent at Canterbury and the University of Iowa. He holds a Bachelor degree in Chemistry (1985), an MPhil in Biochemistry (1988) and a PhD in Biology (1992). Prof. De Koning is a leading researcher in chemotherapy of protozoa, most of all Trypanosoma species, and is considered a world-leading expert in drug delivery/transport in trypanosomes, drug resistance mechanisms, and the investigation of drug mode-of-action in protozoa. He is and has been part of multiple important research consortia in drug development, including PDE4NPD (10-member EU/FP7 consortium on new PDE inhibitors as antiparasitics), Nanotryp (EU/FP7 consortium using nanobodies/nanotechnology in antiparasite control), the Consortium for Parasitic Drug Development (CPDD, BMGF-funded international consortium that developed new sleeping sickness drugs and conducted the first clinical trial for this disease in decades), and in addition specific antiparasitics funding from the GlaxoSmithKline Open Lab Foundation, Otsuka Pharmaceuticals, the Wellcome Trust, The Medical Research Council and the Global Alliance for Livestock Veterinary Medicine (GALVmed) among others. He headed the working group on drug delivery strategies for the recent COST Action 'Targeted chemotherapy towards diseases caused by endoparasites'. He currently has a publication list of 130 items with an H-factor of 32. 
Emmanuel Oluwadare Balogun is a young scientist with research focus on Biochemical and Molecular Parasitology. He obtained BSc (2001) and MSc (2005) degrees in Biochemistry from Ahmadu Bello University (ABU), Zaria, Nigeria. During this period, he was supervised by late Professor Andrew Jonathan Nok (1962 - 2017) to investigate the pathogenesis of anemia in animals infected with Trypanosoma congolense. He became a staff in the Department of Biochemistry, ABU (2005). Emmanuel passed the examinations for the award of Japanese Government Scholarship and the entrance examinations for The University of Tokyo (UT), Japan. He was accepted into the Graduate School of Medicine, for a $\mathrm{PhD}$ program under the supervision of Professor Kita Kiyoshi, in the Department of Biomedical Chemistry (2007-2011). Dr. Balogun acquired expertise in X-ray crystallography during his $\mathrm{PhD}$ studies, and on completion, he became a Postdoc under a grant provided by SBI Pharma to investigate the potential use of 5aminolaevulinic acid for the treatment of malaria. In 2012, he was selected for a Postdoctoral Fellowship by the Japan Society for the Promotion of Science and he worked under Professors Harada Shigeharu and Kita Kiyoshi in Kyoto Institute of Technology (KIT) and UT, Japan, to elucidate the reaction mechanism of ATGK and contributed to determine the 3-D structure of the trypanosome alternative oxidase. He returned to his position in ABU as a Lecturer (2016), and serves as a Visiting Researcher to the Department of Biomedical Chemistry, UT and Department of Applied Biology, KIT, Japan. Dr. Balogun is interested in the development of new therapeutics for Africa-endemic diseases. 
Eduardo José Cueto Díaz graduated in Chemistry (2007) at the Autonomous University of Madrid (UAM) and obtained his master's degree in chemistry (D.E.A.) at the King Juan Carlos University, Spain, in 2010. He moved to France in 2011 with a Marie Curie Fellowship and obtained his $\mathrm{PhD}$ degree in Chemistry (2014) from the Université de Bordeaux under the supervision of Dr. Mireille Blanchard-Desce, where he focused on the synthesis of new organic nanomaterials (organic nanodots) as tools for cell imaging. Following his $\mathrm{PhD}$, he remained as a postdoctoral researcher at the Université de Bordeaux (2015-2016), which allowed him to expand his knowledge in the field. In 2017, he moved as a CNRS researcher to the University of Montpellier where he gained experience in the material science domain, by developing welldefined and biocompatible functionalized porous silicon nanoparticles as a potential platform for cancer theranostic. Recently, he returned to Spain as a postdoctoral researcher in the group of Dr. Dardonville (IQM-CSIC) where he is working on the synthesis of new TAO inhibitors. 


\section{Figure Legends}

Figure 1. A scheme of aerobic (a) and anaerobic (b) glycolysis in bloodstream-form Trypanosoma brucei. The solid lines represent reactions catalysed by a single enzyme, whereas the dashed lines represent multiple sequential reactions. G-6-P = glucose-6-phosphate; F-1,6-BP = fructose-1,6-bisphosphate; GA-3-P = glyceraldehyde-3-phosphate; 1,3-BPG $=1,3-$ bisphosphoglycerate; 3-PG = 3-phosphoglycerate; DHAP = dihydroxyacetone phosphate; G-3-P = glycerol-3-phosphate; 1 = Glycerol-3-phosphate dehydrogenase; $2=$ Glycerol kinase; $3=$ glyceraldehyde-3-phosphate dehydrogenase (GAPDH); 4 = Glycerol-3-phosphate dehydrogenase (G-3-PDH).

Figure 2. $K_{\mathrm{i}}$ and $\mathrm{IC}_{50}$ values for the inhibition of the cyanide-insensitive terminal oxidase pathway (inhibition of oxygen uptake) of T. brucei, skunk cabbage, and mung bean by primary benzhydroxamic acids. ${ }^{55,117,124,150}$

Figure 3. $K_{\mathrm{i}}$ values for the inhibition of the AOX pathway (inhibition of oxygen uptake) of $T$. brucei by secondary benzhydroxamic acids. ${ }^{124}$

Figure 4. $K_{\mathrm{i}}$ values for the inhibition of $T$. brucei alternative oxidase pathway (inhibition of oxygen uptake) by heterocyclic $N$-hydroxy compounds. $\mathrm{IC}_{50}$ value for the inhibition of $T$. vivax AOX. ${ }^{123,124,155}$

Figure 5. $K_{\mathrm{i}}$ and $\mathrm{IC}_{90}$ values for the inhibition of $T$. bruce $i$ alternative oxidase pathway (inhibition of oxygen uptake) by alkyloxybenzhydroxamic acids and related compounds. ${ }^{123}$

Figure 6. SAR of benzhydroxamic acid derivatives

Figure 7. $K_{\mathrm{i}}$ values for the inhibition of $T$. brucei alternative oxidase pathway (inhibition of oxygen uptake) by iron chelators: tropolone (65-69), 8-hydroxyquinoline (70-72), and pyridine derivatives (74-76). ${ }^{124}$

Figure 8. $K_{\mathrm{i}}$ and $\mathrm{IC}_{90}$ values for the inhibition of $T$. bruce $i$ alternative oxidase pathway (inhibition of oxygen uptake) by benzoic acid derivatives. ${ }^{125} \mathrm{IC}_{50}$ values for the inhibition of purified rTAO. ${ }^{13,126}$

Figure 9. SAR of benzoic acid derivatives

Figure 10. $K_{\mathrm{i}}$ and $\mathrm{IC}_{90}$ values for the inhibition of the alternative oxidase pathway (inhibition of oxygen uptake) in $T$. brucei ${ }^{13,125,126}$ and munk bean ${ }^{156}$ by benzoate derivatives. $\mathrm{IC}_{50}$ values for the inhibition of purified rTAO.

Figure 11. (A) $K_{\mathrm{i}}$ and $\mathrm{IC}_{90}$ values for the inhibition of $T$. brucei alternative oxidase pathway (inhibition of oxygen uptake) by 3,4-dihydroxybenzoate, 3,4-dihydroxybenzamide, and 2,4dihydroxybenzoic acid derivatives. $\mathrm{IC}_{50}$ values for the inhibition of purified rTAO. (B) SAR and binding orientation of benzoate and benzamide derivatives with large $\mathrm{R}_{1}$ alkyl substituents. 
Figure 12. $K_{\mathrm{i}}$ values for the inhibition of the alternative oxidase pathway (inhibition of oxygen uptake) by miscellaneous phenol derivatives ${ }^{125,156}$

Figure 13. $\mathrm{IC}_{50}$ values for the inhibition of purified rTAO by 4-hydroxybenzoate derivatives. ${ }^{13}$

Figure 14. $K_{\mathrm{i}}$ and $\mathrm{IC}_{90}$ values for the inhibition of $T$. brucei alternative oxidase pathway (inhibition of oxygen uptake) by benzaldehyde and keto derivatives. $\mathrm{IC}_{50}$ values for the inhibition of purified rTAO. ${ }^{113,125,126,159}$

Figure 15. 3-chloro-4-hydroxybenzonitrile derivatives: influence of tail hydrophilicity and methylene chain length on rTAO inhibition. ${ }^{159,160}$

Figure 16. $K_{\mathrm{i}}$ values for the inhibition of $T$. brucei alternative oxidase pathway (inhibition of oxygen uptake) by ubiquinol analogues. ${ }^{164}$

Figure 17. SAR of ascofuranone (AF): modification of the aromatic head. $\mathrm{IC}_{50}$ values for the inhibition of purified rTAO. ${ }^{10,59}$

Figure 18. SAR of ascofuranone: modification of the aliphatic tail. $\mathrm{IC}_{50}$ values for the inhibition of purified rTAO. ${ }^{10,59}$

Figure 19. SAR of colletochlorin $B(C C B)$. $\mathrm{IC}_{50}$ values for the inhibition of purified rTAO reported by West et al $l^{159,160}$ and Saimoto et al ${ }^{59}$ (left and right $\mathrm{IC}_{50}$ values, respectively).

Figure 20. SAR of ilicicolin derivatives. $\mathrm{IC}_{50}$ value for the inhibition of $T$. vivax AOX.

Figure 21. Ramachandran Plot statistics for TAO-CCB (PDB ID: 3W54). PROCHECK was used to prepare and assess the quality of the TAO structure data and for its suitability for use in SADD. $93.3 \%$ of the residues were in most favored regions, $6.7 \%$ in additional allowed regions, and none in generously allowed and disallowed regions $(0.0 \%)$. The statistics reveals that the structure is above the acceptable accuracy cut-off of $90 \%$, hence, may be useful for SADD.

Figure 22. X-ray crystal structure of TAO. Long $\alpha$-helices are labeled $\alpha \mathrm{L}$, while short helices are labelled $\alpha \mathrm{S}$. Diiron and hydroxo atoms are shown as spheres. (A) Cartoon representation of the dimeric structure viewed roughly parallel to the helix axes. Helices are shown as ribbons. Chain $\mathrm{A}$ is rainbow-colored while chain $\mathrm{B}$ is colored cyan. Each monomer consists of six long helices $\left(\alpha \mathrm{L} 1-\alpha \mathrm{L} 6\right.$ in chain $\mathrm{A}, \alpha \mathrm{L} 1{ }^{\prime}-\alpha \mathrm{L} 6$ ' in chain B) and four short helices $(\alpha \mathrm{S} 1-\alpha \mathrm{S} 4$ in chain $\mathrm{A}$ and $\alpha S 1^{\prime}-\alpha S 4$ ' in chain B). Except for the N-terminal arm, each monomer is shaped as a compact cylinder. Horizontal beige bars depict the two leaflets of the inner mitochondrial membrane, where residues of $\alpha \mathrm{L} 1, \alpha \mathrm{L} 4$ and portions of $\alpha \mathrm{L} 2$ and $\alpha \mathrm{L} 5$ form the membrane-anchoring base. (B) Membrane side of the monomers. Length of the long helices could be visualized to appreciate the broad surface formed by $\alpha \mathrm{L} 1$ and $\alpha \mathrm{L} 4$ for membrane interaction. (C) Dimer formation. Two monomer chains A and B intimately associated to form the functional dimer of TAO. Chain A is represented as cartoon while chain B as surface model. The monomers 'hug' each other with their long N-terminal arm where the short helices are located, additionally, helices $\alpha \mathrm{L} 2, \alpha \mathrm{L} 3$, and $\alpha \mathrm{L} 4$ participate in the dimerization. (D) A zoom-in on the diiron center. The diiron center is created by six amino acid residues, Glu123, Glu162, His165, Glu213, Glu266, and His269. Two iron ions ( $\mathrm{Fe} 1$ and $\mathrm{Fe} 2$ shown as green spheres) are ligated by the glutamate residues via coordinate bonds (shown as solid lines). Iron ion $\mathrm{Fe} 1$ directly coordinates the hydroxo group in the diiron center. The histidine residues participate in the stabilization of the diiron center by forming hydrogen bonds with the glutamate residues. 
Figure 23. Structure of TAO-inhibitor complex. (A) Complex structure of TAO (cyan sticks) bound with ascofuranone derivative AF2779-OH (yellow stick); the structure is superposed with the diiron center of the uninhibited form (green sticks). The diiron and hydroxo of the inhibited form are brown and blue spheres, respectively. While the diiron and hydroxo of the uninhibited form are green and yellow spheres, respectively. The inhibitor is bound in the active site of TAO close to the diiron center. Binding of the inhibitor caused a displacement of the $\mathrm{Fe} 1$, the $\mathrm{Fe} 2$ is not affected. (B) Model structure of SHAM derivative $\mathbf{3 2 2}$.

Figure 24. (A) Structural features of ascofuranone (188). (B) Ascofuranone pharmacophore: functional interaction between $\mathrm{AF}$ and $\mathrm{AOX} .{ }^{59}$ Dash-lines represent $\mathrm{H}$-bonds with amino acids of the inhibitor binding site.

Figure 25. Schematic representation of uptake and accumulation of mitochondria-targeted triphenylphosphonium (TPP) TAO-inhibitor conjugates within BSF trypanosomes. $\Delta \Psi_{\mathrm{p}}$, plasma membrane potential; $\Delta \Psi_{\mathrm{m}}$, mitochondrial membrane potential.

Figure 26. $\mathrm{IC}_{50}$ values for inhibition of purified $\triangle \mathrm{MTS}-\mathrm{TAO}$ and $\mathrm{EC}_{50}$ values against $T$. b. brucei (WT) by 4-hydroxybenzoate-lipocation (LC) conjugates (292-305), 4-alkoxybenzaldehyde-LC conjugates $(\mathbf{3 0 6}, \mathbf{3 0 7})$, and (3)4-alkoxybenzoate-LC conjugates (308-322). The $\mathrm{IC}_{50}$ of SHAM (2) is $5.93 \mu \mathrm{M}$ in this assay. ${ }^{13,62,126} \mathrm{TPP}$ : triphenylphosphonium. Quin: 1-quinolinium. 